THE EAGLE

A MODEL FOR

POLICY ANALYSIS OF

MACROECONOMIC

INTERDEPENDENCE

IN THE EURO AREA

by Sandra Gomes,

Pascal Jacquinot

and Massimiliano Pisani 


\title{
A MODEL FOR POLICY ANALYSIS OF MACROECONOMIC INTERDEPENDENCE IN THE EURO AREA'
}

\author{
by Sandra Gomes ${ }^{2}$, Pascal Jacquinot ${ }^{3}$ and \\ Massimiliano Pisani ${ }^{4}$
}

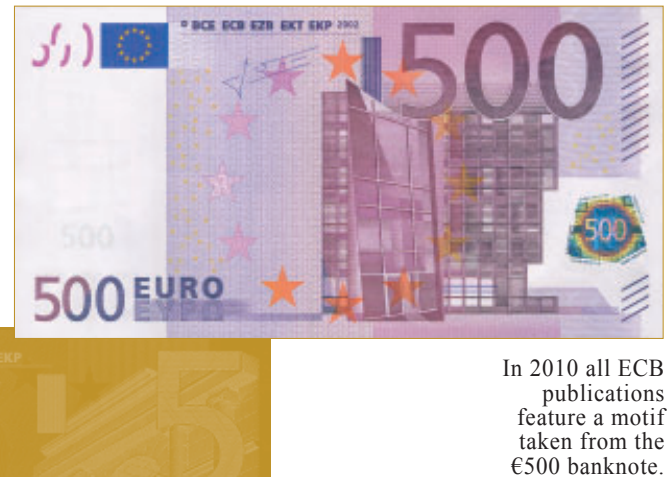

NOTE: This Working Paper should not be reported as representing the views of the European Central Bank (ECB).

The views expressed are those of the authors and do not necessarily reflect those of the ECB.

This paper can be downloaded without charge from http://www.ecb.europa.eu or from the Social Science Research Network electronic library at http://ssrn.com/abstract_id= $=1601272$.

I We thank Günter Coenen for invaluable support. We also thank Giancarlo Corsetti, participants at the Working Group on Econometric Modeling meetings and an anonymous referee. The opinions expressed are those of the authors and do not reflect views of their respective institutions. Any remaining errors are the sole responsibility of the authors. Sandra Gomes and Massimiliano Pisani thank the European Central Bank Econometric Modeling Division for its warm hospitality. 2 Bank of Portugal, Economic Research Department, Av. Almirante Reis 7/, /150-012 Lisbon, Portugal, phone: +35/ 21 3/307/9, e-mail: sandra.cristina.gomes@bportugal.pt 3 European Central Bank, Directorate General of Research, Kaiserstrasse 29, D-603IIFrankfurt am Main, Germany, phone: +4969 1344 8018, e-mail: pascal.jacquinot@ecb.int 4 Bank of Italy, Research Department, Via Nazionale 91, 00184 Rome, Italy, phone: +39-06-4792-3452, e-mail: massimiliano.pisani@bancaditalia.it 
CC European Central Bank, 2010

\section{Address}

Kaiserstrasse 29

60311 Frankfurt am Main, Germany

Postal address

Postfach 160319

60066 Frankfurt am Main, Germany

Telephone

+496913440

Internet

http://www.ecb.europa.eu

Fax

+496913446000

All rights reserved.

Any reproduction, publication and reprint in the form of a different publication, whether printed or produced electronically, in whole or in part, is permitted only with the explicit written authorisation of the ECB or the authors.

Information on all of the papers published in the ECB Working Paper Series can be found on the ECB's website, http://www. ecb.europa.eu/pub/scientific/wps/date/ html/index.en.html

ISSN 1725-2806 (online) 


\section{CONTENTS}

Abstract

Non-technical summary

1 Introduction

2 The model

2.1 Firms

2.2 Household

2.3 Monetary and fiscal authorities

2.4 Aggregate variables

2.5 Market clearing conditions

2.6 Net foreign assets position and international relative prices

Calibration

4 Simulations

4.1 Monetary policy stock

4.2 Home government spending shock

4.3 Markup shock in the home nontradables sector

4.4 Markup shock in the home tradables sector 40

4.5 Markup shock in the home labor market

4.6 Risk premium shock

4.7 Shock to rest of the world consumption preferences

5 Conclusions

References

Tables and figures

Appendices 


\begin{abstract}
Building on the New Area Wide Model, we develop a 4-region macroeconomic model of the euro area and the world economy. The model (EAGLE, Euro Area and Global Economy model) is microfounded and designed for conducting quantitative policy analysis of macroeconomic interdependence across regions belonging to the euro area and between euro area regions and the world economy. Simulation analysis shows the transmission mechanism of region-specific or common shocks, originating in the euro area and abroad.
\end{abstract}

JEL Classification Numbers: C53; E32; E52; F4\%.

Keywords: Open-economy macroeconomics, DSGE models, econometric models, policy analysis. 


\section{Non-technical Summary}

International macroeconomic interdependence is a relevant topic in a monetary union such as the euro area, where monetary policy is conducted taking into account euro area-wide performance, while other policies (fiscal and structural) are mainly conducted at the country level. Understanding the transmission mechanism of region-specific or common shocks across countries and the related role of country-specific structural economic features is crucial for properly analyzing stabilization issues and assessing the appropriate policy responses in the euro area.

To tackle such issues we develop the EAGLE (Euro Area and Global Economy) model. It is a large-scale microfounded model for the analysis of spillovers and macroeconomic interdependence across the different countries belonging to the euro area and between them and other countries outside the monetary union. The open economy version of the new-keynesian paradigm, so called New Open Economy Macroeconomics framework, constitutes EAGLE's theoretical kernel and guarantees a nontrivial role for monetary, exchange rate, fiscal and structural policy measures. The microfoundations of the model together with its rich structure allows to conduct a quantitative analysis in a theoretically coherent and fully consistent model setup, clearly spelling out all the policy implications.

More specifically, EAGLE builds on the ECB New Area Wide Model (NAWM). Differently from the latter, EAGLE includes the following three dimensions. First, in EAGLE the euro area is formalized as a monetary union. The latter is composed of two regions sharing a common monetary authority that sets the common nominal interest rate according to euro area-wide variables. As such, the model allows to assess the implications of the common monetary policy and country-specific characteristics (such as the size, for example) for the transmission of countryspecific or common shocks in the euro area. The second element is its global nature, as there are two countries outside the euro area. This feature allows to study the role played by the euro nominal exchange rate and the extra-euro area trade in transmitting shocks originating outside or inside the euro area (third-country effects). Third, the model includes not only tradable goods, but also intermediate nontradables. The distinction allows to fully characterize the dynamics of international relative prices and trade flows. Overall, the three dimensions imply a rather exhaustive assessment of the macroeconomic interdependence across euro area countries and between them and countries not belonging to the union. Also, given its rich set of nominal and real frictions as well as implementable fiscal and monetary policy measures, the model is well 
suited for conducting realistic policy analysis.

In this paper we initially illustrate the setup of EAGLE. Subsequently, we show EAGLE's implications for an array of illustrative shocks that are often examined in policy simulations at national central banks and international policy institutions. The shocks can originate in the euro area and abroad. In particular, we focus on spillovers across euro area countries related to the monetary union dimension and to changes in international relative prices and trade flows. The overall picture does suggest that accounting for cross-country spillovers is relevant for properly analyzing policy issues in the euro area. 


\section{Introduction}

International macroeconomic interdependence is a relevant topic in a monetary union such as the euro area, where the monetary policy is set accordingly to euro area-wide performance, while other (fiscal and structural) policies are mainly conducted at the country level. Understanding the transmission mechanism of region-specific or common shocks across euro area countries and the related role of country-specific structural economic features is crucial for properly assessing the appropriate stabilization policy responses.

To analyze such issues we develop the EAGLE (Euro Area and Global Economy) model. ${ }^{1}$ It is a large-scale microfounded model for the analysis of spillovers and macroeconomic interdependence across the different countries belonging to the euro area and between them and other countries outside the monetary union. Thanks to the microfoundations, quantitative analysis can be conducted in a fully coherent, disciplined and internally consistent framework. The EAGLE setup builds on the New Area Wide Model (NAWM, Coenen, McAdam and Straub, 2008). ${ }^{2}$ As in the case of the NAWM, in EAGLE the open economy dimension is the key feature. However, EAGLE differs from NAWM along the following dimensions. First, in EAGLE the euro area is formalized as a monetary union. The latter is composed of two regions sharing a common monetary authority that sets the common nominal interest rate according to euro area-wide variables. As such, the model allows to assess the implications of the common monetary policy and country-specific characteristics (such as the size, for example) for the transmission of country-specific or common shocks in the euro area. Second, EAGLE includes two countries outside the euro area. This feature allows to analyze the role of euro nominal exchange rate and extra-euro area trade in transmitting shocks originating outside or inside the euro area. Third, the model includes tradable and nontradable intermediate goods in all regions. ${ }^{3}$ The distinction (jointly with other features such as home bias, local currency pricing and incomplete international financial markets) allows to fully characterize the dynamics of the real exchange rate and the current account. To sum up, the three dimensions imply a rather exhaustive assessment of

\footnotetext{
${ }^{1}$ Jointly developed by staff of the Bank of Italy, the Bank of Portugal and the European Central Bank, EAGLE is a project of the European System of Central Banks.

${ }^{2}$ See also the IMF's Global Economy Model (GEM, Laxton and Pesenti, 2003 and Pesenti, 2008), the Bank of Canada's version of GEM (Lalonde and Muir, 2007), the Federal Reserve Board's SIGMA (Erceg, Guerrieri and Gust, 2006). See also Cova, Pisani and Rebucci (2009), the European Commission's QUEST (Ratto, Roeger and in't Veld, 2009), Alves, Gomes and Sousa (2007) and IMF's Global Integrated Monetary Fiscal Model (GIMF, Kumhof and Laxton, 2007).

${ }^{3}$ See also Jacquinot and Straub (2008) for a two-sector/four-country extension of the NAWM without monetary union.
} 
the macroeconomic interdependence across euro area countries and between them and countries not belonging to the union. Moreover, they make EAGLE relatively new as compared to the existing large scale micro-founded models of the euro area. ${ }^{4}$ Finally, the rich set of nominal and real frictions as well as implementable fiscal and monetary policy measures make the model well suited for conducting realistic policy analysis.

Other features of the model setup are rather standard. In each country there are two types of firms. One type produces final nontradable goods under perfect competition using domestic tradable, imported tradable and nontradable intermediate goods. The final goods can be used for private consumption and for private investment. The intermediate goods are produced by firms under monopolistic competition using domestic labor and capital. Hence, they set nominal prices to maximize profits. Nominal prices are sticky, so that there is a non trivial stabilization role for monetary policy. For tradable intermediate goods, prices are set in the currency of the destination market (the local currency pricing assumption holds). As a consequence, pass-through of the nominal exchange rate into import prices is incomplete in the short run, consistently with empirical evidence.

There are two types of households in each country. The $I$-type households have access to financial and money markets, accumulate physical capital (they rent it to domestic firms), supply labor to domestic firms. They trade domestically a riskless bond denominated in domestic currency and internationally a riskless bond denominated in US dollars. So for $I$-type agents an uncovered interest parity condition holds, linking the interest rate differential to the expected change in the exchange rate of the domestic currency against the worldwide core currency (we assume it is the US dollar). The other households, $J$-type, are liquidity constrained and have access only to the domestic money market. Their only source of income is the labor supplied to domestic firms. $J$-type households allow to introduce Keynesian effects of public expenditure in the model. Both types of agents supply labor under monopolistic competition. So they set their nominal wages, that we assume to be sticky.

Finally, in each country there is a monetary authority and a fiscal authority (as said, in the case of the euro area there is a common monetary authority). The monetary authority sets the nominal interest rate according to a standard Taylor rule, reacting to domestic inflation

\footnotetext{
${ }^{4}$ Andrés, Burriel and Estrada (2006) build a three-country DSGE model including a two-block monetary union, namely Spain and the rest of euro area, and the rest of the world. However, the rest of the world is rather stylized, while in EAGLE all regional blocks are fully structural. Pytlarczyk (2005) builds and estimates a two-region model of the euro area, calibrated to Germany and rest of the euro area.
} 
rate, output growth rate and, possibly, to the nominal exchange rate. The fiscal authority sets public expenditure for purchases (fully biased towards domestic nontradable intermediate goods, consistently with empirical evidence) and lump-sum transfers. It is financed by rising taxes or public debt, issued on domestic financial markets. Taxes can be lump-sum or distortionary (the latter are raised on labor income, capital income and consumption). A fiscal rule guarantees the stability of public debt. In the case of the two regions belonging to the monetary union, the monetary and nominal exchange rate policies are shared at union level. To the contrary, fiscal policies are region-specific.

In this paper we calibrate EAGLE to Germany, the rest of the euro area, the US and the rest of the world. The goal is to illustrate macroeconomic interdependence across regions belonging to the euro area. The spillovers can be due to shocks originating inside or outside the euro area.

The paper is organized as follows. Next section illustrates the model setup. Section 3 reports the calibration of the model. Section 4 shows the results of simulation exercises. Some concluding remarks are reported in the final section.

\section{The model}

In this section we report the EAGLE setup, outlining the behavior of firms, households, monetary and fiscal authorities, defining the aggregate outcomes and characterizing the market clearing conditions. The world economy consists of four regions and its size is normalized to one. The size of each region measures the share of resident households and domestic sector-specific firms, both defined over a continuum of mass $s$. In what follows the focus is on Home country $(H)$, as other countries are similarly characterized. ${ }^{5}$

\section{$2.1 \quad$ Firms}

There are two types of firms. One type produces internationally tradable and nontradable intermediate goods. The other type produces nontraded final goods for consumption and investment purposes, using as inputs all intermediate goods.

\footnotetext{
${ }^{5}$ The description of the model setup follows closely those in Coenen, McAdam and Straub (2008) and Pesenti (2008).
} 


\section{Final goods sector}

Firms producing final nontradable goods are symmetric, act under perfect competition and use nontradable, domestic and imported tradable intermediate goods as inputs. The intermediate goods are assembled according to a constant elasticity of substitution (CES) technology. Final goods can be used for private consumption and investment.

Technology For the consumption sector, each firm $x\left(x \in\left[0, s^{H}\right]\right)$ produces a consumption good $Q^{C}(x)$ with the following CES technology:

$$
Q_{t}^{C}(x)=\left[v_{C}^{\frac{1}{\mu_{C}}} T T_{t}^{C}(x)^{\frac{\mu_{C}-1}{\mu_{C}}}+\left(1-v_{C}\right)^{\frac{1}{\mu_{C}}} N T_{t}^{C}(x)^{\frac{\mu_{C}-1}{\mu_{C}}}\right]^{\frac{\mu_{C}}{\mu_{C}-1}}
$$

where:

$$
T T_{t}^{C}(x)=\left[v_{T C}^{\frac{1}{\mu_{T C}}} H T_{t}^{C}(x)^{\frac{\mu_{T C}-1}{\mu_{T C}}}+\left(1-v_{T C}\right)^{\frac{1}{\mu_{T C}}} I M_{t}^{C}(x)^{\frac{\mu_{T C}-1}{\mu_{T C}}}\right]^{\frac{\mu_{T C}}{\mu_{T C}}}
$$

Two intermediate inputs are used in the production of the consumption good. A basket $N T_{t}^{C}$ of nontradable intermediate goods and a composite bundle $T T_{t}^{C}$ of domestic $\left(H T_{t}^{C}\right)$ and imported $\left(I M_{t}^{C}\right)$ tradable goods. The parameter $\mu_{C}>0$ denotes the intratemporal elasticity of substitution between tradable and nontradable goods, while $v_{C}\left(0 \leq v_{C} \leq 1\right)$ measures the weight of the tradable bundle in the production of the consumption good. For the bundle of tradable goods, the parameter $\mu_{T C}>0$ denotes the intratemporal elasticity of substitution between the bundles of domestic and foreign tradable intermediate goods, while $v_{T C}\left(0 \leq v_{T C} \leq 1\right)$ measures the weight of domestic tradable intermediate goods. Imports $I M_{t}^{C}(x)$ are a CES function of basket of goods imported from other countries:

$I M_{t}^{C}(x)=\left[\sum_{C O \neq H}\left(v_{I M^{C}}^{H, C O}\right)^{\frac{1}{\mu_{I M C}}}\left(I M_{t}^{C, C O}(x)\left(1-\Gamma_{I M^{C}}^{H, C O}\left(\frac{I M_{t}^{C, C O}(x)}{Q_{t}^{C}(x)}\right)\right)\right)^{\frac{\mu_{I M C}-1}{\mu_{I M C}}}\right]^{\frac{\mu_{I M C C}}{\mu_{I M C}-1}}$

where $\mu_{I M C}>0$ and the coefficients $v_{I M C}^{H, C O}$ are such that:

$$
0 \leq v_{I M^{C}}^{H, C O} \leq 1, \quad \sum_{C O \neq H} v_{I M^{C}}^{H, C O}=1
$$


The term $\Gamma_{I M^{C}}^{H, C O}\left(\frac{I M_{t}^{C, C O}(x)}{Q_{t}^{C}(x)}\right)$ represents adjustment costs on bilateral consumption imports of country H from country CO:

$$
\Gamma_{I M^{C}}^{H, C O}\left(\frac{I M_{t}^{C, C O}(x)}{Q_{t}^{C}(x)}\right) \equiv \frac{\gamma_{I M^{C}}}{2}\left(\frac{I M_{t}^{C, C O}(x) / Q_{t}^{C}(x)}{I M_{t-1}^{C, C O} / Q_{t-1}^{C}}-1\right)^{2}, \gamma_{I M^{C}} \geq 0
$$

By assumption, each firm $x$ takes the previous period (sector-wide) import share, $I M_{t-1}^{C, C O} / Q_{t-1}^{C}$, and the current demand for its output, $Q_{t}^{C}(x)$, as given. The adjustment costs lower the shortrun price elasticity of imports. To the opposite, the level of imports is permitted to jump in response to changes in overall consumption demand.

Similar equations hold for the firms $e\left(e \epsilon\left[0, s^{H}\right]\right)$ producing the final nontradable investment good. The related production function is isomorphic to that of the consumption goods (equation 1). Possible differences across consumption and investment bundles are in the elasticity of substitution, the nontradable and import intensities and in the size of import adjustment costs. In particular, the investment bundle $Q_{t}^{I}(e)$ is defined as:

$$
Q_{t}^{I}(e)=\left[v_{I}^{\frac{1}{\mu_{I}}} T T_{t}^{I}(e)^{\frac{\mu_{I}-1}{\mu_{I}}}+\left(1-v_{I}\right)^{\frac{1}{\mu_{I}}} N T_{t}^{I}(e)^{\frac{\mu_{I}-1}{\mu_{I}}}\right]^{\frac{\mu_{I}}{\mu_{I}-1}}
$$

where the parameter $\mu_{I}>0$ denotes the intratemporal elasticity of substitution between tradable and nontradable bundles, while the parameter $v_{I}\left(0 \leq v_{I} \leq 1\right)$ measures the weight of the tradable bundle. The bundles used in the production of the investment good are defined similarly to those of the consumption sector.

Cost minimization Firm $x$ chooses the combination of the tradable and nontradable bundles $H T_{t}^{C}, I M_{t}^{C}$ and $N T_{t}^{C}$ that minimizes the expenditure $P_{H T, t} H T_{t}^{C}+P_{I M^{C}, t} I M_{t}^{C}+P_{N T, t} N T_{t}^{C}$ subject to technology constraints (1) and (2) and taking the input price indexes $P_{H T, t}, P_{I M^{C}, t}$ and $P_{N T, t}$ as given. The implied demand functions are:

$$
\begin{aligned}
& H T_{t}^{C}(x)=v_{T C} v_{C}\left(\frac{P_{H T, t}}{P_{T T^{C}, t}}\right)^{-\mu_{T C}}\left(\frac{P_{T T^{C}, t}}{P_{C, t}}\right)^{-\mu_{C}} Q_{t}^{C}(x) \\
& I M_{t}^{C}(x)=\left(1-v_{T C}\right) v_{C}\left(\frac{P_{I M^{C}, t}}{P_{T T^{C}, t}}\right)^{-\mu_{T C}}\left(\frac{P_{T T^{C}, t}}{P_{C, t}}\right)^{-\mu_{C}} Q_{t}^{C}(x) \\
& N_{t}^{C}(x)=\left(1-v_{C}\right)\left(\frac{P_{N T, t}}{P_{C, t}}\right)^{-\mu_{C}} Q_{t}^{C}(x)
\end{aligned}
$$


and for every good imported by country $H$ from country $C O$ :

$I M_{t}^{C, C O}(x)=v_{I M^{C}}^{H, C O}\left(\frac{P_{I M, t}^{H, C O}}{P_{I M^{C}, t} \Gamma_{I M^{C}}^{H, C O \dagger}\left(I M_{t}^{C, C O}(x) / Q_{t}^{C}(x)\right)}\right)^{-\mu_{I M C}} \frac{I M_{t}^{C}(x)}{1-\Gamma_{I M^{C}}^{H, C O}\left(I M_{t}^{C, C O}(x) / Q_{t}^{C}(x)\right)}$

where the implied cost-minimizing prices are: ${ }^{6}$

$$
\begin{aligned}
P_{C, t} & =\left[v_{C} P_{T T^{C}, t}^{1-\mu_{C}}+\left(1-v_{C}\right) P_{N T, t}^{1-\mu_{C}}\right]^{\frac{1}{1-\mu_{C}}} \\
P_{T T^{C}, t} & =\left[v_{T C} P_{H T, t}^{1-\mu_{T C}}+\left(1-v_{T C}\right) P_{I M^{C}, t}^{1-\mu_{T C}}\right]^{\frac{1}{1-\mu_{T C}}} \\
P_{I M^{C}, t} & =\left(\sum_{C O \neq H} v_{I M^{C}}^{H, C O}\left(\frac{P_{I M, t}^{H, C O}}{\Gamma_{I M^{C}}^{H, C O \dagger}\left(I M_{t}^{C, C O}(x) / Q_{t}^{C}(x)\right)}\right)^{1-\mu_{I M C}}\right)^{\frac{1}{1-\mu_{I M C}}}
\end{aligned}
$$

Similar demands and prices can be derived for the generic firm $e$ belonging to the investment sector. Note that the prices $P_{I, t}, P_{T T^{I}, t}$ and $P_{I M^{I}, t}$ can differ from $P_{C, t}, P_{T T^{C}, t}$ and $P_{I M^{C}, t}$, respectively, because of the different composition of the bundles. To the contrary, $P_{H T, t}$ and $P_{N T, t}$ are the same across the consumption and investment sectors.

In the case of the basket $N T_{t}^{C}$, the following CES technology is exploited by final firms $x$ in the consumption sector:

$$
N T_{t}^{C}(x)=\left[\left(\frac{1}{s^{H}}\right)^{\frac{1}{\theta_{N}}} \int_{0}^{s^{H}} N T_{t}^{C}(x, n)^{\frac{\theta_{N}-1}{\theta_{N}}} d n\right]^{\frac{\theta_{N}}{\theta_{N}-1}}
$$

where $N T_{t}^{C}(x, n)$ defines the use of the nontradable intermediate goods $n$ by the firm $x$ and $\theta_{N}>1$ is the intratemporal elasticity of substitution between the differentiated goods.

The firm $x$ takes the prices of the nontradable goods $P_{t}(n)$ as given and chooses the optimal use of each differentiated intermediate good $n$ by minimizing the expenditure $\int_{0}^{s^{H}} P_{t}(n) N T_{t}^{C}(x, n) d n$ subject to the production function. This yields the following demand for each nontradable in-

${ }^{6}$ The variable $\Gamma_{I M^{C}}^{H, C O \dagger}\left(\frac{I M_{t}^{C, C O}(x)}{Q_{t}^{C}(x)}\right)$ in the bilateral import bundle is defined as:

$$
\Gamma_{I M^{C}}^{H, C O \dagger}\left(\frac{I M_{t}^{C, C O}(x)}{Q_{t}^{C}(x)}\right) \equiv 1-\Gamma_{I M^{C}}^{H, C O}\left(\frac{I M_{t}^{C, C O}(x)}{Q_{t}^{C}(x)}\right)-\left(\Gamma_{I M^{C}}^{H, C O}\left(\frac{I M_{t}^{C, C O}(x)}{Q_{t}^{C}(x)}\right)\right)^{\prime} I M_{t}^{C}(x) .
$$

The term $\left(\Gamma_{I M^{C}}^{H, C O}\left(\frac{I M_{t}^{C, C O}(x)}{Q_{t}^{C}(x)}\right)\right)^{\prime}$ is the first derivative of $\Gamma_{I M^{C}}^{H, C O}\left(\frac{I M_{t}^{C, C O}(x)}{Q_{t}^{C}(x)}\right)$ with respect to imports $I M_{t}^{C, C O}(x)$. 
termediate good $n$ :

$$
N T_{t}^{C}(x, n)=\frac{1}{s^{H}}\left(\frac{P_{t}(n)}{P_{N T, t}}\right)^{-\theta_{N}} N T_{t}^{C}(x)
$$

where $P_{N T, t}$ is the cost-minimizing price of one unit of the nontradable basket:

$$
P_{N T, t}=\left[\frac{1}{s^{H}} \int_{0}^{s^{H}} P_{t}(n)^{1-\theta_{N}} d n\right]^{\frac{1}{1-\theta_{N}}}
$$

The basket $N T_{t}^{I}(e)$ is similarly defined. Total demand for good $n$ can be obtained by aggregating across firms and taking account of public sector consumption (that is fully biased towards nontradable intermediate goods):

$$
\begin{aligned}
& \int_{0}^{s^{H}} N T_{t}^{C}(x, n) d x+\int_{0}^{s^{H}} N T_{t}^{I}(e, n) d e+G_{t}(n) \\
= & \left(\frac{P_{t}(n)}{P_{N T, t}}\right)^{-\theta_{N}}\left(N T_{t}^{C}+N T_{t}^{I}+G_{t}\right)=\left(\frac{P_{t}(n)}{P_{N T, t}}\right)^{-\theta_{N}} N T_{t}
\end{aligned}
$$

where:

$$
\begin{aligned}
N T_{t}^{C} & \equiv \frac{1}{s^{H}} \int_{0}^{s^{H}} N T_{t}^{C}(x) d x \\
N T_{t}^{I} & \equiv \frac{1}{s^{H}} \int_{0}^{s^{H}} N T_{t}^{I}(e) d e \\
G_{t} & =\left[\left(\frac{1}{s^{H}}\right)^{\frac{1}{\theta_{N}}} \int_{0}^{s^{H}} G_{t}(n)^{\frac{\theta_{N}-1}{\theta_{N}}} d n\right]^{\frac{\theta_{N}}{\theta_{N}-1}}
\end{aligned}
$$

In a similar way it is possible to derive domestic demand for domestic tradable intermediate 
goods $h .{ }^{7}$ The implied total demand for the generic brand $h$ is:

$$
\begin{aligned}
& \int_{0}^{s^{H}} H T_{t}^{C}(x, h) d x+\int_{0}^{s^{H}} H T_{t}^{I}(e, h) d e \\
= & \left(\frac{P_{t}(h)}{P_{H T, t}}\right)^{-\theta_{T}}\left(H T_{t}^{C}+H T_{t}^{I}\right)=\left(\frac{P_{t}(h)}{P_{H T, t}}\right)^{-\theta_{T}} H T_{t}
\end{aligned}
$$

where:

$$
\begin{aligned}
H T_{t}^{C} & \equiv \frac{1}{s^{H}} \int_{0}^{s^{H}} H T_{t}^{C}(x) d x \\
H T_{t}^{I} & \equiv \frac{1}{s^{H}} \int_{0}^{s^{H}} H T_{t}^{I}(e) d e
\end{aligned}
$$

Demand for imports is similarly defined and is illustrated at the end of the next section.

\section{Intermediate goods sector}

There are firms producing tradable and nontradable intermediate goods (brands) under monopolistic competition regime. Each tradable brand is produced by a firm $h$ belonging to the continuum of mass $s^{H}\left(h \in\left[0, s^{H}\right]\right)$. Similarly, each nontradable brand is produced by a firm $n$, also defined over the continuum of mass $s^{H}\left(n \in\left[0, s^{H}\right]\right)$.

Technology Each nontradable and tradable intermediate good, respectively $n$ and $h$, is produced using a Cobb-Douglas technology:

$$
\begin{aligned}
Y_{N, t}^{S}(n) & =\max \left\{z_{N, t} K_{t}^{D}(n)^{\alpha_{N}} N_{t}^{D}(n)^{1-\alpha_{N}}-\psi_{N}, 0\right\} \\
Y_{T, t}^{S}(h) & =\max \left\{z_{T, t} K_{t}^{D}(h)^{\alpha_{T}} N_{t}^{D}(h)^{1-\alpha_{T}}-\psi_{T}, 0\right\}
\end{aligned}
$$

${ }^{7}$ The generic firm $x$ in the consumption sector exploits the following CES technology:

$$
H T_{t}^{C}(x)=\left[\left(\frac{1}{s^{H}}\right)^{\frac{1}{\theta_{T}}} \int_{0}^{s^{H}} H T_{t}^{C}(x, h)^{\frac{\theta_{T}-1}{\theta_{T}}} d h\right]^{\frac{\theta_{T}}{\theta_{T}-1}}, \theta_{T}>1
$$

The firm $x$ takes the prices of the tradable goods $P(h)$ as given and chooses the optimal use of each differentiated intermediate good $h$ by minimizing the expenditure for the bundle, $\int_{0}^{s^{H}} P_{t}(h) H T_{t}^{C}(x, h) d h$, subject to the production function. This yields the following demand for each tradable intermediate good $h$ :

$$
H T_{t}^{C}(x, h)=\frac{1}{s^{H}}\left(\frac{P_{t}(h)}{P_{H T, t}}\right)^{-\theta_{T}} H T_{t}^{C}(x)
$$

where $P_{H T, t}$ is the cost-minimizing price of one unit of the tradable basket:

$$
P_{H T, t}=\left[\frac{1}{s^{H}} \int_{0}^{s^{H}} P_{t}(h)^{1-\theta_{T}} d h\right]^{\frac{1}{1-\theta_{T}}} .
$$


where $\psi_{N}$ and $\psi_{T}$ are fixed costs taking the same values across firms belonging to the same sector. The inputs are homogenous capital services, $K_{t}^{D}(n)$ and $K_{t}^{D}(h)$, and an index of differentiated labor services, $N_{t}^{D}(n)$ and $N_{t}^{D}(h)$. Capital and labor services are supplied by domestic households under perfect competition and monopolistic competition, respectively. In addition, $z_{N, t}$ and $z_{T, t}$ are sector-specific productivity shocks (they are identical across firms within each sector). The shocks $z_{N, t}$ and $z_{T, t}$ can be permanent or transitory. ${ }^{8}$

For the labor input, $N_{t}^{D}(n)$ is a combination of two types bundles of the labor varieties supplied by domestic households. $I$-type households represent a share $1-\omega$ of domestic households and are indexed by $i \epsilon\left[0, s^{H}(1-\omega)\right]$ while $J$-type households represent a share $\omega$ and are indexed by $j \epsilon\left(s^{H}(1-\omega), s^{H}\right]$. Each firm $n$ uses a CES combination of the two types of labor:

$$
N_{t}^{D}(n)=\left[(1-\omega)^{\frac{1}{\eta}} N_{I, t}^{D}(n)^{\frac{\eta-1}{\eta}}+\omega^{\frac{1}{\eta}} N_{J, t}^{D}(n)^{\frac{\eta-1}{\eta}}\right]^{\frac{\eta}{\eta-1}}
$$

where $\eta>0$ denotes the elasticity of substitution between the two household-specific bundles of labor services $I$ and $J$. The household-specific labor bundles are:

$$
\begin{aligned}
& N_{I, t}^{D}(n)=\left[\left(\frac{1}{s^{H}(1-\omega)}\right)^{\frac{1}{\eta_{I}}} \int_{0}^{s^{H}(1-\omega)} N_{t}^{D}(n, i)^{\frac{\eta_{I}-1}{\eta_{I}}} d i\right]^{\frac{\eta_{I}}{\eta_{I}-1}} \\
& N_{J, t}^{D}(n)=\left[\left(\frac{1}{s^{H} \omega}\right)^{\frac{1}{\eta_{J}}} \int_{s^{H}(1-\omega)}^{s^{H}} N_{t}^{D}(n, j)^{\frac{\eta_{J}-1}{\eta_{J}}} d j\right]^{\frac{\eta_{J}}{\eta_{J}-1}}
\end{aligned}
$$

where $\eta_{I}, \eta_{J}>1$ are the elasticities of substitution between the differentiated services of labor varieties $i$ and $j$, respectively. Similar equations hold for the firms producing tradables, $h$.

Cost minimization Firms belonging to the intermediate sectors take the rental cost of capital $R_{t}^{K}$ and the aggregate wage index $W_{t}$ as given. Firms belonging to the tradables sector demand capital and labor services to minimize total input cost, $R_{t}^{K} K_{t}^{D}(h)+\left(1+\tau_{t}^{W_{f}}\right) W_{t} N_{t}^{D}(h)$, subject to the production function, (25). Similarly, firms in the nontradables intermediate sector minimize the cost $R_{t}^{K} K_{t}^{D}(n)+\left(1+\tau_{t}^{W_{f}}\right) W_{t} N_{t}^{D}(n)$ subject to the production function (24). The variable $\tau_{t}^{W_{f}}$ is a payroll tax rate levied by the domestic government on wage payments. We assume it is the same across firms.

The first-order conditions of the firms' cost minimization problem with respect to capital and labor inputs - respectively $K_{t}^{D}(n)$ and $N_{t}^{D}(n)$ for the nontradables sector, $K_{t}^{D}(h)$ and $N_{t}^{D}(h)$

\footnotetext{
${ }^{8}$ In the case of the euro area there is also a technology shock which is common to both sectors and regions, $z_{t}$.
} 
for the tradables sector - are sector-specific. They are rather standard and to save on space we do not report them (see details in the Appendix). Given that all firms face the same factor prices and all firms use the same technology, the nominal marginal cost is identical across firms within each sector (i.e., $M C_{N, t}=M C_{t}(n)$ and $\left.M C_{T, t}=M C_{t}(h)\right):^{9}$

$$
\begin{aligned}
M C_{N, t} & =\frac{1}{z_{N, t}\left(\alpha_{N}\right)^{\alpha_{N}}\left(1-\alpha_{N}\right)^{1-\alpha_{N}}}\left(R_{t}^{K}\right)^{\alpha_{N}}\left(\left(1+\tau_{t}^{W_{f}}\right) W_{t}\right)^{1-\alpha_{N}} \\
M C_{T, t} & =\frac{1}{z_{T, t}\left(\alpha_{T}\right)^{\alpha_{T}}\left(1-\alpha_{T}\right)^{1-\alpha_{T}}}\left(R_{t}^{K}\right)^{\alpha_{T}}\left(\left(1+\tau_{t}^{W_{f}}\right) W_{t}\right)^{1-\alpha_{T}}
\end{aligned}
$$

Nominal wage contracts for differentiated labor services $i$ and $j$ are set in monopolistic competitive markets by $I$-type and $J$-type households, respectively. Each firm takes wages as given and chooses the optimal input of each variety $i$ and $j$ by minimizing the cost of forming householdspecific labor bundles subject to the aggregation constraints (27) and (28), respectively. This setup yields the following demand functions for varieties $i$ and $j$ by the generic firm $n$ :

$$
\begin{aligned}
& N_{t}^{D}(n, i)=\frac{1}{s^{H}}\left(\frac{W_{t}(i)}{W_{I, t}}\right)^{-\eta_{I}}\left(\frac{W_{I, t}}{W_{t}}\right)^{-\eta} N_{t}^{D}(n) \\
& N_{t}^{D}(n, j)=\frac{1}{s^{H}}\left(\frac{W_{t}(j)}{W_{J, t}}\right)^{-\eta_{J}}\left(\frac{W_{J, t}}{W_{t}}\right)^{-\eta} N_{t}^{D}(n)
\end{aligned}
$$

where:

$$
\begin{aligned}
W_{I, t} & =\left[\frac{1}{s^{H}(1-\omega)} \int_{0}^{s^{H}(1-\omega)} W_{t}(i)^{1-\eta_{I}} d i\right]^{\frac{1}{1-\eta_{I}}} \\
W_{J, t} & =\left[\frac{1}{s^{H} \omega} \int_{s^{H}(1-\omega)}^{s^{H}} W_{t}(j)^{1-\eta_{J}} d j\right]^{\frac{1}{1-\eta_{J}}} \\
W_{t} & =\left[(1-\omega)\left(W_{I, t}\right)^{1-\eta}+\omega\left(W_{J, t}\right)^{1-\eta}\right]^{\frac{1}{1-\eta}}
\end{aligned}
$$

Similar considerations hold for the generic firm $h$ in the tradables sector. Total demand for labor input $i$ can be obtained by aggregating across firms:

$$
\begin{aligned}
& \int_{0}^{s^{H}} N_{t}^{D}(h, i) d h+\int_{0}^{s^{H}} N_{t}^{D}(n, i) d n \\
= & \left(\frac{W_{t}(i)}{W_{I, t}}\right)^{-\eta_{I}}\left(\frac{W_{I, t}}{W_{t}}\right)^{-\eta} N_{t}^{D}
\end{aligned}
$$

\footnotetext{
${ }^{9} \mathrm{As}$ mentioned above, in the case of the euro area there is also a shock that is common to both sectors and regions, $z_{t}$.
} 
where $N_{t}^{D}$ is per-capita total labor in the economy.

Similarly, total demand for labor input $j$ is:

$$
\begin{aligned}
& \int_{0}^{s^{H}} N_{t}^{D}(h, j) d h+\int_{0}^{s^{H}} N_{t}^{D}(n, j) d n \\
= & \left(\frac{W_{t}(j)}{W_{J, t}}\right)^{-\eta_{J}}\left(\frac{W_{J, t}}{W_{t}}\right)^{-\eta} N_{t}^{D}
\end{aligned}
$$

Price setting in the nontradable goods sector Each firm in the nontradable intermediate goods sector sells its differentiated output under monopolistic competition. There is sluggish price adjustment due to staggered price contracts à la Calvo (1983). The probability of optimally resetting prices in a given period $t$ is $1-\xi_{N}\left(0 \leq \xi_{N} \leq 1\right)$. All firms that are able to re-optimize their price contracts in a given period $t$ choose the same price, i.e. $\widetilde{P}_{N T, t}=P_{t}(n)$. Those firms which do not re-optimize are allowed to adjust their prices according to the following scheme:

$$
P_{t}(n)=\left(\Pi_{N T, t-1}\right)^{\chi_{N}} \bar{\Pi}^{1-\chi_{N}} P_{t-1}(n)
$$

meaning that the price contracts are indexed to a geometric average of past (gross) sector-specific inflation, $\Pi_{N T, t-1} \equiv P_{N T, t-1} / P_{N T, t-2}$ and the monetary authority's (gross) inflation objective, $\bar{\Pi}$, assumed to be constant. The parameter $\chi_{N}\left(0 \leq \chi_{N} \leq 1\right)$ measures the degree of sectorspecific indexation.

Each firm that re-optimizes at time $t$ maximizes the discounted sum of its expected nominal profits $\left(\Lambda_{I, t, t+k}\right.$, with $\Lambda_{I, t, t}=1$, is the stochastic discount factor of $I$-type households, that by assumption own the domestic firms):

$$
E_{t}\left[\sum_{k=0}^{\infty}\left(\xi_{N}\right)^{k} \Lambda_{I, t, t+k}\left(P_{t+k}(n) N T_{t+k}(n)-M C_{N, t+k}\left(N T_{t+k}(n)+\psi_{N}\right)\right)\right]
$$

subject to the price-indexation scheme (38) and taking as given the demand for its brand:

$$
N T_{t+k}(n)=\left(\frac{P_{t+k}(n)}{P_{N T, t+k}}\right)^{-\theta_{N}} N T_{t+k}
$$

As said above, the marginal costs are symmetric across producers $\left(M C_{t}(n)=M C_{N, t} \forall n\right)$. 
The implied first-order condition is: ${ }^{10}$

$$
E_{t}\left[\sum_{k=0}^{\infty}\left(\xi_{N}\right)^{k} \Lambda_{I, t, t+k}\left(\prod_{s=1}^{k} \Pi_{N T, t+s-1}^{\chi_{N}} \bar{\Pi}^{1-\chi_{N}} \widetilde{P}_{N T, t}-\frac{\theta_{N}}{\theta_{N}-1} M C_{N, t+k}\right) N T_{t+k}(n)\right]=0
$$

Therefore those firms whose price contracts are re-optimized set prices to equate the discounted sum of expected revenues to the discounted sum of expected marginal costs. When prices are fully flexible $\left(\xi_{N}=0\right)$, all firms set the same price and the standard constant markup rule for pricing holds:

$$
P_{N T, t}=\frac{\theta_{N}}{\theta_{N}-1} M C_{N, t}
$$

reflecting the existence of monopoly power. If $\theta_{N}$ is very large (perfect competition regime), then $P_{N T, t}=M C_{N, t}$.

With firms setting prices according to the setup described above (equations (41) and (38)), the sector-specific price index $P_{N T, t}$ evolves according to:

$$
P_{N T, t}=\left[\xi_{N}\left(\Pi_{N T, t-1}^{\chi_{N}} \bar{\Pi}^{1-\chi_{N}} P_{N T, t-1}\right)^{1-\theta_{N}}+\left(1-\xi_{N}\right)\left(\widetilde{P}_{N T, t}\right)^{1-\theta_{N}}\right]^{\frac{1}{1-\theta_{N}}}
$$

To clarify the intuition of the stated price setting problem, it is useful to write the first-order condition in its log-linearized (in the neighborhood of a deterministic steady state) form: ${ }^{11}$

$$
\hat{\pi}_{N T, t}=\frac{\beta}{1+\beta \chi_{N}} E_{t}\left[\hat{\pi}_{N T, t+1}\right]+\frac{\chi_{N}}{1+\beta \chi_{N}} \hat{\pi}_{N T, t-1}+\frac{\left(1-\beta \xi_{N}\right)\left(1-\xi_{N}\right)}{\xi_{N}\left(1+\beta \chi_{N}\right)} \widehat{m c}_{N, t}
$$

where the parameter $\beta(0<\beta<1)$ is the households' discount rate. This expression explicitly shows the relations between current sector-specific inflation, forward- and backward-looking components of the inflation process as well as the real marginal costs $\left(\widehat{m c}_{N, t}\right)$.

Price setting in the tradable goods sector The maximization problem is similar to the one solved by firms belonging to the nontradable intermediate goods sector. Each firm sells its differentiated output under monopolistic competition in the domestic and the foreign markets. The firm charges different prices in local currency at home and in each foreign region. We initially describe the pricing problem in the domestic market and subsequently the pricing problem in the export markets.

\footnotetext{
${ }^{10}$ This first order condition can be rewritten in a recursive way, as in equations (A.57), (A.58) and (A.59) in the Appendix.

${ }^{11}$ The generic variable $\widehat{x}$ is defined as $\log \left(X_{t}\right)-\log (\bar{X})$ where $\bar{X}$ represents the steady state value of $X_{t}$.
} 
Pricing in the domestic market There is sluggish price adjustment due to staggered price contracts à la Calvo (1983). The probability of optimally resetting prices in a given period $t$ is $1-\xi_{H}\left(0 \leq \xi_{H} \leq 1\right)$. All firms that receive permission to reset their price contracts in a given period $t$ choose the same price, $\widetilde{P}_{H T, t}$, while those firms which do not re-optimize update their prices according to the following scheme:

$$
P_{t}(h)=\left(\Pi_{H T, t-1}\right)^{\chi_{H}} \bar{\Pi}^{1-\chi_{H}} P_{t-1}(h)
$$

where $\Pi_{H T, t-1} \equiv P_{H T, t-1} / P_{H T, t-2}$ is the (gross) sector-specific inflation at time $t-1$.

So firm $h$ at time $t$ maximizes the following profit function for the domestic market:

$$
E_{t}\left[\sum_{k=0}^{\infty}\left(\xi_{H}\right)^{k} \Lambda_{I, t, t+k}\left(P_{t+k}(h) H T_{t+k}(h)-M C_{T, t+k}\left(H T_{t+k}(h)+\psi_{T}\right)\right)\right]
$$

subject to the price-indexation scheme (45) and taking as given the total domestic demand for its brand:

$$
H T_{t+k}(h)=\left(\frac{P_{t+k}(h)}{P_{H T, t+k}}\right)^{-\theta_{T}} H T_{t+k} .
$$

The implied first-order condition is: ${ }^{12}$

$$
E_{t}\left[\sum_{k=0}^{\infty}\left(\xi_{H}\right)^{k} \Lambda_{I, t, t+k}\left(\prod_{s=1}^{k} \Pi_{H T, t+s-1}^{\chi_{H}} \bar{\Pi}^{1-\chi_{H}} \widetilde{P}_{H T, t}-\frac{\theta_{T}}{\theta_{T}-1} M C_{T, t+k}\right) H T_{t+k}(h)\right]=0
$$

With firms setting prices according to the setup described above (equations (48) and (45)), the sector-specific price index $P_{H T, t}$ evolves according to:

$$
P_{H T, t}=\left[\xi_{H}\left(\Pi_{H T, t-1}^{\chi_{H}} \bar{\Pi}^{1-\chi_{H}} P_{H T, t-1}\right)^{1-\theta_{T}}+\left(1-\xi_{H}\right)\left(\widetilde{P}_{H T, t}\right)^{1-\theta_{T}}\right]^{\frac{1}{1-\theta_{T}}}
$$

Pricing in the export markets Firm $h$ discriminates across countries, by invoicing and setting the price of its brand in the currency of the generic destination market $C O$. Hence, the local currency pricing assumption holds. There is sluggish price adjustment due to staggered price contracts à la Calvo (1983). The probability of optimally resetting prices in a given period $t$ is $1-\xi_{X}\left(0 \leq \xi_{X} \leq 1\right)$. All firms that receive permission to reset their price contracts in a given period $t$ choose the same price, $\widetilde{P}_{X, t}^{H, C O}$, while those firms which do not re-optimize update

\footnotetext{
${ }^{12}$ This first order condition can be rewritten in a recursive way, as in equations (A.47), (A.48) and (A.49) in the Appendix.
} 
their prices according to the following scheme:

$$
P_{X, t}^{C O}(h)=\left(\Pi_{X, t-1}^{H, C O}\right)^{\chi X} \bar{\Pi}^{1-\chi X} P_{X, t-1}^{C O}(h)
$$

where $\Pi_{X, t-1}^{H, C O} \equiv P_{X, t-1}^{H, C O} / P_{X, t-2}^{H, C O}$ is the sector-specific inflation rate and the foreign inflation objective is assumed to be time invariant and equal to the Home long-run inflation objective, $\bar{\Pi}^{C O}=\bar{\Pi}$.

Each exporting firm $h$ that re-optimizes at time $t$ maximizes the discounted sum of its expected nominal profits, expressed in domestic currency: ${ }^{13}$

$E_{t}\left[\sum_{k=0}^{\infty} \Lambda_{I, t, t+k}\left[\sum_{C O \neq H}\left(\left(\xi_{X}\right)^{k}\left(S_{t+k}^{H, C O} P_{X, t+k}^{C O}(h) I M_{t+k}^{C O}(h)-M C_{T, t+k}\left(I M_{t+k}^{C O}(h)+\psi_{T}\right)\right)\right)\right]\right]$

subject to price-indexation scheme (50) and taking as given the demand function of importing country $C O:^{14}$

$$
I M_{t+k}^{C O}(h)=\left(\frac{P_{X, t+k}^{C O}(h)}{P_{X, t+k}^{H, C O}}\right)^{-\theta_{T}} I M_{t+k}^{C O, H} .
$$

${ }^{13} S^{H, C O}$ is the nominal exchange rate between the Home country $(H)$ and country $C O$, expressed in units of the Home country currency per unit of $C O$ currency.

${ }^{14}$ Note that $s^{H} \times X_{t+k}^{C O}(h)=s^{C O} \times I M_{t+k}^{C O}(h)$, where $X$ stands for the amount of exports and $I M$ stands for the amount of imports. The generic firm $x^{C O}$ in the consumption sector of the importing country $C O$ exploits the following CES technology:

$$
I M_{t}^{C}\left(x^{C O}\right)=\left[\left(\frac{1}{s^{H}}\right)^{\frac{1}{\theta_{T}}} \int_{0}^{s^{H}} I M_{t}^{C}\left(x^{C O}, h\right)^{\frac{\theta_{T}-1}{\theta_{T}}} d h\right]^{\frac{\theta_{T}}{\theta_{T}-1}}, \theta_{T}>1
$$

The firm $x^{C O}$ takes the prices of the imported tradable goods $P_{X}^{C O}(h)$ as given and chooses the optimal use of each differentiated intermediate good $h$ by minimizing the expenditure for the bundle, $\int_{0}^{s^{H}} P_{X, t}^{C O}(h) I M_{t}^{C}\left(x^{C O}, h\right) d h$ subject to the production function. This yields the following demand for each tradable intermediate good $h$ :

$$
I M_{t}^{C}\left(x^{C O}, h\right)=\frac{1}{s^{H}}\left(\frac{P_{X, t}^{C O}(h)}{P_{X, t}^{H, C O}}\right)^{-\theta_{T}} I M_{t}^{C}\left(x^{C O}\right)
$$

where $P_{X, t}^{H, C O}$ is the cost-minimizing price of one unit of the tradable basket:

$$
P_{X, t}^{H, C O}=\left[\frac{1}{s^{H}} \int_{0}^{s^{H}} P_{X, t}^{C O}(h)^{1-\theta_{T}} d h\right]^{\frac{1}{1-\theta_{T}}} .
$$


The implied first-order condition is: ${ }^{15}$

$$
\begin{aligned}
& E_{t}\left[\sum_{k=0}^{\infty}\left(\xi_{X}\right)^{k} \Lambda_{I, t, t+k}\left(\prod_{s=1}^{k}\left(\Pi_{X, t+s-1}^{H, C O}\right)^{\chi X} \bar{\Pi}^{1-\chi X} \widetilde{P}_{X, t}^{H, C O}-\frac{\theta_{T}}{\theta_{T}-1}\left(S_{t+k}^{H, C O}\right)^{-1} M C_{T, t+k}\right) I M_{t+k}^{C O}(h)\right] \\
= & 0
\end{aligned}
$$

Given the price setting setup described above (equations 53 and 50), the bilateral exports price index (of country $H$ to the generic country $C O$ ) evolves according to:

$$
P_{X, t}^{H, C O}=\left[\xi_{X}\left(\left(\Pi_{X, t-1}^{H, C O}\right)^{\chi X} \bar{\Pi}^{1-\chi X} P_{X, t-1}^{H, C O}\right)^{1-\theta_{T}}+\left(1-\xi_{X}\right)\left(\widetilde{P}_{X, t}^{H, C O}\right)^{1-\theta_{T}}\right]^{\frac{1}{1-\theta_{T}}}
$$

\subsection{Households}

There are two types of households, $I$ and $J$. $I$-type households are indexed by $i \in\left[0, s^{H}(1-\omega)\right]$. They have access to financial markets, where they buy and sell domestic government bonds and internationally traded bonds, accumulate physical capital and rent its services to firms, hold money for transaction purposes. $J$-type households are indexed by $j \in\left(s^{H}(1-\omega), s^{H}\right]$. They cannot trade in financial and physical assets but they can intertemporally smooth consumption by adjusting their holdings of money. Both types of households supply differentiated labor services and act as wage setters in monopolistically competitive markets. In what follows we initially describe $I$-type households, then $J$-type households.

\section{I-type households}

Household $i$ gains utility from consumption $C_{t}(i)$ and disutility from working $N_{t}(i)$. In particular, there is external habit formation in consumption, which means that its utility depends positively on the difference between the current level of individual consumption, $C_{t}(i)$, and the lagged average consumption level of households of type $I, C_{I, t-1}$.

Household $i$ lifetime utility function is then:

$$
E_{t}\left[\sum_{k=0}^{\infty} \beta^{k}\left(\frac{1-\kappa}{1-\sigma}\left(\frac{C_{t+k}(i)-\kappa C_{I, t+k-1}}{1-\kappa}\right)^{1-\sigma}-\frac{1}{1+\zeta} N_{t+k}(i)^{1+\zeta}\right)\right]
$$

where $\beta(0<\beta<1)$ is the discount rate, $\sigma(\sigma>0)$ denotes the inverse of the intertemporal elasticity of substitution and $\zeta(\zeta>0)$ is the inverse of the elasticity of work effort with respect

\footnotetext{
${ }^{15}$ This first order condition can be rewritten in a recursive way, as in equations (A.52), (A.53) and (A.54) in the Appendix.
} 
to the real wage (Frisch elasticity). The parameter $\kappa(0 \leq \kappa \leq 1)$ measures the degree of external habit formation in consumption.

The individual budget constraint for household $i$ is:

$$
\begin{aligned}
& \left(1+\tau_{t}^{C}+\Gamma_{v}\left(v_{t}(i)\right)\right) P_{C, t} C_{t}(i)+P_{I, t} I_{t}(i) \\
& +R_{t}^{-1} B_{t+1}(i) \\
& +\left(\left(1-\Gamma_{B^{*}}\left(\frac{S_{t}^{H, U S} B_{t+1}^{*}}{P_{Y, t} Y_{t}} ; r p_{t}\right)\right) R_{t}^{*}\right)^{-1} S_{t}^{H, U S} B_{t+1}^{*}(i)+M_{t}(i)+\Phi_{t}(i)+\Xi_{t} \\
= & \left(1-\tau_{t}^{N}-\tau_{t}^{W_{h}}\right) W_{t}(i) N_{t}(i)+\left(1-\tau_{t}^{K}\right)\left(R_{K, t} u_{t}(i)-\Gamma_{u}\left(u_{t}(i)\right) P_{I, t}\right) K_{t}(i) \\
& +\tau_{t}^{K} \delta P_{I, t} K_{t}(i)+\left(1-\tau_{t}^{D}\right) D_{t}(i)+T R_{t}(i)-T_{t}(i) \\
& +B_{t}(i)+S_{t}^{H, U S} B_{t}^{*}(i)+M_{t-1}(i)
\end{aligned}
$$

where $P_{C, t}$ and $P_{I, t}$ are the prices of a unit of the private consumption good and the investment good, respectively. $R_{t}$ and $R_{t}^{*}$ denote, respectively, the risk-less returns on domestic government bonds, $B_{t+1}(i)$, and internationally traded bonds, $B_{t+1}^{*}(i) .{ }^{16}$ They are paid at the beginning of period $t+1$ and known at time $t$. Domestically traded bond are denominated in domestic currency. Internationally traded bonds are denominated in the currency of the core country of the model, let's call it the US. ${ }^{17}$ The term $\Gamma_{B^{*}}\left(\frac{S_{t}^{H, U S} B_{t+1}^{*}}{P_{Y, t} Y_{t}} ; r p_{t}\right)$ represents a financial intermediation premium that the household must pay when taking a position in the international bond market. It has the following functional form:

$$
\Gamma_{B^{*}}\left(\frac{S_{t}^{H, U S} B_{t+1}^{*}}{P_{Y, t} Y_{t}} ; r p_{t}\right) \equiv \gamma_{B^{*}}\left(\exp \left(\frac{S_{t}^{H, U S} B_{t+1}^{*}}{P_{Y, t} Y_{t}}-\overline{B_{Y}^{*}}\right)-1\right)-r p_{t}
$$

where $\gamma_{B^{*}}>0$ is a parameter, $\overline{B_{Y}^{*}}$ is the long-run (steady-state) net foreign asset position, $r p_{t}$ is a risk premium shock, $P_{Y, t}$ is the gross domestic product (GDP from now on) deflator, $Y_{t}$ is the GDP in real terms. The incurred premium is rebated in a lump-sum manner (see variable $\Xi_{t}$ in the budget constraint) to domestic I-type households, that own firms. The term $M_{t}(i)$ represents domestic money holdings.

The household provides labor services, $N_{t}(i)$, at wage rate $W_{t}(i)$ and rents capital services $u_{t}(i) K_{t}(i)$, at the rental rate $R_{K, t}$, to domestic firms. Varying the intensity of capital utilization

\footnotetext{
${ }^{16}$ In the case of euro area regions, there exists also a bond traded inside the union, denominated in euros. To stabilize the model there is also a transaction cost on the euro denominated bond. For further details see the Appendix.

${ }^{17} S_{t}^{H, U S}$ is the nominal exchange rate, expressed in terms of units of Home currency per unit of the US dollars.
} 
is subject to a proportional cost $\Gamma_{u}\left(u_{t}(i)\right)$, defined as:

$$
\Gamma_{u}\left(u_{t}(i)\right) \equiv \gamma_{u, 1}\left(u_{t}(i)-1\right)+\frac{\gamma_{u, 2}}{2}\left(u_{t}(i)-1\right)^{2}
$$

The law of motion for the capital stock owned by household $i$ is:

$$
K_{t+1}(i)=(1-\delta) K_{t}(i)+\left(1-\Gamma_{I}\left(\frac{I_{t}(i)}{I_{t-1}(i)}\right)\right) I_{t}(i)
$$

where $\delta>0$ is the depreciation rate and $\Gamma_{I}\left(\frac{I_{t}(i)}{I_{t-1}(i)}\right)$ represents an adjustment cost formulated in terms of changes in investment:

$$
\Gamma_{I}\left(\frac{I_{t}(i)}{I_{t-1}(i)}\right) \equiv \frac{\gamma_{I}}{2}\left(\frac{I_{t}(i)}{I_{t-1}(i)}-1\right)^{2}, \gamma_{I}>0
$$

The purchases of the consumption good are subject to a proportional transaction cost, $\Gamma_{v}\left(v_{t}(i)\right)$, defined as:

$$
\Gamma_{v}\left(v_{t}(i)\right) \equiv \gamma_{v, 1} v_{t}(i)+\gamma_{v, 2} v_{t}^{-1}(i)-2 \sqrt{\gamma_{v, 1} \gamma_{v, 2}}
$$

which depends on consumption-based velocity (i.e., the inverse of the household money-toconsumption ratio):

$$
v_{t}(i)=\frac{\left(1+\tau_{t}^{C}\right) P_{C, t} C_{t}(i)}{M_{t}(i)}
$$

The variable $D_{t}(i)$ in the budget constraint represents the dividends paid by firms to $I$-type households (the latter own firms).

The fiscal authority levies taxes on the household's gross income and spending. In particular, $\tau_{t}^{C}$ denotes the consumption tax rate levied on consumption purchases, $\tau_{t}^{N}, \tau_{t}^{K}$ and $\tau_{t}^{D}$ represent tax rates levied respectively on wage income, rental capital income and dividends from firms ownership, while $\tau_{t}^{W_{h}}$ is an additional pay-roll tax rate levied on household wage income that represents the household contribution to social security. Following Coenen, McAdam and Straub (2008) we assume that the utilization cost of physical capital and physical capital depreciation are exempted from taxation. The variable $T R_{t}(i)$ represents lump-sum transfers received from the government and $T_{t}(i)$ lump-sum taxes.

The generic household $i$ holds state-contingent securities, $\Phi_{t}(i)$, which are traded amongst $I$-type households and provide insurance against individual income risk. This guarantees that the marginal utility of consumption out of wage income is identical across individual households and consequently all households choose identical allocations in equilibrium. 
Each household $i$ maximizes its lifetime utility by choosing the consumption and investment goods, $C_{t}(i)$ and $I_{t}(i)$ respectively, the level of the physical capital stock, $K_{t+1}(i)$ and its utilization rate, $u_{t}(i)$, holdings of domestic government bonds and internationally traded bonds, $B_{t+1}(i)$ and $B_{t+1}^{*}(i)$ respectively, and holdings of money, $M_{t}(i)$.

Each household $i$ acts as wage setter for its differentiated labor services $N_{t}(i)$ in monopolistically competitive markets. It is assumed that wages are determined by staggered nominal contracts à la Calvo (1983). Each household receives permission to optimally reset its nominal wage contract in a given period $t$ with probability $1-\xi_{I}$. All households that receive permission to reset their wage contracts in a given period $t$ choose the same wage rate $\widetilde{W}_{I, t}=\widetilde{W}_{t}(i)$. Those households that do not receive permission to re-optimize are allowed to update their wage contracts according to the following indexation scheme:

$$
W_{t}(i)=\left(\Pi_{C, t-1}\right)^{\chi_{I}} \bar{\Pi}^{1-\chi_{I}} W_{t-1}(i)
$$

that is, the nominal wage contracts are indexed to a geometric average of past (gross) consumer price index (CPI from now on) inflation, $\Pi_{C, t-1} \equiv \frac{P_{C, t-1}}{P_{C, t-2}}$ and the monetary authority's (gross) inflation objective, $\bar{\Pi} . \chi_{I}$ is an indexation parameter $\left(0 \leq \chi_{I} \leq 1\right)$.

Each household that is able to re-optimize the wage contract in period $t$ maximizes its lifetime utility function subject to the wage-indexation scheme (63), its budget constraint (56) and the demand for its differentiated labor services (36). The first-order condition is therefore:

$$
E_{t}\left[\sum_{k=0}^{\infty}\left(\beta \xi_{I}\right)^{k}\left(\begin{array}{c}
\Lambda_{t+k}(i)\left(1-\tau_{t+k}^{N}-\tau_{t+k}^{W_{h}}\right) \frac{\widetilde{W}_{I, t}}{P_{C, t+k}}\left(\frac{P_{C, t+k-1}}{P_{C, t-1}}\right)^{\chi_{I}} \bar{\Pi}^{\left(1-\chi_{I}\right) k} \\
-\frac{\eta_{I}}{\eta_{I}-1} N_{t+k}(i)^{\zeta}
\end{array}\right) N_{t+k}(i)\right]=0
$$

where the variable $\Lambda_{t+k}(i)$ is the stochastic discount factor between period $t$ and $t+k$ that can be obtained from the consumption Euler equation of the $I$-type households. ${ }^{18}$ As such, wages are optimally set to equate the household's discounted sum of expected marginal cost, expressed in terms of the disutility of labor, to the expected (after tax) marginal revenues (in terms of consumption-based utility). ${ }^{19}$

When nominal wages are fully flexible, the real wage is equal to marginal rate of substitution between consumption and leisure augmented by the constant markup $\frac{\eta_{I}}{\eta_{I}-1}$ implied by the

\footnotetext{
${ }^{18}$ The variable $\Lambda_{t}(i)$ represents the marginal utility of consumption of household $i$. Given the assumption of domestic complete markets, it is the same across all I-type households.

${ }^{19}$ This first order condition can be rewritten in a recursive way, as in equations (A.18), (A.19) and (A.20) in the Appendix.
} 
monopolistic competition in the labor market:

$$
\left(1-\tau_{t}^{N}-\tau_{t}^{W_{h}}\right) \frac{W_{t}(i)}{P_{C, t}}=\frac{\eta_{I}}{\eta_{I}-1} \Lambda_{t}^{-1}(i) N_{t}(i)^{\zeta}
$$

When households set wage contracts for their differentiated labor services according to the scheme described above, the aggregate wage index evolves as:

$$
W_{I, t}=\left[\xi_{I}\left(\Pi_{C, t-1}^{\chi_{I}} \bar{\Pi}^{1-\chi_{I}} W_{I, t-1}\right)^{1-\eta_{I}}+\left(1-\xi_{I}\right)\left(\widetilde{W}_{I, t}\right)^{1-\eta_{I}}\right]^{\frac{1}{1-\eta_{I}}}
$$

Remaining first-order conditions with respect to $I_{t}(i), K_{t+1}(i), u_{t}(i), B_{t+1}(i), B_{t+1}^{*}(i)$ and $M_{t}(i)$ are rather standard and to save on space we do not report them here (we report them in the Appendix).

\section{J-type households}

In each country there is a continuum of $J$-type households indexed by $j \epsilon\left[s^{H}(1-\omega), s^{H}\right]$. Even though $J$-type households do not have access to capital and bond markets, they can intertemporally smooth consumption by adjusting their holdings of money. The household $j$ chooses purchases of the consumption good $C_{t}(j)$ and holdings of money $M_{t}(j)$ that maximize its lifetime utility function (that is assumed to be similar to that of $I$-type households), subject to its budget constraint:

$$
\begin{aligned}
& \left(1+\tau_{t}^{C}+\Gamma_{v}\left(v_{t}(j)\right)\right) P_{C, t} C_{t}(j)+M_{t}(j)+\Phi_{t}(j) \\
= & \left(1-\tau_{t}^{N}-\tau_{t}^{W_{h}}\right) W_{t}(j) N_{t}(j)+T R_{t}(j)-T_{t}(j)+M_{t-1}(j)
\end{aligned}
$$

where the transaction cost $\Gamma_{v}\left(v_{t}(j)\right)$ depends on consumption-based velocity and is defined in a similar way to equation (61).

Similarly to $I$-type households, $J$-type households act as wage setters for their differentiated labor services (the probability of not adjusting wages in each period is $1-\xi_{J}$ ). Thus, the implied 
first-order condition is: ${ }^{20} 21$

$$
E_{t}\left[\sum_{k=0}^{\infty}\left(\beta \xi_{J}\right)^{k}\left(\begin{array}{c}
\Lambda_{t+k}(j)\left(1-\tau_{t+k}^{N}-\tau_{t+k}^{W_{h}}\right) \frac{\widetilde{W}_{J, t}}{P_{C, t+k}}\left(\frac{P_{C, t+k-1}}{P_{C, t-1}}\right)^{\chi_{J}} \bar{\Pi}^{\left(1-\chi_{J}\right) k} \\
-\frac{\eta_{J}}{\eta_{J}-1} N_{t+k}(j)^{\zeta}
\end{array}\right) N_{t+k}(j)\right]=0
$$

When households set wage contracts for their differentiated labor services according to the scheme described above, the aggregate wage index evolves as:

$$
W_{J, t}=\left[\xi_{J}\left(\Pi_{C, t-1}^{\chi_{J}} \bar{\Pi}^{1-\chi_{J}} W_{J, t-1}\right)^{1-\eta_{J}}+\left(1-\xi_{J}\right)\left(\widetilde{W}_{J, t}\right)^{1-\eta_{J}}\right]^{\frac{1}{1-\eta_{J}}}
$$

The remaining first-order conditions with respect to $C_{t}(j)$ and $M_{t}(j)$ are rather standard and we do not report them here (we report them in the Appendix).

\subsection{Monetary and fiscal authorities}

Monetary authorities In each country $C O$ not belonging to the monetary union, the monetary authority faces a Taylor-type interest rate rule specified in terms of annual CPI inflation, $\Pi_{C, t}^{C O, 4}\left(\Pi_{C, t}^{C O, 4} \equiv P_{t}^{C O} / P_{t-4}^{C O}\right)$ and quarterly output growth, $Y \operatorname{gr}_{t}^{C O}\left(Y \operatorname{gr}_{t}^{C O} \equiv Y_{t}^{C O} / Y_{t-1}^{C O}\right)$ :

$$
\begin{aligned}
\left(R_{t}^{C O}\right)^{4}= & \phi_{R}^{C O}\left(R_{t-1}^{C O}\right)^{4}+\left(1-\phi_{R}^{C O}\right)\left[\left(\bar{R}^{C O}\right)^{4}+\phi_{\Pi}^{C O}\left(\Pi_{C, t}^{C O, 4}-\bar{\Pi}^{C O, 4}\right)\right] \\
& +\phi_{g Y}^{C O}\left(Y \operatorname{gr}_{t}^{C O}-1\right)+\varepsilon_{R, t}^{C O}
\end{aligned}
$$

where $\left(\bar{R}^{C O}\right)^{4}=\beta^{-4} \bar{\Pi}^{C O}$ is the equilibrium nominal interest rate in country $C O, \bar{\Pi}^{C O}$ is the monetary authority's inflation target and the term $\varepsilon_{R^{C O}, t}$ is a serially uncorrelated monetary policy shock.

In the case of the euro area $(E A)$, a similar equation holds for the (single) monetary authority, that targets a weighted (by regional size) average of regional (Home, $H$, and rest of the euro area, $R E A$ ) annual CPI inflation and real quarterly output growth:

$$
\begin{aligned}
\left(R_{t}^{E A}\right)^{4}= & \phi_{R}^{E A}\left(R_{t-1}^{E A}\right)^{4}+\left(1-\phi_{R}^{E A}\right)\left[\left(\bar{R}^{E A}\right)^{4}+\phi_{\Pi}^{E A}\left(\Pi_{C, t}^{E A, 4}-\bar{\Pi}^{E A, 4}\right)\right] \\
& +\phi_{g Y}^{E A}\left(Y \operatorname{gr}_{t}^{E A}-1\right)+\varepsilon_{R, t}^{E A}
\end{aligned}
$$

\footnotetext{
${ }^{20} \mathrm{As}$ in the case of $I$-type households, the variable $\Lambda_{t+k}(j)$ is the stochastic discount factor between period $t$ and $t+k$ that can be obtained from the consumption Euler equation of the $J$-type households.

${ }^{21}$ This first order condition can be rewritten in a recursive way, as in equations (A.30), (A.31) and (A.32) in the Appendix.
} 
where:

$$
\begin{gathered}
Y \operatorname{gr}_{t}^{E A} \equiv \frac{Y_{t}^{E A}}{Y_{t-1}^{E A}} \equiv \frac{s^{H} Y_{t}^{H}+s^{R E A} Y_{t}^{R E A}}{s^{H} Y_{t-1}^{H}+s^{R E A} Y_{t-1}^{R E A}} \\
\Pi_{C, t}^{E A, 4} \equiv\left(\Pi_{C, t}^{H, 4}\right)^{\frac{{ }^{H}}{s^{H}+s^{R E A}}}\left(\Pi_{C, t}^{R E A, 4}\right)^{\frac{s^{R E A}}{s^{H}+s^{R E A}}}
\end{gathered}
$$

with:

$$
\Pi_{C, t}^{H, 4} \equiv \frac{P_{C, t}^{H}}{P_{C, t-4}^{H}}, \Pi_{C, t}^{R E A, 4} \equiv \frac{P_{C, t}^{R E A}}{P_{C, t-4}^{R E A}}
$$

Fiscal authorities In each country the fiscal authority purchases $G$, a final good which is a composite of nontradable intermediate goods only. ${ }^{22}$ The fiscal authority also makes transfer payments to households, $T R_{t}$, issues bonds to refinance its debt, $B_{t}$, earns seigniorage on outstanding money holdings, $M_{t-1}$, and levies taxes. As previously said, there are tax rates on consumption purchases $\left(\tau_{t}^{C}\right)$ and on wage, capital and dividend income $\left(\tau_{t}^{N}, \tau_{t}^{K}, \tau_{t}^{D}\right.$, respectively). There are also pay-roll tax rates levied on household wage income $\left(\tau_{t}^{W_{h}}\right)$ and on wages paid by firms (social contributions, $\tau_{t}^{W_{f}}$ ). Therefore the fiscal authority's period-by-period budget constraint is:

$$
\begin{aligned}
& P_{G, t} G_{t}+T R_{t}+B_{t}+M_{t-1} \\
= & \tau_{t}^{C} P_{C, t} C_{t}+\left(\tau_{t}^{N}+\tau_{t}^{W_{h}}\right) \frac{1}{s^{H}}\left(\int_{0}^{s^{H}(1-\omega)} W_{t}(i) N_{t}(i) d i+\int_{s^{H}(1-\omega)}^{s^{H}} W_{t}(j) N_{t}(j) d j\right) \\
& +\tau_{t}^{W_{f}} W_{t} N_{t}+\tau_{t}^{K}\left(R_{k, t} u_{t}-\left(\Gamma_{u}\left(u_{t}\right)+\delta\right) P_{I, t}\right) K_{t}+\tau_{t}^{D} D_{t} \\
& +T_{t}+R_{t}^{-1} B_{t+1}+M_{t}
\end{aligned}
$$

where all quantities are expressed in domestic per-capita-terms (defined below), except for the labor services and wages, which are differentiated across the two types of households. The fiscal authority's purchases of the final public consumption good and the fiscal authority's transfers, both specified as a fraction of steady-state nominal output, $g_{t} \equiv \frac{P_{G, t} G_{t}}{P_{Y} Y}$ and $t r_{t} \equiv \frac{T R_{t}}{P_{Y} Y}$ respectively, follow $\mathrm{AR}(1)$ processes:

$$
\begin{aligned}
g_{t} & =\left(1-\rho_{g}\right) \bar{g}+\rho_{g} g_{t-1}+\varepsilon_{g, t} \\
t r_{t} & =\left(1-\rho_{t r}\right) \overline{t r}+\rho_{t r} t r_{t-1}+\varepsilon_{t r, t}
\end{aligned}
$$

${ }^{22}$ Therefore $P_{G, t}=P_{N T, t}$. 
Lump-sum taxes as a fraction of steady-state nominal output, $\tau_{t} \equiv \frac{T_{t}}{P_{Y} Y}$, are adjusted to make public debt stable according to the following rule:

$$
\tau_{t}=\phi_{B_{Y}}\left(\frac{B_{t}}{\overline{P_{Y} Y}}-\overline{B Y}\right)
$$

where $\overline{B_{Y}}$ is the fiscal authority's target for the ratio of government debt to output and $\phi_{B_{Y}}>0$ is a parameter. All distortionary tax rates are assumed to be exogenously set by the fiscal authority and constant (unless otherwise stated).

\subsection{Aggregate variables}

Given that all households of the same type choose identical allocations in equilibrium, the aggregate quantity expressed in domestic per capita terms of any household's variable (let's call it $\left.X_{t}\right)$ is: ${ }^{23}$

$$
X_{t} \equiv \frac{1}{s^{H}}\left(\int_{0}^{s^{H}(1-\omega)} X_{t}(i) d i+\int_{s^{H}(1-\omega)}^{s^{H}} X_{t}(j) d j\right) \equiv(1-\omega) X_{I, t}+\omega X_{J, t}
$$

where $X_{I, t}$ and $X_{J, t}$ are in per capita terms. Therefore, aggregate per capita consumption, money holdings, lump-sum transfers and taxes are respectively given by:

$$
\begin{aligned}
C_{t} & =(1-\omega) C_{I, t}+\omega C_{J, t} \\
M_{t} & =(1-\omega) M_{I, t}+\omega M_{J, t} \\
T R_{t} & =(1-\omega) T R_{I, t}+\omega T R_{J, t} \\
T_{t} & =(1-\omega) T_{I, t}+\omega T_{J, t}
\end{aligned}
$$

Since only $I$-type households hold financial assets, accumulate physical capital and own domestic firms, the following conditions hold for aggregate per capita holdings of domestic government,

\footnotetext{
${ }^{23}$ Except for labor services that are differentiated across households members.
} 
internationally traded bonds, physical investment, physical capital and dividends, respectively:

$$
\begin{aligned}
B_{t} & =(1-\omega) B_{I, t} \\
B_{t}^{*} & =(1-\omega) B_{I, t}^{*} \\
I_{t} & =(1-\omega) I_{I, t} \\
K_{t} & =(1-\omega) K_{I, t} \\
D_{t} & =(1-\omega) D_{I, t}
\end{aligned}
$$

\subsection{Market clearing conditions}

The market clearing condition for nontradable intermediate good $n$ is:

$$
Y_{N, t}^{S}(n)=N T_{t}^{C}(n)+N T_{t}^{I}(n)+G_{t}(n), \forall n
$$

Aggregating over the continuum of firms:

$$
\begin{aligned}
Y_{N, t}^{S} & =\frac{1}{s^{H}} \int_{0}^{s^{H}} Y_{N T, t}^{S}(n) d n \\
& =\frac{1}{s^{H}}\left(\int_{0}^{s^{H}}\left(N T_{t}^{C}(n)+N T_{t}^{I}(n)+G_{t}(n)\right) d n\right) \\
& =\frac{1}{s^{H}} \int_{0}^{s^{H}}\left(\frac{P_{t}(n)}{P_{N T, t}}\right)^{-\theta_{T}} d n N T_{t} \\
& =s_{N, t} N T_{t}
\end{aligned}
$$

where:

$$
s_{N, t} \equiv \frac{1}{s^{H}} \int_{0}^{s^{H}}\left(\frac{P_{t}(n)}{P_{N T, t}}\right)^{-\theta_{N}} d n
$$

measures the degree of dispersion across the differentiated goods $n$. Given the optimal pricesetting strategies for firms producing intermediate goods, the measure of price dispersion evolves according to:

$$
s_{N, t}=\left(1-\xi_{N}\right)\left(\frac{\widetilde{P}_{N T, t}}{P_{N T, t}}\right)^{-\theta_{N}}+\xi_{N}\left(\frac{\Pi_{N T, t}}{\Pi_{N T, t-1}^{\chi_{N}} \bar{\Pi}^{1-\chi_{N}}}\right)^{\theta_{N}} s_{N, t-1}
$$

where $\widetilde{P}_{N T, t}$ denotes the optimal price contracts chosen by those firms that have received permission to reset their prices in period $t$, while $\Pi_{N T, t} \equiv \frac{P_{N T, t}}{P_{N T, t-1}}$. 
For each tradable intermediate good, the following market clearing condition holds:

$$
Y_{T, t}^{S}(h)=H T_{t}(h)+\sum_{C O \neq H} I M_{t}^{C O}(h), \forall h
$$

Aggregating across firms:

$$
\begin{aligned}
Y_{T, t}^{S}= & \frac{1}{s^{H}} \int_{0}^{s^{H}} Y_{T, t}^{S}(h) d h \\
= & \frac{1}{s^{H}}\left(\int_{0}^{s^{H}}\left(H T_{t}^{C}(h)+H T_{t}^{I}(h)\right) d h\right) \\
& +\frac{1}{s^{H}}\left(\int_{0}^{s^{H}} \sum_{C O \neq H}\left(I M_{t}^{C, C O}(h)+I M_{t}^{I, C O}(h)\right) d h\right) \\
= & \frac{1}{s^{H}} \int_{0}^{s^{H}}\left(\frac{P_{t}(h)}{P_{H T, t}}\right)^{-\theta_{T}} H T_{t} d h \\
& +\frac{1}{s^{H}} \sum_{C O \neq H} \int_{0}^{s^{H}}\left(\frac{P_{X, t}^{C O}(h)}{P_{X, t}^{C O}}\right)^{-\theta_{T}} I M_{t}^{C O, H} d h \\
= & s_{H T, t} H T_{t}+\sum_{C O \neq H} s_{X, C}^{H, C O} I M_{t}^{C O, H}
\end{aligned}
$$

where:

$$
\begin{aligned}
s_{H T, t} & \equiv \frac{1}{s^{H}} \int_{0}^{s^{H}}\left(\frac{P_{t}(h)}{P_{H T, t}}\right)^{-\theta_{T}} d h \\
s_{X, t}^{H, C O} & \equiv \frac{1}{s^{H}} \int_{0}^{s^{H}}\left(\frac{P_{X, t}^{C O}(h)}{P_{X, t}^{C O}}\right)^{-\theta_{T}} d h, \forall C O \neq H
\end{aligned}
$$

measure the degree of dispersion across the differentiated goods $h$ in each destination market. ${ }^{24}$

Market clearing condition in the consumption and investment markets respectively imply:

$$
\begin{aligned}
Q_{t}^{C} & =C_{t}+\Gamma_{v, t} \\
Q_{t}^{I} & =I_{t}+\Gamma_{u}\left(u_{t}\right) K_{t}
\end{aligned}
$$

Each household $i$ acts as wage setter in domestic monopolistically competitive labor market.

\footnotetext{
${ }^{24}$ Given the optimal price-setting strategies for firms producing intermediate goods, the measures of price dispersion in the home tradables and export sectors evolve in a similar fashion to equation (92).
} 
Therefore, the corresponding market clearing conditions are:

$$
N_{t}(i)=N_{t}^{D}(i), \forall i
$$

Aggregating over the continuum of household $i$ :

$$
\begin{aligned}
N_{I, t} & =\frac{1}{s^{H}(1-\omega)} \int_{0}^{s^{H}(1-\omega)} N_{t}(i) d i \\
& =\frac{1}{s^{H}(1-\omega)} \int_{0}^{s^{H}(1-\omega)} N_{t}^{D}(i) d i \\
& =\frac{1}{s^{H}(1-\omega)} \int_{0}^{s^{H}(1-\omega)}\left(\frac{W_{t}(i)}{W_{I, t}}\right)^{-\eta_{I}} N_{I, t}^{D} d i \\
& =s_{I, t} N_{I, t}^{D}
\end{aligned}
$$

where:

$$
s_{I, t} \equiv \frac{1}{s^{H}(1-\omega)} \int_{0}^{s^{H}(1-\omega)}\left(\frac{W_{t}(i)}{W_{I, t}}\right)^{-\eta_{I}} d i
$$

is a measure of the degree of dispersion across the differentiated labor varieties $i$. Given the optimal wage-setting strategies for households $i$, this measure evolves according to:

$$
s_{I, t}=\left(1-\xi_{I}\right)\left(\frac{\tilde{W}_{I, t}}{W_{I, t}}\right)^{-\eta_{I}}+\xi_{I}\left(\frac{W_{I, t}}{W_{I, t-1} \Pi_{C, t-1}^{\chi_{I}} \bar{\Pi}^{1-\chi_{I}}}\right)^{\eta_{I}} s_{I, t-1}
$$

where $\tilde{W}_{I, t}$ denotes the optimal wage contracts chosen by those households that receive permission to reset their wages in the labor market in period $t$, while $\Pi_{C, t} \equiv \frac{P_{C, t}}{P_{C, t-1}}$.

Similar conditions hold for $J$-type households:

$$
\begin{aligned}
N_{t}(j) & =N_{t}^{D}(j), \forall j \\
N_{J, t} & =s_{J, t} N_{J, t}^{D}
\end{aligned}
$$

where:

$$
s_{J, t} \equiv \frac{1}{s^{H} \omega} \int_{s^{H}(1-\omega)}^{s^{H}}\left(\frac{W_{t}(j)}{W_{J, t}}\right)^{-\eta_{J}} d j
$$

is a measure of the degree of dispersion across the differentiated labor varieties $j .^{25}$

Finally, total supply of the composite labor bundle equals total demand by firms in tradables

${ }^{25}$ The measure of degree of dispersion across the differentiated labor varieties $j$ evolves in a similar fashion to equation (101). 
and nontradables intermediate sectors:

$$
N_{t}=\frac{1}{s^{H}}\left(\int_{0}^{s^{H}} N_{t}^{D}(n) d n+\int_{0}^{s^{H}} N_{t}^{D}(h) d h\right)=N_{N, t}^{D}+N_{T, t}^{D}=N_{t}^{D}
$$

Each firm demands capital services to produce its differentiated good. Total demand for capital services in each sector is obtained by aggregating across firms:

$$
\begin{aligned}
K_{T, t}^{D} & =\frac{1}{s^{H}} \int_{0}^{s^{H}} K_{t}^{D}(h) d h \\
K_{N, t}^{D} & =\frac{1}{s^{H}} \int_{0}^{s^{H}} K_{t}^{D}(n) d n
\end{aligned}
$$

Total demand for capital in the economy is therefore:

$$
K_{t}^{D} \equiv K_{T, t}^{D}+K_{N, t}^{D}
$$

The market clearing condition in the rental market for capital services implies that the effective utilization of capital satisfies:

$$
u_{t} K_{t}=K_{t}^{D}
$$

As for the distribution of profits:

$$
D_{t}=\frac{1}{s^{H}}\left(\int_{0}^{s^{H}} D_{H, t}(h) d h+\int_{0}^{s^{H}} D_{X, t}(h) d h+\int_{0}^{s^{H}} D_{N, t}(n) d n\right)
$$

The equilibrium holdings of domestic government bonds evolve over time according to the fiscal authority's budget constraint, reflecting the fiscal authority's need to issue debt in order to finance its deficit.

\subsection{Net foreign assets position and international relative prices}

The market clearing conditions, jointly with the budget constraints of the households and the fiscal authority, imply the following aggregate resource constraint:

$$
\begin{aligned}
P_{Y, t} Y_{t}= & P_{C, t}\left(C_{t}+\Gamma_{v, t}\right)+P_{I, t}\left(I_{t}+\Gamma_{u}\left(u_{t}\right) K_{t}\right)+P_{G, t} G_{t}+\sum_{C O \neq H} \frac{s^{C O}}{s^{H}} S_{t}^{H, C O} P_{X, t}^{H, C O} I M_{t}^{C O, H} \\
& -\sum_{C O \neq H} P_{I M, t}^{H, C O} I M_{t}^{H, C O}
\end{aligned}
$$


where:

$$
\Gamma_{v, t} \equiv \int_{0}^{s^{H}(1-\omega)} \Gamma_{v}\left(v_{t}(i)\right) C_{t}(i) d i+\int_{s^{H}(1-\omega)}^{s^{H}} \Gamma_{v}\left(v_{t}(j)\right) C_{t}(j) d j
$$

and imports of country $H$ from country $C O$ are:

$$
I M_{t}^{H, C O} \equiv I M_{t}^{C, C O} \frac{1-\Gamma_{I M^{C}}^{H, C O}\left(I M_{t}^{C, C O} / Q_{t}^{C}\right)}{\Gamma_{I M^{C}}^{H, C O}\left(I M_{t}^{C, C O} / Q_{t}^{C}\right)}+I M_{t}^{I, C O} \frac{1-\Gamma_{I M^{I}}^{H, C O}\left(I M_{t}^{I, C O} / Q_{t}^{I}\right)}{\Gamma_{I M^{I}}^{H, C O \dagger}\left(I M_{t}^{I, C O} / Q_{t}^{I}\right)}
$$

The Home holdings of foreign bonds (that is, the Home economy's net foreign asset position), denominated in foreign currency, evolve according to:

$$
R_{t}^{*-1} B_{t+1}^{*}=B_{t}^{*}+\frac{T B_{t}^{H}}{S_{t}^{H, U S}}
$$

where $T B_{t}^{H}$ stands for the Home economy's trade balance:

$$
T B_{t}^{H} \equiv \sum_{C O \neq H} \frac{s^{C O}}{s^{H}} S_{t}^{H, C O} P_{X, t}^{H, C O} I M_{t}^{C O, H}-\sum_{C O \neq H} P_{I M, t}^{H, C O} I M_{t}^{H, C O}
$$

The Home bilateral terms of trade are defined as the domestic price of imports relative to the price of exports, both expressed in Home currency:

$$
T O T_{t}^{H, C O} \equiv \frac{P_{I M, t}^{H, C O}}{S_{t}^{H, C O} P_{X, t}^{H, C O}}
$$

The Home bilateral real exchange rate is defined as the CPI of country $C O$ relative to the CPI of country $H$, both expressed in Home currency:

$$
R E R_{t}^{H, C O} \equiv \frac{S_{t}^{H, C O} P_{C, t}^{C O}}{P_{C, t}^{H}}
$$

The Home effective real exchange rate is computed as the geometric weighted average of bilateral real exchange rates with a double-weighting scheme: ${ }^{26}$

$$
R E E R_{t}^{H} \equiv \prod_{C O \neq H}\left(R E R_{t}^{H, C O}\right)^{\nu^{H, C O}}
$$

\footnotetext{
${ }^{26}$ The construction of the indexes follows the BIS methodology. See Buldorini, Makrydakis and Thimann (2002) and Turner and Van’t dack (1993).
} 
The parameter $\nu^{H, C O}$ is the overall weight of the bilateral real exchange rate between country $\mathrm{H}$ and country CO. It is a combination of the export weight $\nu_{X}^{H, C O}$ and import weight $\nu_{I M}^{H, C O}$ :

$$
\begin{gathered}
\nu^{H, C O}=\frac{P_{X, t}^{H} X_{t}^{H}}{P_{I M, t}^{H} I M_{t}^{H}+P_{X, t}^{H} X_{t}^{H}} \nu_{X}^{H, C O}+\frac{P_{I M, t}^{H} I M_{t}^{H}}{P_{I M, t}^{H} I M_{t}^{H}+P_{X, t}^{H} X_{t}^{H}} \nu_{I M}^{H, C O} \\
P_{I M, t}^{H} I M_{t}^{H} \equiv \sum_{C O \neq H} P_{I M, t}^{H, C O} I M_{t}^{H, C O} \\
X_{t}^{H} \equiv \sum_{C O \neq H} \frac{s^{C O}}{s^{H}} I M_{t}^{C O, H} \\
\nu_{X}^{H, C O}=\frac{X_{t}^{H, C O}}{X_{t}^{H}} \frac{P_{X}^{H} S_{t}^{H, C O} X_{C O \neq H}^{H} \frac{s^{C O}}{P^{H}} S_{t}^{H, C O} P_{X, t}^{H, C O} I M_{t}^{C O, H} Y_{t}^{C O}+\sum_{K \neq\{C O, H\}} S_{t}^{H, K} P_{X, t}^{K} X_{t}^{K, C O}}{\sum_{K \neq\{C O, H\}} \frac{X_{t}^{H, K}}{X_{t}^{H}} \frac{S_{t}^{H, C O} P_{X, t}^{C O} X_{t}^{C O, K}}{P_{Y, t}^{K} Y_{t}^{K}+\sum_{J \neq K} S_{t}^{H, J} P_{X, t}^{J} X_{t}^{J, K}}} \\
\sum_{I M}^{H, C O}=S_{t}^{H, C O} \frac{P_{X, t}^{C O} I M_{t}^{H, C O}}{P_{I M, t}^{H} I M_{t}^{H}}
\end{gathered}
$$

Note that the export weight $\nu_{X}^{H, C O}$ (equation 123) captures both direct and third-market competition (the second term in the equation 123). The import weight (equation 124) measures the competition between the country $C O$ and other exporters to $H$.

\section{Calibration}

Tables 1 to 7 summarize the (quarterly) calibration of the model. We set parameter values according to the empirical evidence or existing literature on NAWM and GEM. We calibrate the model to Germany (Home country), rest of the euro area (REA), United States (US) and rest of the world (RW). Germany and rest of the euro area share the monetary policy and the nominal exchange rate against third countries, consistently with the monetary union framework. We choose Germany because it is the largest economy of the euro area.

Table 1 reports preference and technology parameters. Preferences are the same across household types and regions. We set the discount factor, the habit persistence parameter, the intertemporal elasticity of substitution and the Frisch elasticity respectively to 0.9926 (implying 
a steady-state annualized real interest rate of about 3 percent), 0.70, 1 and 0.50 . We set the quarterly depreciation rate of capital to 0.025 , consistent with an annual depreciation rate of 10 percent and the share of $J$-type households to 0.25 in each region.

For the production side, there is a bias toward capital of 0.3 in the Cobb-Douglas production functions of tradable and nontradable intermediate goods. As for the final goods baskets, the degree of substitutability between domestic and imported tradables is higher than that between tradables and nontradables, consistent with existing literature. In particular, we set the elasticity of substitution between tradables and nontradables to 0.5 while the elasticity between domestic and imported tradables to $2.5 .^{27}$ The biases towards the tradable bundle in the consumption and investment baskets are equal respectively to 0.45 and 0.75 in each region of the euro area, respectively to 0.35 and 0.75 in the US and rest of the world. The weight of domestic tradable goods in the consumption and investment tradable baskets is different across countries, to be coherent with multilateral import-to-GDP ratios.

Table 2 reports the implied great ratios. ${ }^{28}$ We set region sizes to match the share of world GDP. We calibrate the net foreign asset position of each economy to match the corresponding data. $^{29}$

Markups in the euro area nontradables sector (that can be thought as a proxy for the services sector) and labor market are higher than the corresponding values in the US and rest of the world (see Table 3). In all regions the markup in the tradables sector (that can be thought as a proxy for the manufacturing sector) has the same value and the markup in the nontradables sector is higher than that in the labor market. Specifically, the net price markup in Germany and rest of the euro area is 20 percent in the tradables sector, 30 percent in the labor market and 50 per cent in the nontradables sector. In the US and the rest of the world we set these markups respectively to 20,16 and 28 percent. ${ }^{30}$

Table 4 reports nominal and real rigidities. We set Calvo price parameters in the domestic tradables and nontradables sector to 0.92 (12.5 quarters) in the euro area, consistently with estimates by Christoffel, Coenen and Warne (2008) and Smets and Wouters (2003). Correspond-

\footnotetext{
${ }^{27}$ Note that the short-run elasticity for imported goods is lower because of adjustment costs on imports. Numbers are consistent with Bayoumi, Laxton and Pesenti (2004).

${ }^{28}$ National accounts data are from the European Commission AMECO database.

${ }^{29}$ Given the calibrated import shares, net foreign asset position and international interest rate, the steady-state trade balance and real exchange rate level endogenously adjust.

${ }^{30}$ The chosen values are consistent with estimates from Martins, Scarpetta and Pilat (1996), suggesting that the degree of competition in the nontradable sector is lower than in the tradable sector. Also, these values are in line with other similar studies, such as Bayoumi, Laxton and Pesenti (2004), Faruqee, Laxton and Muir (2007) and Everaert and Schule (2008)
} 
ing nominal rigidities outside the euro area are equal to 0.75 , implying an average frequency of adjustment equal to 4 quarters, in line with Faruqee, Laxton and Muir (2007). Calvo wage parameters and price parameters in the export sector are equal to 0.75 in all the regions. The indexation parameters on prices and wages are equal respectively to 0.50 and 0.75 , so to get sufficiently hump-shaped response of wages and price. For real rigidities, we set adjustment costs on investment changes to 6 in the euro area and to 4 in the case of the US and rest of the world; and adjustment costs on consumption and investment imports to 2 and 1, respectively. We set weights of bilateral imports (Table 5) to match the trade matrix reported in Table $6 .{ }^{31}$ Finally, Table 7 reports parameters in the monetary rules and fiscal rules. The interest rate reacts to the its lagged value (inertial component of the monetary policy), annual inflation and quarterly output growth. In the monetary union, monetary policy reacts to euro area wide variables. For fiscal rules, lump-sum taxes stabilize public debt. Steady-state ratios of government debt over output are equal to 2.40 in all the regions (0.6 in annual terms). Consistently with the empirical evidence (see Coenen, MacAdam and Straub, 2008), steady state tax rates on consumption and labor income are respectively equal to 0.183 and 0.122 in the euro area; and to 0.077 and 0.154 outside the euro area. We set the tax rate on capital income to match the investment-to-output ratio. The rates on social contributions paid by firms are equal to 0.219 in the euro area and 0.071 outside the euro area while those paid by households are equal to 0.118 and 0.071 in the euro area and outside the euro area, respectively.

\section{Simulations}

In what follows we report the effects of several shocks to show the main transmission channels operating in EAGLE. Specifically, a monetary policy shock in the euro area, an array of Home shocks, a shock to the euro area nominal exchange rate and, finally, a shock to extra-euro area aggregate demand. The model can be simulated under perfect foresight using TROLL or, equivalently, DYNARE codes.

\subsection{Monetary policy shock}

Figures 1a-1d show the implications of a monetary policy shock in the euro area. The shock is such that there is an initial decline in the (annualized) short-term nominal interest rate of about

\footnotetext{
${ }^{31}$ The trade matrix is calibrated using Eurostat and IMF trade statistics.
} 
100 basis points.

As shown in Figure 1a, in the Home economy the associated reduction in the (ex-ante) real interest rate stimulates consumption and investment by $I$-type households. Firms increase labor demand to satisfy higher aggregate demand. Both hours worked and real wages increase. In the case of $J$-type households, the higher real wage income stimulates higher consumption. Aggregate consumption and labor closely follow $I$-type households corresponding variables, whose share in the population is relatively high. Higher aggregate demand favors an increase in both tradables and nontradables production. The strong increase in investment, whose tradable component is relatively high, implies that tradables production expands more than nontradables production. Overall, Home real output increases up to a maximum of 0.7 percent five quarters after the shock, while the annualized CPI inflation rate increases up to 0.4 p.p. a year after the shock.

For trade variables, the lower interest rate favors the depreciation of the nominal (and real) exchange rate. The terms of trade improve, because of the real exchange rate depreciation and the local currency pricing assumption. ${ }^{32}$ The Home trade balance-to-GDP ratio initially improves, as the real exchange rate depreciation induces an increase in the domestic currency value of exports. Subsequently, it deteriorates, because in the short run imports closely track aggregate demand and are rather insensitive to changes in relative prices, given the assumption of the low elasticity of substitution between domestic and imported tradable goods. ${ }^{33}$

Figure $1 \mathrm{~b}$ reports the effects of the shock in the rest of the euro area. They are rather similar to those obtained in the Home economy, both qualitatively and quantitatively. Figures 1c and $1 \mathrm{~d}$ report the bilateral trade variables of the Home economy and the rest of the euro area, respectively. Bilateral intra-euro area imports increase slightly more than extra-euro area bilateral imports and exports, as the euro area aggregate demand (in particular the investment component) is biased towards euro area tradables. However, the increase in intra-euro area imports is less persistent than the increase in imports from the rest of the world and the US. Their relative prices increase in the medium term because of the high level of economic activity in the euro area. As a consequence, households in the euro area gradually substitute extra-euro area tradables for those produced in the euro area. For international relative prices, the change in bilateral real exchange rate between the two euro area regions, which corresponds to the CPI

\footnotetext{
${ }^{32}$ In all Figures, an increase in the real exchange rate represents a depreciation, while an increase in the terms of trade represents a worsening.

${ }^{33}$ The short-run elasticity of imports with respect to relative prices is lower than the corresponding long-run value because of the adjustment costs on imports.
} 
inflation differential, is smaller than the changes in the bilateral real exchange rates against the US and the rest of the world. Specifically, the inflation rate in the rest of the euro area increases (slightly) more than in the Home country, because the lower interest rate stimulates investment, which is relatively biased towards domestically produced goods. As a consequence, the inflation rate of goods produced in the rest of the euro area increases, driving up the CPI inflation. Consistently, the terms of trade of the rest of the euro area against the Home country improve, albeit by a rather small amount. Similarly, given the local currency pricing assumption and the nominal (and real) exchange rate depreciation, the Home and rest of the euro area bilateral terms of trade against the US and the rest of the world improve.

\subsection{Home government spending shock}

Figures 2a-2d show the effects of an exogenous rise in the Home government spending equal to one percent of ex-ante GDP. The persistence of the shock is equal to 0.90. Higher government spending induces an immediate expansion of output by roughly 1 percent, while inflation increases, by almost 0.1 percentage points three periods after the shock. Households aggregate consumption decreases to a small extent, for two reasons. First, the presence of liquidity-constrained ( $J$-type) households. Differently from I-type households, they are not subject to the negative wealth effect associated to the higher government spending, but benefit from the higher real wage income. Hence their consumption increases. The second reason is that the negative wealth effect on unconstrained household consumption is partially compensated by the positive intertemporal substitution effect associated to the lower real interest rate in the Home region. The latter decreases because the nominal interest rate, that reacts to euro area wide inflation and output growth, does not increase as much as Home inflation does. The increase in aggregate demand stimulates labor demand and hence hours worked and real wage. Capital and labor move from the tradables sector, whose output decreases, to nontradables sector, whose output increases because public expenditure is fully biased towards nontradables. The increase in demand for nontradables favors the appreciation of the Home real exchange rate. The Home terms of trade improve, because the increase in the marginal cost of production is partially passed-through into higher prices. ${ }^{34}$ The higher demand and the real exchange rate appreciation favor the decrease in the trade balance-to-GDP ratio. In the rest of the monetary union (Figure 2b), output ba-

\footnotetext{
${ }^{34}$ The higher demand for capital and labor drives up the rental rate of capital and wages, and, as a consequence, production costs of tradables.
} 
sically does not move after the shock but afterwards slightly decreases. The real exchange rate depreciation and the terms of trade deterioration favor the increase in global demand for rest of the euro area tradables, whose production slightly increases. Capital and labor in the rest of the euro area move from the nontradables to the tradables sector. Consistently, the nontradable output decreases. The trade balance moves into surplus, albeit only slightly. Both aggregate consumption and investment slightly decrease, so to that there is enough saving to contribute to finance the Home economy's trade deficit.

Figure $2 \mathrm{c}$ and $2 \mathrm{~d}$ report bilateral trade variables of Home economy and the rest of the euro area, respectively. The Home bilateral real exchange rates appreciate and the Home terms of trade improve, driven by the increase in public sector demand. Consistently, all bilateral exports decrease, while imports slightly increase on impact and then decrease. Households in the rest of the world and in the US substitute domestic and rest of the euro area tradables for Home tradables, because the former are cheaper than the latter. As such extra-euro area net exports of the rest of the euro area region increase, albeit only slightly. The bilateral exchange rates of the rest of the euro area depreciate, given the decrease in domestic demand, while the terms of trade against the US and the rest of the world slightly improve on impact.

\subsection{Markup shock in the Home nontradables sector}

Figures 3a-3d show the implications of a transitory markup shock in the nontradables sector of the Home country. The shock is normalized to (roughly) get a one per cent maximum increase in Home output. Its persistence is 0.90 .

Given the reduction in the markup, firms in the nontradables sector expand their output. Tradables production increases as well, as nontradables and tradables are complement goods (the elasticity of substitution between tradables and nontradables is calibrated to a rather low value). Higher production leads firms to increase demand for inputs, so hours worked and capital accumulation increase, pushing up the real wage and the rental rate of capital (not shown). The relative price and inflation rate of nontradables decrease and, given the high weight of the nontradable goods in the consumption basket, the CPI inflation decreases as well. The Home real interest rate increases, because the monetary union nominal interest rate decreases less than Home inflation. However, both consumption and investment increase, driven by the relatively cheap price of nontradables. The excess supply of nontradables induces a depreciation of the real exchange rate. The latter limits the decrease in net exports, driven by higher imports. The 
rest of the monetary union (Figure 3b), which is the main trade partner of the Home country, is positively affected by the lower nominal interest rate and the depreciation of its real exchange rate. Both variables positively impact on the level of aggregate demand and economic activity.

For bilateral trade variables (Figure 3c), Home imports increase, while exports decrease, as higher Home marginal costs of producing both tradables and nontradables imply a loss of Home competitiveness. The Home terms of trade, consistently, improve. Rest of the euro area exports and imports increase (Figure 3d). Rest of euro area exports increase in the short term because cheaper than the Home tradables, while imports augment because of higher aggregate demand in the rest of the euro area. The rest of the euro area bilateral real exchange rates depreciate, driven by the excess supply of goods in the euro area. The rest of the euro area bilateral terms of trade improve, as global demand for rest of euro area tradables increases.

\subsection{Markup shock in the Home tradables sector}

Figures 4a-4d show the effects of a transitory markup shock in the tradables sector of the Home country. The shock is normalized to get a roughly one per cent maximum increase in Home output. Its persistence is 0.90 .

As for the nontradable price markup shock, the complementarity between tradables and nontradables implies that production increases in both sectors. Differently from the case of nontradables price markup shock, Home inflation increases, driven by the higher production costs (demand for labor and capital increase driving up input prices) and by the higher price of nontradables, whose share in the CPI is relatively high. As a consequence, the real interest rate decreases, further stimulating consumption and investment. The former increases also because $J$-type households augment their consumption, as their labor income increases following the higher labor demand.

Differently from the case of nontradable markup shock, there is now excess demand for nontradables, that induces a real exchange rate appreciation. Higher aggregate demand and the real appreciation induce a decrease in the trade balance-to-GDP ratio. The rest of the monetary union (Figure 4b) reduces the production of domestic tradables, that have become relatively more expensive than Home tradables. Overall, output in the rest of the euro area decreases. Investment benefits from the lower price of imports from the Home country, while consumption of $I$-type households is negatively affected by the higher real interest rate (the CPI inflation rate is negative, because of the decrease in the aggregate demand for domestic goods). $J$-type 
households consumption, to the contrary, increases, taking advantage of the higher real wage income.

For bilateral trade variables (Figures 4c and 4d), Home country exports and imports increase, the former more than the latter. Home imports increase because of the higher Home aggregate demand.

The Home real exchange rate appreciates against all other countries because of the increased demand for nontradables, while the terms of trade deteriorate, because of the high tradables supply. Rest of the euro area exports and imports respectively to and from the U.S. and the rest of the world decrease, given that both have become relatively expensive with respect to the Home tradables. The rest of the euro area real exchange rate appreciates against the US and the rest of the world, consistently with the higher aggregate demand for goods produced in the euro area. The terms of trade against US and the rest of the world deteriorate on impact.

\subsection{Markup shock in the Home labor market}

Figures 5a-5d show the implications of a transitory markup shock in the labor market of the Home country. The shock is normalized to get a (roughly) one per cent maximum increase in Home output. Its persistence is 0.90 .

I-type households benefit from higher profits from domestic firms ownerships. The associated positive income effect favor an increase in consumption and a decrease in hours worked. Firms substitute $J$-type households' hours worked for $I$-type households' hours worked. As a consequence, in equilibrium the $J$-type real wages increase, while $I$-type real wages decrease. Higher $J$-type labor income drives up consumption. Firms increase production of both tradables and nontradables. The Home CPI inflation decreases, driving up the Home real interest rate. The latter partially attenuates the increase in consumption. Both consumption and investment increase, driving down the trade balance-to-GDP ratio. The real exchange rate depreciates and the terms of trade deteriorate, consistently with the Home excess supply of goods. Figure 5b shows the spillovers to the rest of the euro area. The high level of Home economic activity slightly improves the rest of the euro area trade balance and, hence, production and income. Aggregate demand and inflation increase. The latter drives down the real interest rate, further stimulating aggregate demand.

Figure $5 \mathrm{c}$ reports Home trade variables. Home exports increase towards all markets, given that they are relatively cheap (the excess supply translates into the real depreciation and deteri- 
oration of the bilateral exchange rate and terms of trade, respectively). Home imports increase as well, albeit in a smooth manner, thanks to higher aggregate demand. Rest of the euro area trade variables (Figure 5d) show an increase in imports from all countries and a decrease in exports toward US and the rest of the world, as the worldwide demand shifts towards cheaper Home tradables. To the opposite, exports toward the Home region increase. The real exchange rate depreciates against US and rest of the world, so to absorb the excess supply of goods produced in the euro area. The terms of trade improve, consistently with the local currency pricing assumption and the exchange rate depreciation.

\subsection{Risk premium shock}

Figures 6a-6d show the effects of a shock to the risk-premium on US currency-denominated assets paid by the Home and the rest of the euro area. The shock is calibrated to induce on impact a depreciation of the euro against the core currency (the US dollar) by roughly two percent in real terms (one percent for the real effective exchange rate). The persistence of the shock is set to 0.90 .

The effects on the two regions of the euro area are rather symmetric. ${ }^{35}$ The higher risk premium paid to undertake an international financial position in US dollar induces $I$-type households in the euro area to postpone consumption and investment and increase saving. Consistently with higher exports (see later), tradables production in the euro area increases. To the opposite, production of nontradables decreases, consistently with lower consumption and investment. On impact real wages decrease while hours worked increase, as the negative wealth effect associated the exchange rate depreciation induce households to increase labor supply. Home and rest of the euro area trade balances move towards surplus. For bilateral trade variables (Figure $6 \mathrm{c}$ and 6d), Home and rest of the euro area exports increase towards the US and the rest of the world, while imports decrease, as the expenditure-switching effect associated to the real exchange rate depreciation induces world demand to shift towards euro area tradables. Consistently, and given the assumption of local currency pricing, the Home and rest of the euro area terms of trade improve. Note that the Home real exchange rate and terms of trade respectively depreciates and deteriorate against the rest of the euro area. The reason is the stronger increase in rest of the euro area demand for domestic goods, driven by the relatively higher degree of home bias.

\footnotetext{
${ }^{35}$ The effects are also qualitatively and quantitatively similar to those obtained in the NAWM, see Christoffel, Coenen and Warne (2008).
} 


\subsection{Shock to rest of the world consumption preferences}

Figure $7 \mathrm{a}$ and $7 \mathrm{~b}$ show the effects of a preference (i.e. demand) shock outside the euro area, that drives up both the US and rest of the world outputs by around one percent. The persistence of the shock is set to 0.90. Qualitatively, the shock has rather similar effects on both Home and rest of the euro area regions. There is a positive impact on the trade balance. The production of tradables increases in the euro area, while the production of nontradables decreases. The overall effect on euro area output is expansionary. In both regions of the monetary union the shock induces a reduction in consumption and investment to make room for loans to US and rest of the world households, whose aggregate demand has increased. To the contrary, hours worked increase to sustain the higher level of production. Home and rest of the euro area real effective exchange rates depreciate, while the terms of trade, differently from the case of the risk premium shock, deteriorate. The reason is that aggregate demand in the US and in the rest of the world is biased towards goods produced outside the euro area. For bilateral trade variables (Figure 7c and $7 \mathrm{~d}$ ), there is an increase in euro area exports toward the US and the rest of the world while imports decline, as the bilateral relative prices (against US and the rest of the world) deteriorate. Intra-euro area exports decrease, because of the lower aggregate domestic demand in both Home and rest of the euro area regions.

\section{Conclusions}

The monetary union dimension of the euro area has potentially deep implications for the transmission of shocks originating in the euro area or abroad. Spillovers related to changes in relative prices and to the common monetary policy can be sizeable, and, as a consequence, call for appropriate stabilization policy measures. This paper has outlined a model, EAGLE, aimed at analyzing these issues. Its large scale, jointly with its microfoundations, allows to properly analyze the spillovers in the euro area. In other terms, EAGLE allows to conduct a quantitative analysis in a theoretically coherent and fully consistent model setup, clearly spelling out all the policy implications. The model can be improved along several dimensions, that can be crucial for further understanding the transmission of spillovers in the euro area. For example, the financial structure is relatively simple. It could be made more complex by adding financial frictions, such as borrowing constraints and a financial accelerator. Other real rigidities can also be added, for example the labor market setup could be based on a search model. Or, finally, the assumption 
of rational expectations could be relaxed, by introducing some kind of gradual learning. These issues and their policy implications constitute an exciting research agenda. 


\section{References}

[1] Alves, N., S. Gomes and J. Sousa (2007). An Open Economy Model of the Euro Area and the US. Bank of Portugal Working Paper 18.

[2] Andrés, J., P. Burriel and A. Estrada (2006). BEMOD: A DSGE Model for the Spanish Economy and the Rest of the Euro Area. Bank of Spain Working Paper 0631.

[3] Bayoumi, T., D. Laxton and P. Pesenti (2004). Benefits and Spillovers of Greater Competition in Europe: A Macroeconomic Assessment. ECB Working Paper Series 341.

[4] Buldorini, L., S. Makrydakis and C. Thimann (2002). The Effective Exchange Rate of the Euro. ECB Occasional Paper Series 2.

[5] Calvo, G. A. (1983). Staggered Prices in a Utility-Maximizing Framework. Journal of Monetary Economics 12, 383.

[6] Christoffel, K., G. Coenen and A. Warne (2008). The New Area-Wide Model of the Euro Area: A Micro-Founded Open-Economy Model for Forecasting and Policy Analysis. ECB Working Paper Series 944.

[7] Coenen, G., P. McAdam and R. Straub (2008). Tax reform and labour-market performance in the euro area: A simulation-based analysis using the New Area-Wide Model. Journal of Economic Dynamics and Control 32, 2543-2583.

[8] Cova, P., M. Pisani and A. Rebucci (2009). Global Imbalances: The Role of Emerging Asia. Review of International Economics 17(4), 716-733.

[9] Erceg, C. J., L. Guerrieri and C. Gust (2006). SIGMA: A New Open Economy Model for Policy Analysis. International Journal of Central Banking 2, 1-50.

[10] Everaert, L. and W. Schule (2008). Why It Pays to Synchronize Structural Reforms in the Euro Area Across Markets and Countries. IMF Staff Papers, 55(2).

[11] Faruquee, H., D. Laxton and D. Muir (2007). Smooth Landing or Crash? Model-Based Scenarios of Global Current Account Rebalancing. in R. Clarida (ed.) G7 Current Account Imbalances: Sustainability and Adjustment, Chicago, IL: University of Chicago Press. 
[12] Jacquinot, P. and R. Straub (2008). Globalisation and the Euro Area. Simulation Based Analysis Using the New Area Wide Model. ECB Working Paper Series 907.

[13] Kumhof, M. and D. Laxton (2007). A Party without a Hangover? On the Effects of U.S. Government Deficits. IMF Working Paper 07/202.

[14] Lalonde, R. and D. Muir (2007). The Bank of Canada's Version of the Global Economy Model (BoC-GEM). Bank of Canada Technical Report, 98.

[15] Laxton, D. and P. Pesenti (2003). Monetary Policy Rules for Small, Open, Emerging Economies. Journal of Monetary Economics 50, 1109-1146.

[16] Martins, J. O., S. Scarpetta and D. Pilat (1996). Mark-up Pricing, Market Structure and the Business Cycle. OECD Economic Studies, 27, 71-106.

[17] Pesenti, P. (2008). The Global Economy Model (GEM): Theoretical Framework. IMF Staff Papers 55(2).

[18] Pytlarczyk, E. (2005). An estimated DSGE model for the German economy within the euro area. Deutsche Bundesbank, Discussion Paper Series 1: Economic Studies, 33/2005.

[19] Ratto, M., W. Roeger and J. in 't Veld (2009). QUEST III: An estimated open-economy DSGE model of the euro area with fiscal and monetary policy. Economic Modelling 26, 222-233.

[20] Smets, F. and R. Wouters (2003). An Estimated Dynamic Stochastic General Equilibrium Model of the Euro Area. Journal of the European Economic Association 1 (5), 1124-1175.

[21] Turner, P. and J. Van 't dack (1993). Measuring International Price and Cost Competitiveness. BIS Economic Papers, 39. 


\begin{tabular}{|c|c|c|c|c|}
\hline & Home & REA & US & RW \\
\hline \multicolumn{5}{|l|}{ Households } \\
\hline Discount factor $(\beta)$ & $1.03^{-\frac{1}{4}}$ & $1.03^{-\frac{1}{4}}$ & $1.03^{-\frac{1}{4}}$ & $1.03^{-\frac{1}{4}}$ \\
\hline Intertemporal elasticity of substitution $\left(\sigma^{-1}\right)$ & 1.00 & 1.00 & 1.00 & 1.00 \\
\hline Inverse of the Frisch elasticity of labor $(\zeta)$ & 2.00 & 2.00 & 2.00 & 2.00 \\
\hline Habit persistence $(\kappa)$ & 0.70 & 0.70 & 0.70 & 0.70 \\
\hline Share of J-type households $(\omega)$ & 0.25 & 0.25 & 0.25 & 0.25 \\
\hline Depreciation rate $(\delta)$ & 0.025 & 0.025 & 0.025 & 0.025 \\
\hline \multicolumn{5}{|l|}{ Intermediate-good firms (trad. and nontrad. sectors) } \\
\hline Substitution btw. labor and capital & 1.00 & 1.00 & 1.00 & 1.00 \\
\hline Bias towards capital $(\alpha)$ & 0.30 & 0.30 & 0.30 & 0.30 \\
\hline Substitution btw. I-type and J-type labor $(\eta)$ & 4.33 & 4.33 & 4.33 & 4.33 \\
\hline \multicolumn{5}{|l|}{ Final consumption-good firms } \\
\hline Substitution btw. domestic and imported trad. goods $\left(\mu_{T C}\right)$ & 2.50 & 2.50 & 2.50 & 2.50 \\
\hline Bias towards domestic tradables goods $\left(v_{T C}\right)$ & 0.31 & 0.21 & 0.65 & 0.58 \\
\hline Substitution btw. tradables and nontradables $\left(\mu_{C}\right)$ & 0.50 & 0.50 & 0.50 & 0.50 \\
\hline Bias towards tradable goods $\left(v_{C}\right)$ & 0.45 & 0.45 & 0.35 & 0.35 \\
\hline \multicolumn{5}{|l|}{ Final investment-good firms } \\
\hline Substitution btw. domestic and imported trad. goods $\left(\mu_{T I}\right)$ & 2.50 & 2.50 & 2.50 & 2.50 \\
\hline Bias towards domestic tradables goods $\left(v_{T I}\right)$ & 0.42 & 0.75 & 0.70 & 0.54 \\
\hline Substitution btw. tradables and nontradables $\left(\mu_{I}\right)$ & 0.50 & 0.50 & 0.50 & 0.50 \\
\hline Bias towards tradable goods $\left(v_{I}\right)$ & 0.75 & 0.75 & 0.75 & 0.75 \\
\hline
\end{tabular}




\begin{tabular}{|c|c|c|c|c|}
\hline & Home & REA & US & RW \\
\hline \multicolumn{5}{|l|}{ Domestic demand } \\
\hline Private consumption & 60 & 60 & 63 & 64 \\
\hline Private investment & 20 & 20 & 20 & 20 \\
\hline Public consumption & 20 & 20 & 16 & 16 \\
\hline \multicolumn{5}{|l|}{ Trade } \\
\hline Imports (total) & 28 & 24 & 11 & 15 \\
\hline Imports of consumption goods & 18 & 20 & 7 & 9 \\
\hline Imports of investment goods & 9 & 4 & 4 & 6 \\
\hline Net foreign assets (ratio to annual GDP) & 10 & -3.75 & -15 & 10 \\
\hline \multicolumn{5}{|l|}{ Production } \\
\hline Tradables & 38 & 39 & 37 & 37 \\
\hline Nontradables & 61 & 61 & 63 & 63 \\
\hline Labor & 52 & 52 & 59 & 59 \\
\hline Share of World GDP & 7 & 16 & 30 & 46 \\
\hline
\end{tabular}

Note: REA=Rest of Euro Area; US=United States; RW=Rest of World

Table 3: Price and Wage Markups (Implied Elasticities of Substitution)

\begin{tabular}{llll}
\hline \hline & Tradables $\left(\theta_{T}\right)$ & Nontradables $\left(\theta_{N}\right)$ & Wages $\left(\eta_{I}=\eta_{J}\right)$ \\
Home & $1.20(6.0)$ & $1.50(3.0)$ & $1.30(4.3)$ \\
REA & $1.20(6.0)$ & $1.50(3.0)$ & $1.30(4.3)$ \\
US & $1.20(6.0)$ & $1.28(4.6)$ & $1.16(7.3)$ \\
RW & $1.20(6.0)$ & $1.28(4.6)$ & $1.16(7.3)$
\end{tabular}

Note: REA=Rest of Euro Area; US=United States; RW=Rest of World 


\begin{tabular}{lllll}
\hline \hline & Home & REA & US & RW \\
& & & & \\
Adjustment costs & 2.00 & 2.00 & 2.00 & 2.00 \\
Imports of consumption goods $\left(\gamma_{I M^{C}}\right)$ & 1.00 & 1.00 & 1.00 & 1.00 \\
Imports of investment goods $\left(\gamma_{I M^{I}}\right)$ & 2000 & 2000 & 2000 & 2000 \\
Capital utilization $\left(\gamma_{u 2}\right)$ & 6.00 & 6.00 & 4.00 & 4.00 \\
Investment $\left(\gamma_{I}\right)$ & 0.029 & 0.029 & 0.029 & 0.029 \\
Transaction cost function $\left(\gamma_{v 1}\right)$ & 0.15 & 0.15 & 0.15 & 0.15 \\
$\quad\left(\gamma_{v 2}\right)$ & 0.01 & 0.01 & $\ldots$ & 0.01 \\
Intermediation cost function $\left(\gamma_{B^{*}}\right)$ & & & & \\
Calvo parameters and $J\left(\xi_{I}\right.$ and $\left.\xi_{J}\right)$ & 0.75 & 0.75 & 0.75 & 0.75 \\
Wages - households $I$ and & 0.92 & 0.92 & 0.75 & 0.75 \\
Prices - domestic tradables $\left(\xi_{H}\right)$ and nontradables $\left(\xi_{N}\right)$ & 0.75 & 0.75 & 0.75 & 0.75 \\
Prices - exports $\left(\xi_{X}\right)$ & & & & \\
Degree of indexation & & & & \\
Wages - households $I$ and $J\left(\chi_{I}\right.$ and $\left.\chi_{J}\right)$ & 0.75 & 0.75 & 0.75 & 0.75 \\
Prices - domestic tradables $\left(\chi_{H}\right)$ and nontradables $\left(\chi_{N}\right)$ & 0.50 & 0.50 & 0.50 & 0.50 \\
Prices - exports $\left(\chi_{X}\right)$ & 0.50 & 0.50 & 0.50 & 0.50 \\
& & & & \\
\hline \hline
\end{tabular}

Note: REA=Rest of Euro Area; US=United States; RW=Rest of World

Table 5: International Linkages (Parameters of Tradable Bundles)

\begin{tabular}{lcccc}
\hline \hline & & & & \\
& Home & REA & US & RW \\
Consumption-good imports & & & & \\
Substitution btw. consumption good imports $\left(\mu_{I M C}\right)$ & 2.50 & 2.50 & 2.50 & 2.50 \\
Bias towards imported consumption goods from $\left(v_{I M C}^{H, C O}\right)$ & & & & \\
Home & - & 0.211 & 0.061 & 0.155 \\
REA & 0.546 & - & 0.135 & 0.462 \\
US & 0.053 & 0.021 & - & 0.383 \\
RW & 0.401 & 0.768 & 0.804 & - \\
& & & & \\
Investment-good imports & & & & \\
Substitution btw. investment good imports $\left(\mu_{I M I}\right)$ & 2.50 & 2.50 & 2.50 & 2.50 \\
Bias towards imported investment goods from $\left(v_{I M I}^{H, C O}\right)$ & & & & \\
Home & - & 0.697 & 0.064 & 0.149 \\
REA & 0.546 & - & 0.112 & 0.400 \\
US & 0.053 & 0.134 & - & 0.451 \\
RW & 0.401 & 0.169 & 0.824 & - \\
& & & & \\
\hline \hline
\end{tabular}

Note: REA=Rest of Euro Area; US=United States; RW=Rest of World 
Table 6: International Linkages (Trade Matrix, Share of Domestic GDP, Percent)

Home REA US RW

\section{Consumption-good imports}

Total consumption good imports

$\begin{array}{llll}18.4 & 20.1 & 7.3 & 8.6\end{array}$

Bias towards imported consumption goods from

Home

$\begin{array}{lrrr}- & 3.1 & 0.3 & 1.1 \\ 8.7^{-} & - & 0.8 & 3.5 \\ 1.2 & 0.5 & - & 4.0 \\ 8.5 & 16.6 & 6.2 & -\end{array}$

\section{Investment-good imports}

Total investment good imports

Bias towards imported investment goods from

Home

REA

US

RW

$\begin{array}{rrrc}9.3 & 3.7 & 4.2 & 6.3 \\ & & & \\ - & 2.2 & 0.2 & 0.7 \\ 4.4 & - & 0.4 & 2.2 \\ 0.6 & 0.7 & - & 3.4 \\ 4.3 & 0.8 & 3.6 & -\end{array}$

Note: REA=Rest of Euro Area; US=United States; RW=Rest of World

Table 7: Monetary and Fiscal Policy

\begin{tabular}{|c|c|c|c|c|}
\hline & Home & REA & US & RW \\
\hline \multicolumn{5}{|l|}{ Monetary authority } \\
\hline Inflation target $\left(\bar{\Pi}^{4}\right)$ & 1.02 & 1.02 & 1.02 & 1.02 \\
\hline Interest rate inertia $\left(\phi_{R}\right)$ & 0.87 & 0.87 & 0.87 & 0.87 \\
\hline Interest rate sensitivity to inflation gap $\left(\phi_{\Pi}\right)$ & 1.70 & 1.70 & 1.70 & 1.70 \\
\hline Interest rate sensitivity to output growth $\left(\phi_{Y}\right)$ & 0.10 & 0.10 & 0.10 & 0.10 \\
\hline \multicolumn{5}{|l|}{ Fiscal authority } \\
\hline Government debt-to-output ratio $\left(\overline{B_{Y}}\right)$ & 2.40 & 2.40 & 2.40 & 2.40 \\
\hline Sensitivity of lump-sum taxes to debt-to-output ratio $\left(\phi_{B_{Y}}\right)$ & 0.10 & 0.10 & 0.10 & 0.10 \\
\hline Consumption tax rate $\left(\tau^{C}\right)$ & 0.183 & 0.183 & 0.077 & 0.077 \\
\hline Dividend tax rate $\left(\tau^{D}\right)$ & 0.00 & 0.00 & 0.00 & 0.00 \\
\hline Capital income tax rate $\left(\tau^{K}\right)$ & 0.19 & 0.19 & 0.16 & 0.16 \\
\hline Labor income tax rate $\left(\tau^{N}\right)$ & 0.122 & 0.122 & 0.154 & 0.154 \\
\hline Rate of social security contribution by firms $\left(\tau^{W_{f}}\right)$ & 0.219 & 0.219 & 0.071 & 0.071 \\
\hline Rate of social security contribution by households $\left(\tau^{W_{h}}\right)$ & 0.118 & 0.118 & 0.071 & 0.071 \\
\hline
\end{tabular}


Figure 1a. Reduction in the euro area interest rate - Effects on Home region


Horizontal axis: quarters. Vertical axis: percentage deviations from the baseline, except for inflation and interest rates (annualized percentage-point deviations), and the trade balance-to-GDP ratio (percentagepoint deviations). GDP and its components are reported in real terms. 
Figure 1b. Reduction in the euro area interest rate - Effects on rest of euro area
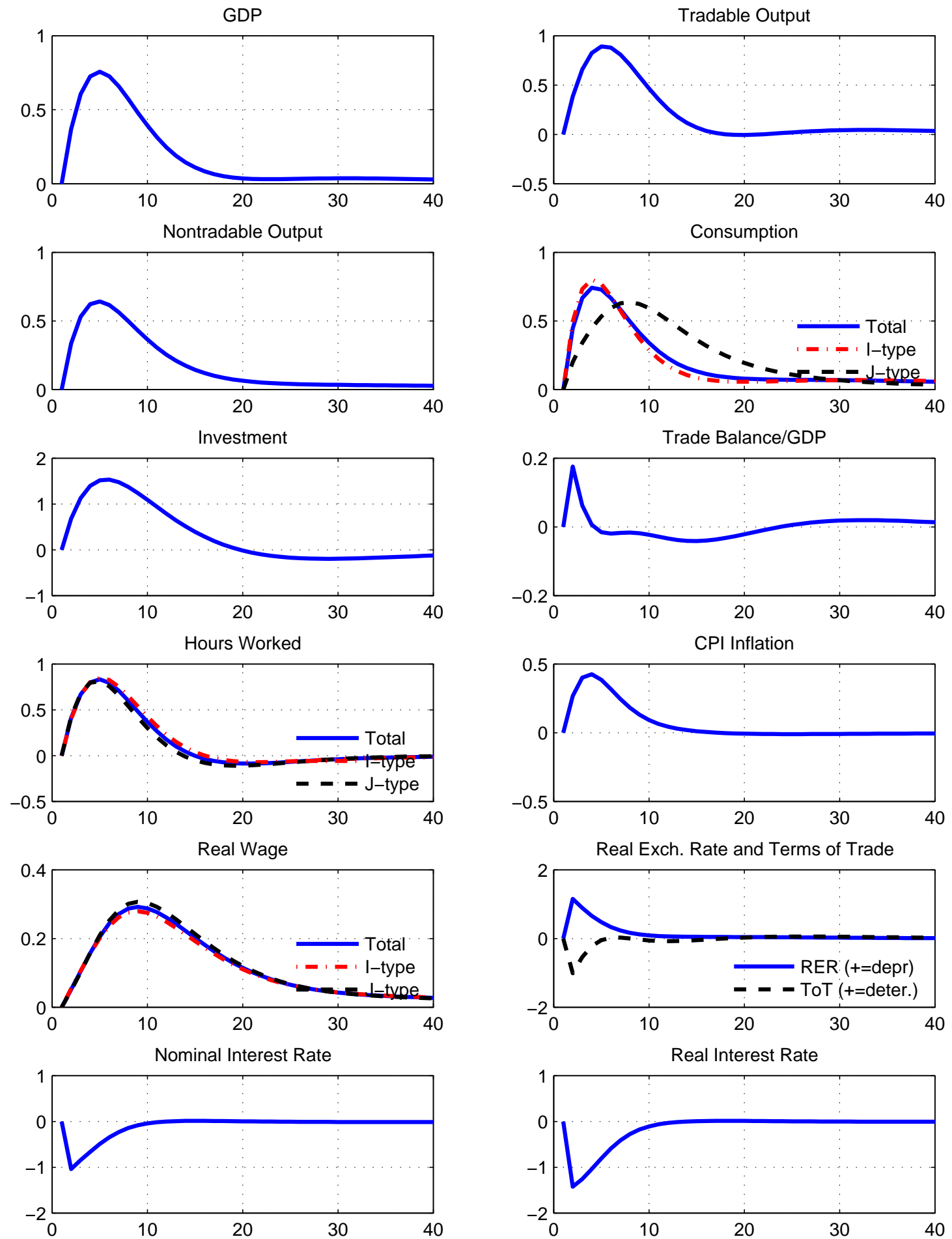

Horizontal axis: quarters. Vertical axis: percentage deviations from the baseline, except for inflation and interest rates (annualized percentage-point deviations), and the trade balance-to-GDP ratio (percentagepoint deviations). GDP and its components are reported in real terms. 
Figure 1c. Reduction in the euro area interest rate - Effects on Home trade variables
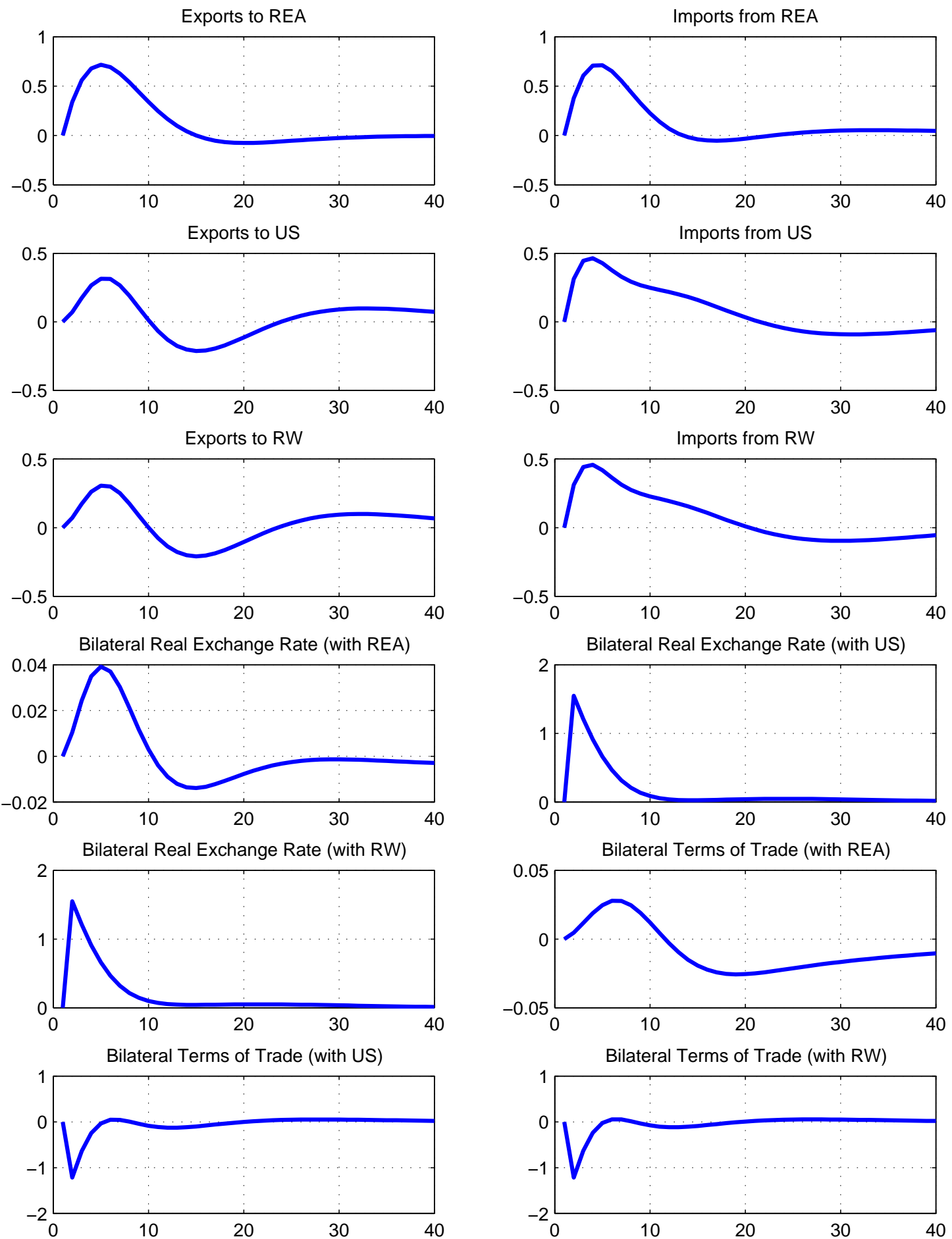

Horizontal axis: quarters. Vertical axis: percentage deviations from the baseline, except for inflation and interest rates (annualized percentage-point deviations), and the trade balance-to-GDP ratio (percentagepoint deviations). GDP and its components are reported in real terms. 
Figure 1d. Reduction in the euro area interest rate - Effects on rest of euro area trade variables
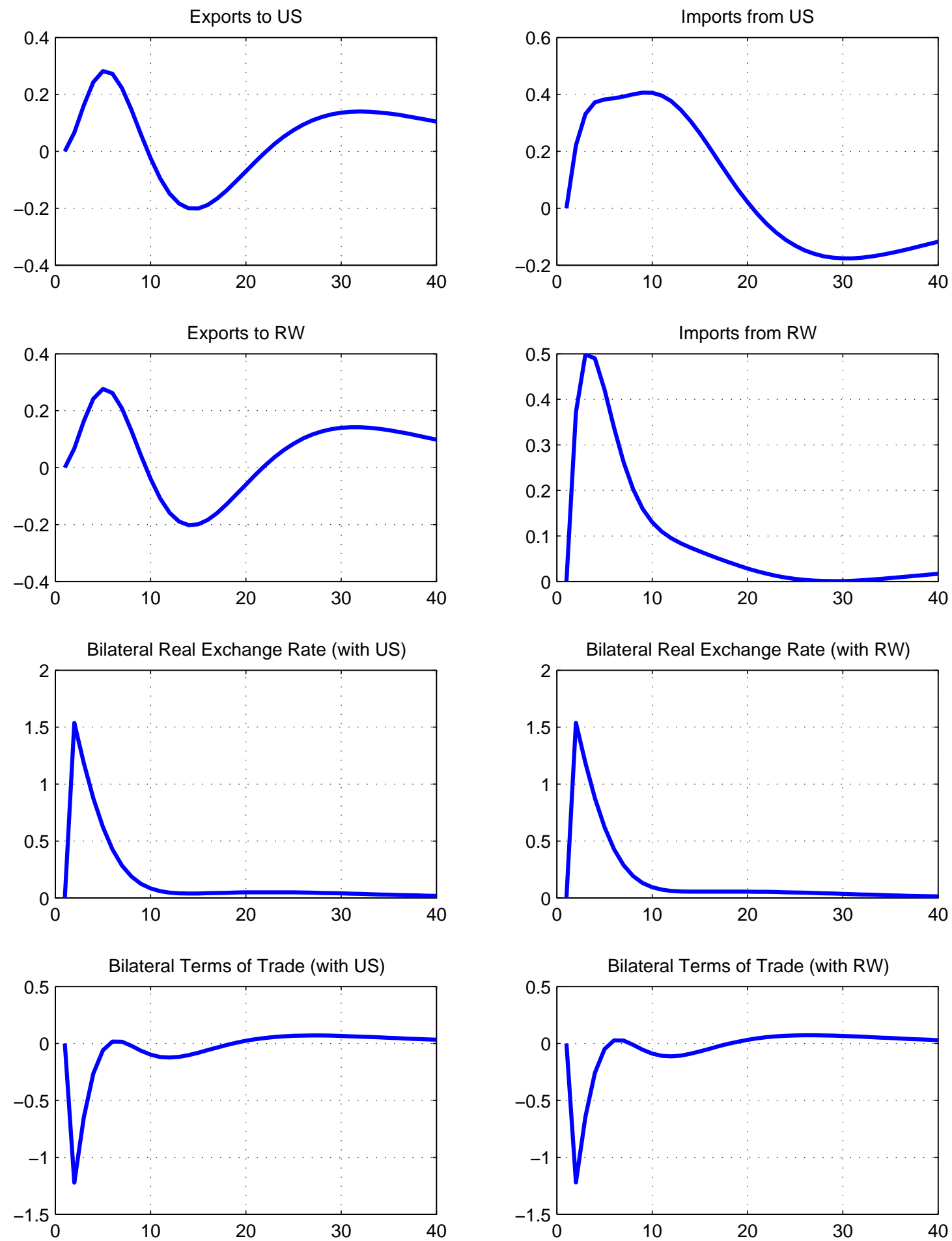

Horizontal axis: quarters. Vertical axis: percentage deviations from the baseline, except for inflation and interest rates (annualized percentage-point deviations), and the trade balance-to-GDP ratio (percentagepoint deviations). GDP and its components are reported in real terms. 
Figure 2a. Positive Home public expenditure shock - Domestic effects
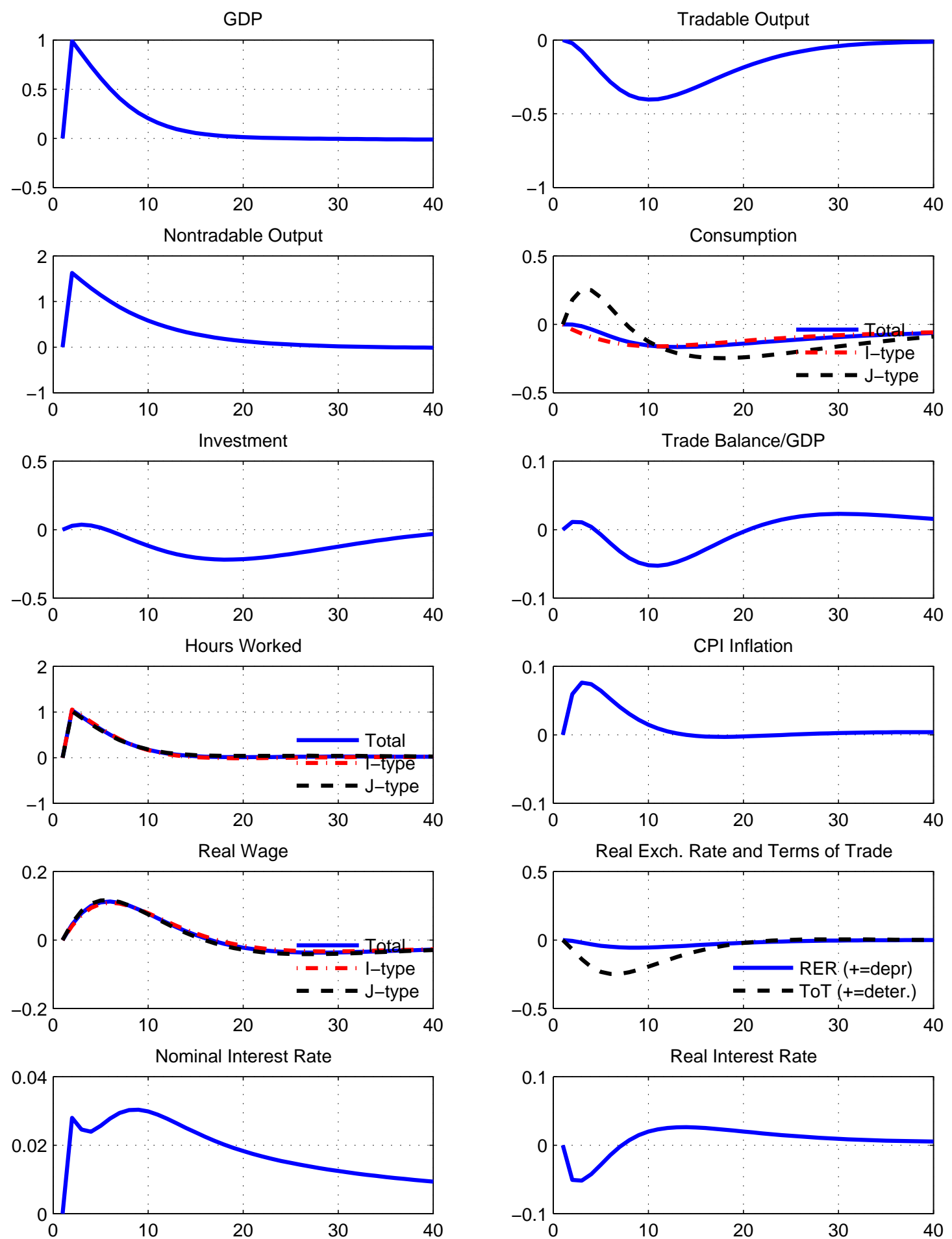

Horizontal axis: quarters. Vertical axis: percentage deviations from the baseline, except for inflation and interest rates (annualized percentage-point deviations), and the trade balance-to-GDP ratio (percentagepoint deviations). GDP and its components are reported in real terms. 
Figure 2b. Positive Home public expenditure shock - Effects on rest of euro area
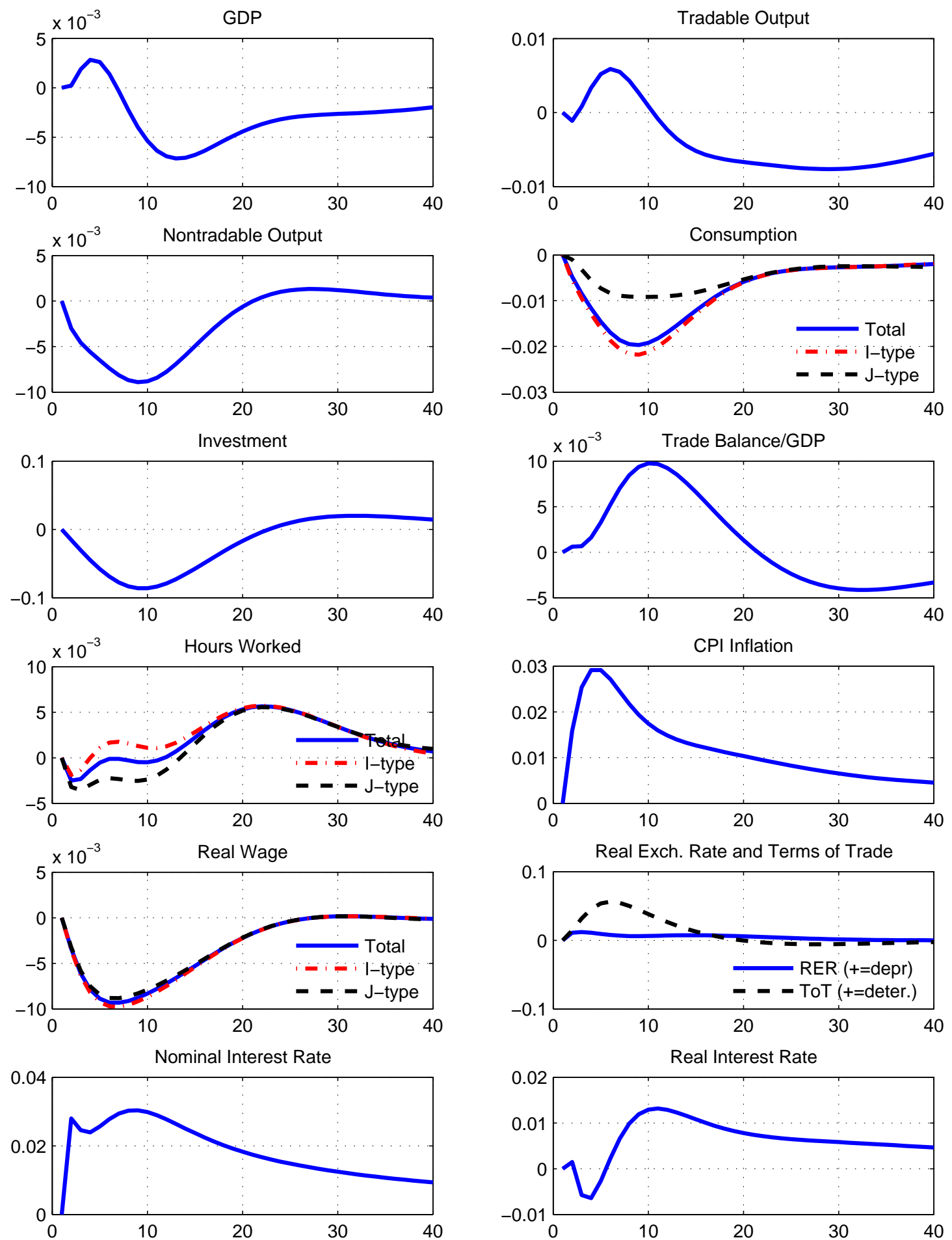

Horizontal axis: quarters. Vertical axis: percentage deviations from the baseline, except for inflation and interest rates (annualized percentage-point deviations), and the trade balance-to-GDP ratio (percentagepoint deviations). GDP and its components are reported in real terms. 
Figure 2c. Positive Home public expenditure shock - Effects on Home trade variables
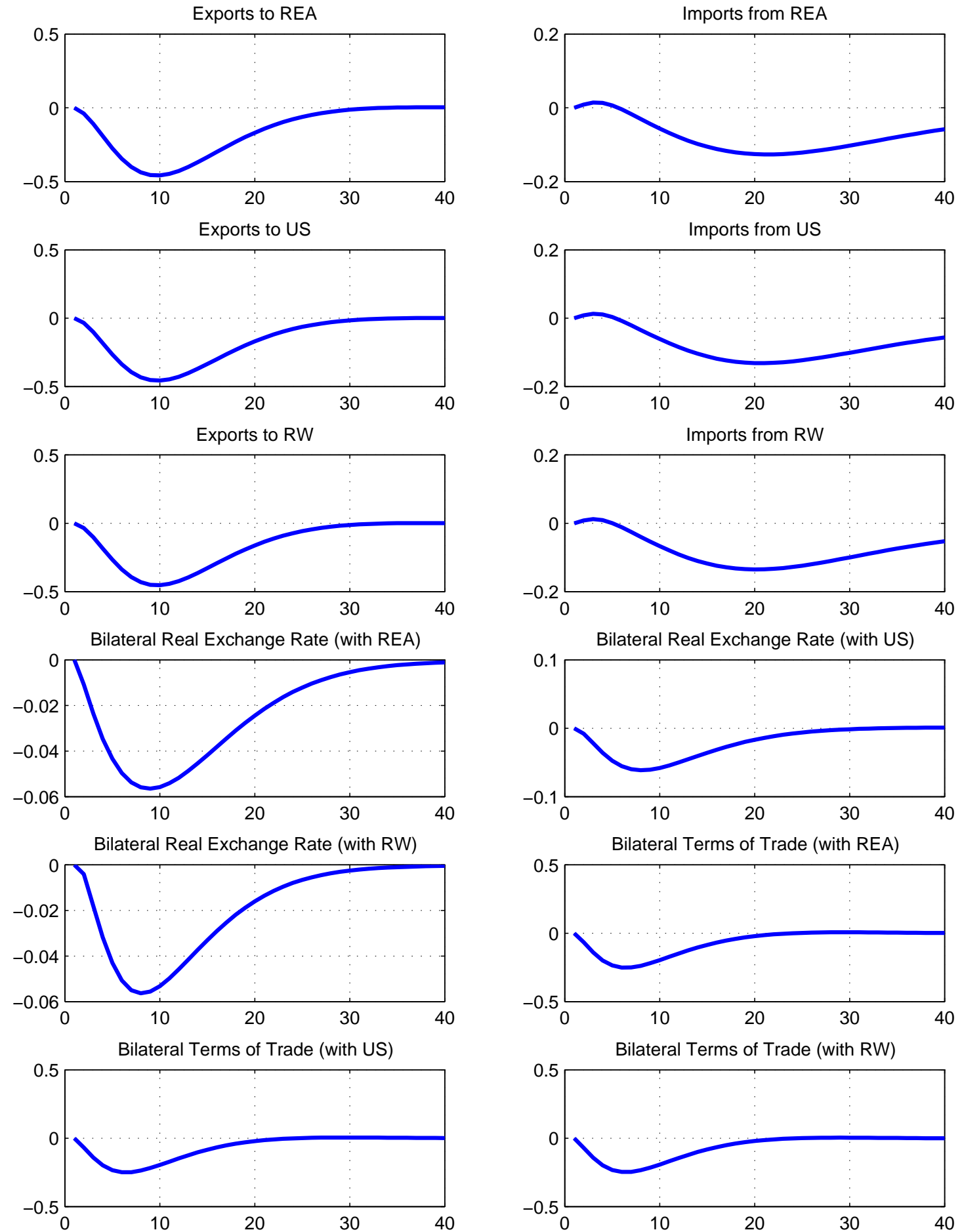

Horizontal axis: quarters. Vertical axis: percentage deviations from the baseline, except for inflation and interest rates (annualized percentage-point deviations), and the trade balance-to-GDP ratio (percentagepoint deviations). GDP and its components are reported in real terms. 
Figure 2d. Positive Home public expenditure shock - Effects on rest of euro area trade variables
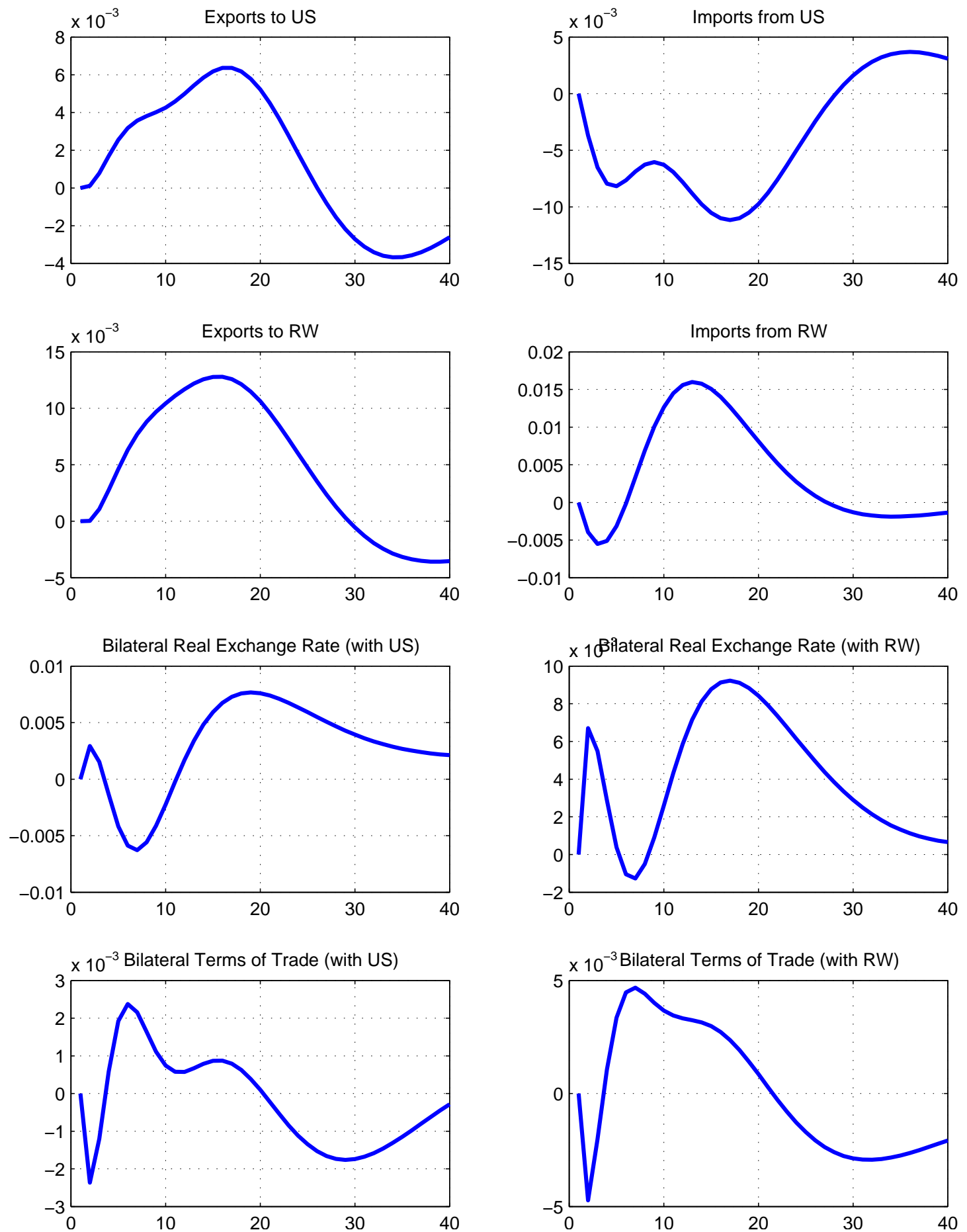

Horizontal axis: quarters. Vertical axis: percentage deviations from the baseline, except for inflation and interest rates (annualized percentage-point deviations), and the trade balance-to-GDP ratio (percentagepoint deviations). GDP and its components are reported in real terms. 
Figure 3a. Negative markup shock in the Home nontradables sector - Domestic effects
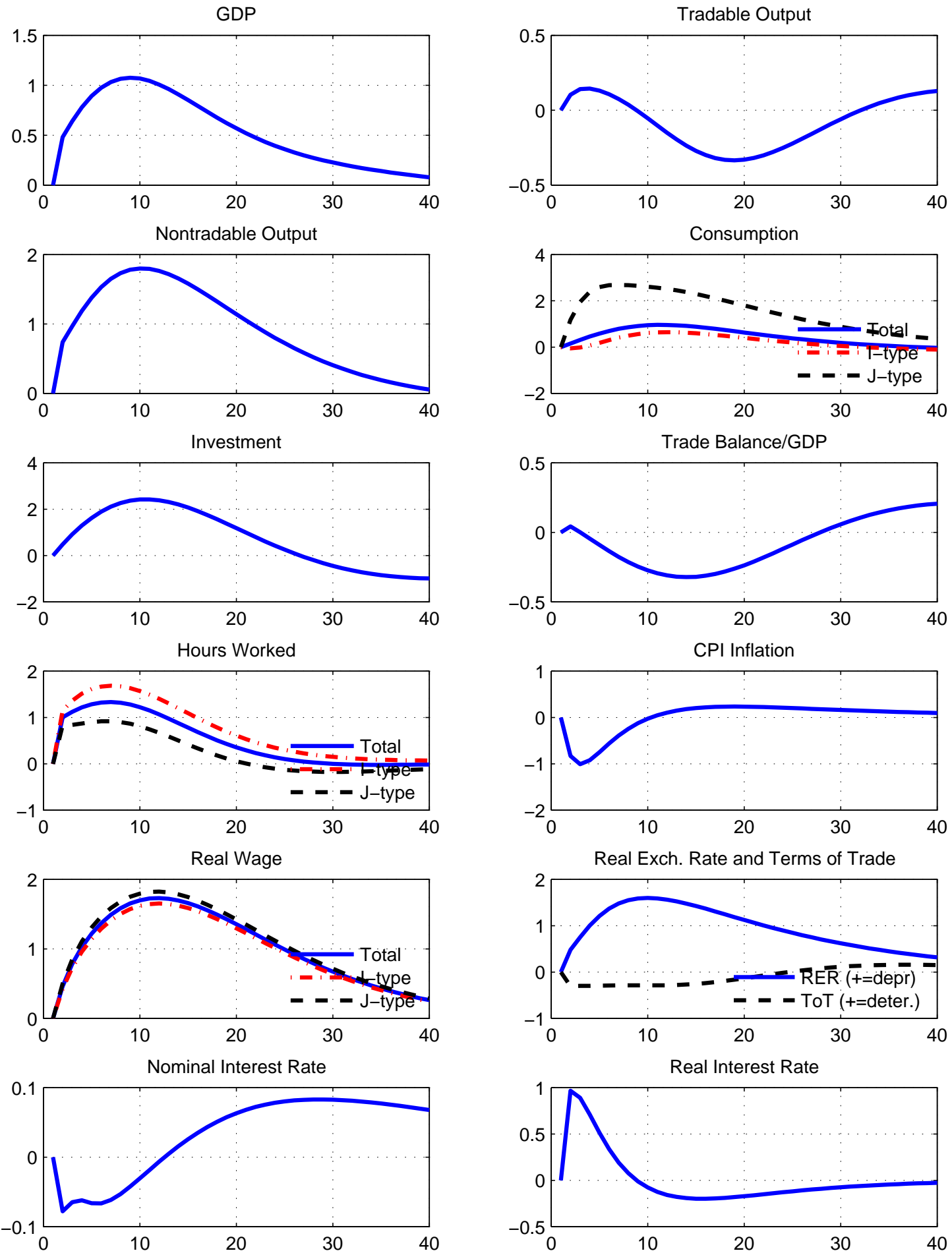

Horizontal axis: quarters. Vertical axis: percentage deviations from the baseline, except for inflation and interest rates (annualized percentage-point deviations), and the trade balance-to-GDP ratio (percentagepoint deviations). GDP and its components are reported in real terms. 
Figure 3b. Negative markup shock in the Home nontradables sector - Effects on rest of euro area
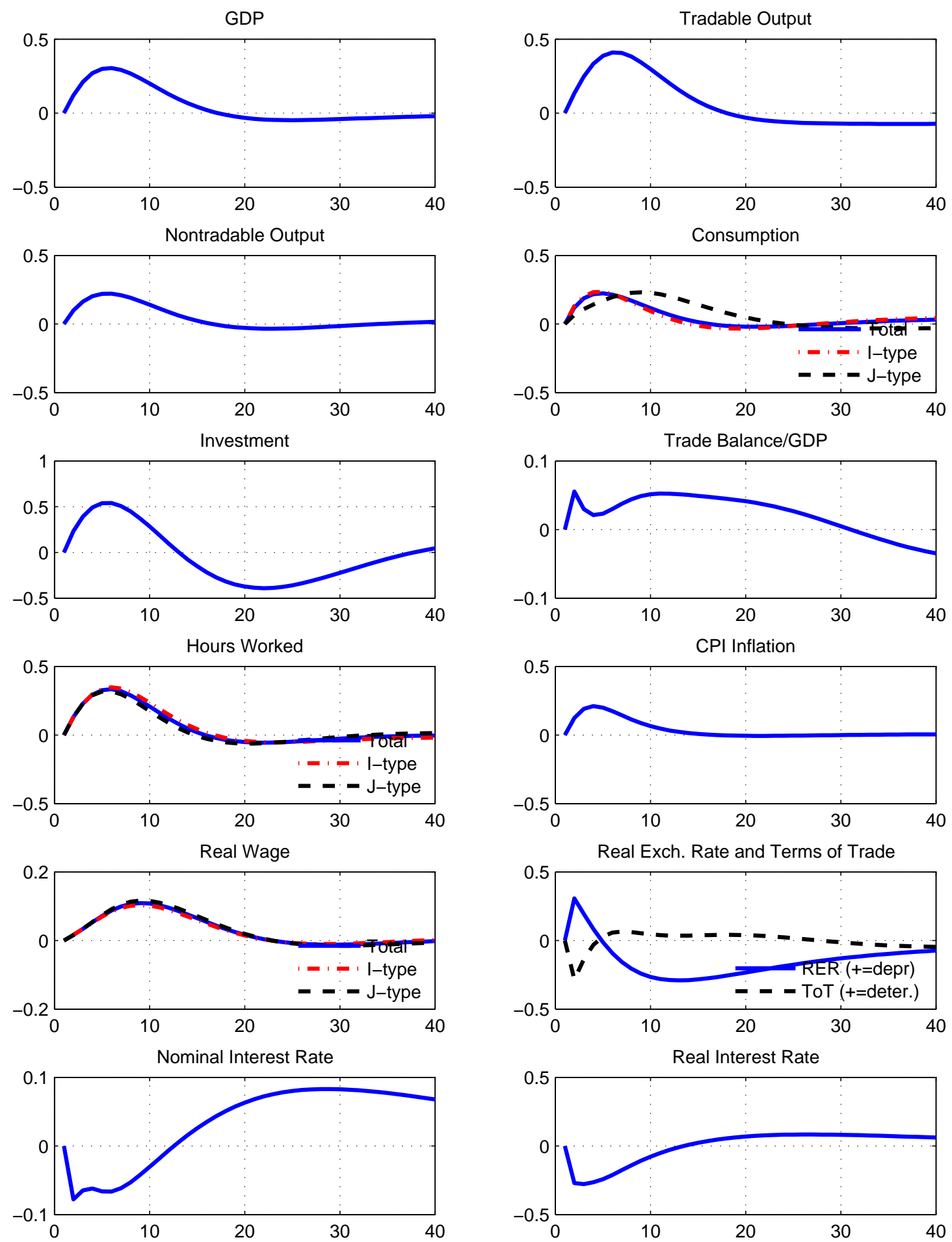

Horizontal axis: quarters. Vertical axis: percentage deviations from the baseline, except for inflation and interest rates (annualized percentage-point deviations), and the trade balance-to-GDP ratio (percentagepoint deviations). GDP and its components are reported in real terms. 
Figure 3c. Negative markup shock in the Home nontradables sector - Effects on Home trade variables
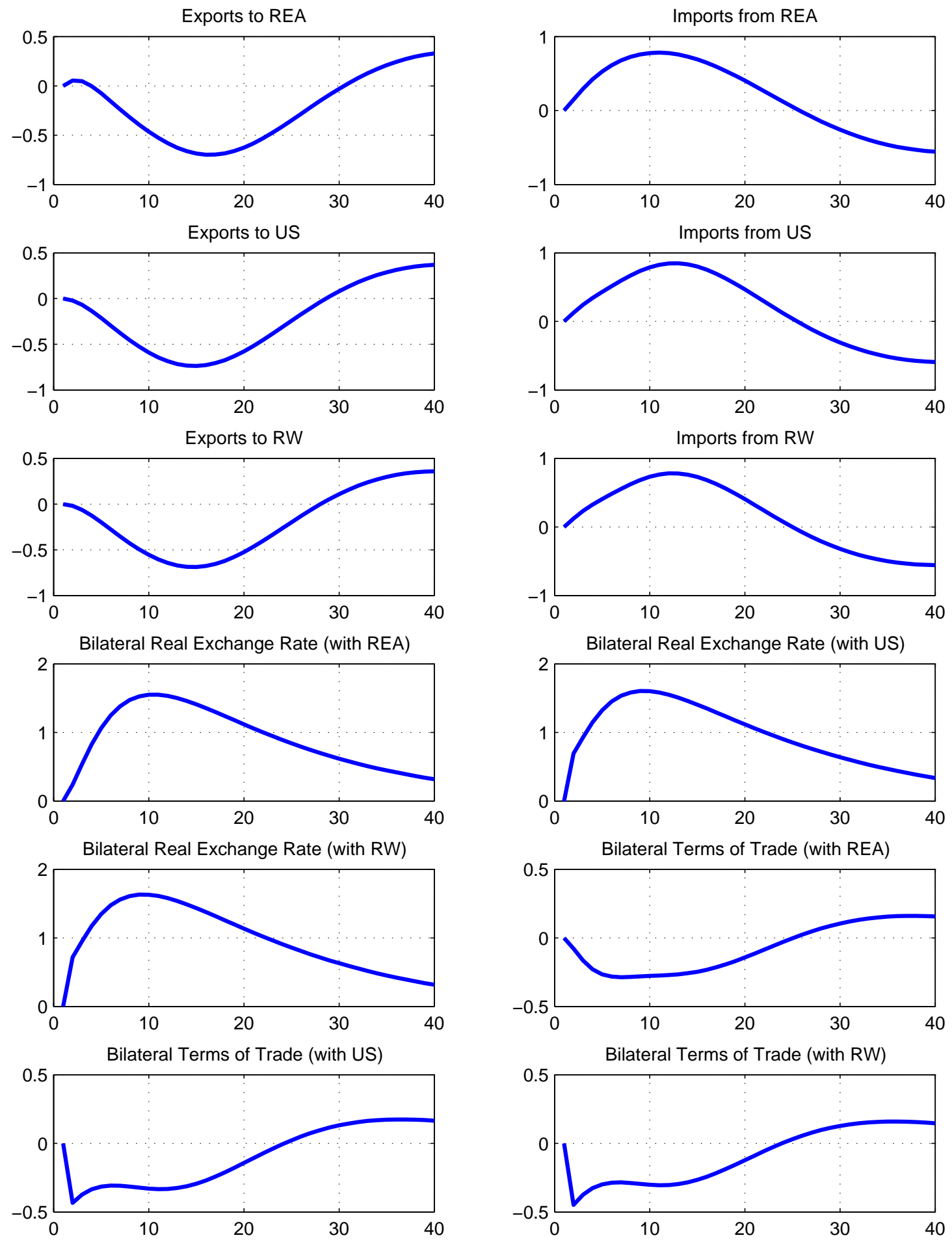

Horizontal axis: quarters. Vertical axis: percentage deviations from the baseline, except for inflation and interest rates (annualized percentage-point deviations), and the trade balance-to-GDP ratio (percentagepoint deviations). GDP and its components are reported in real terms. 
Figure 3d. Negative markup shock in the Home nontradables sector - Effects on rest of euro area trade variables
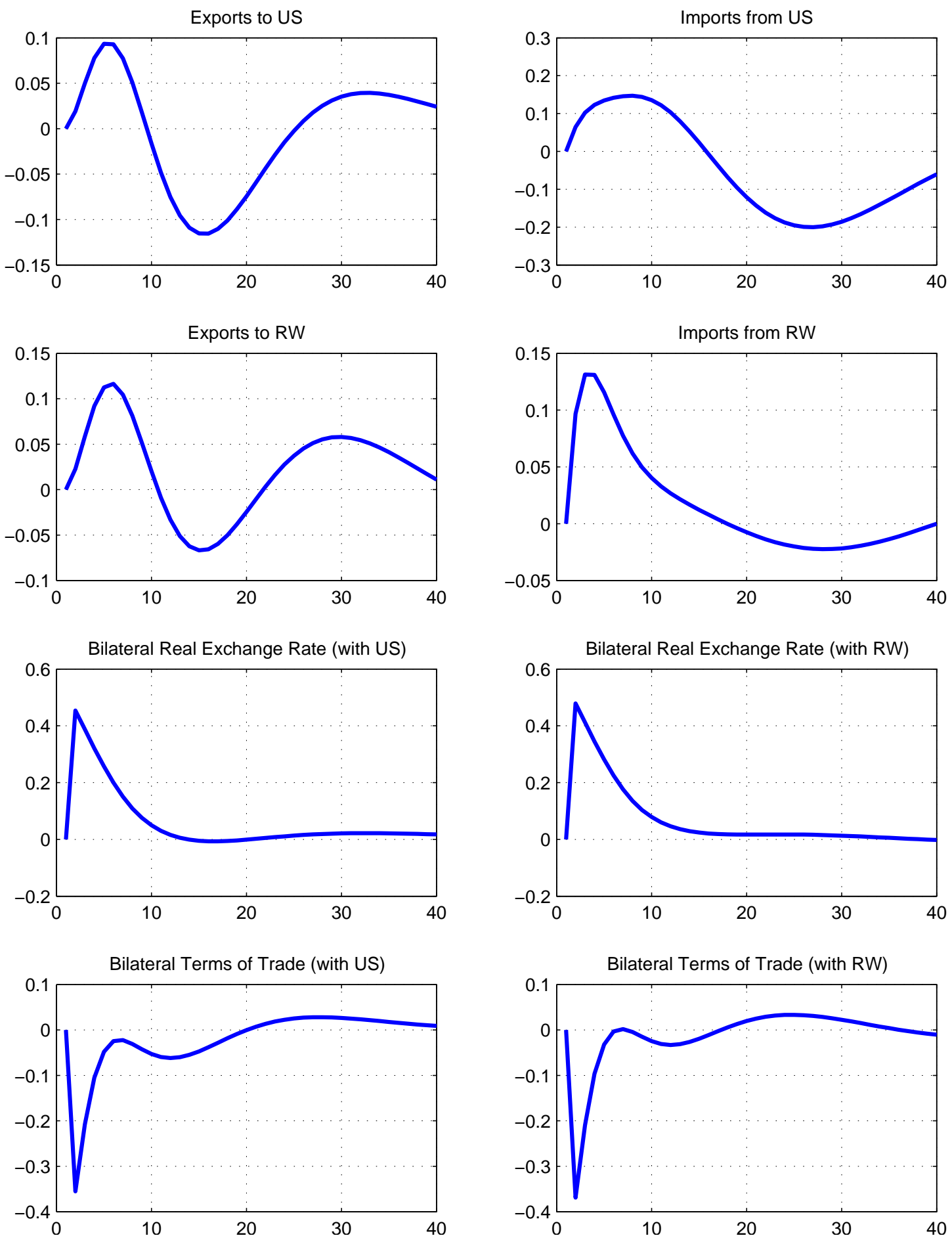

Horizontal axis: quarters. Vertical axis: percentage deviations from the baseline, except for inflation and interest rates (annualized percentage-point deviations), and the trade balance-to-GDP ratio (percentagepoint deviations). GDP and its components are reported in real terms. 
Figure 4a. Negative markup shock in the Home tradables sector - Domestic effects
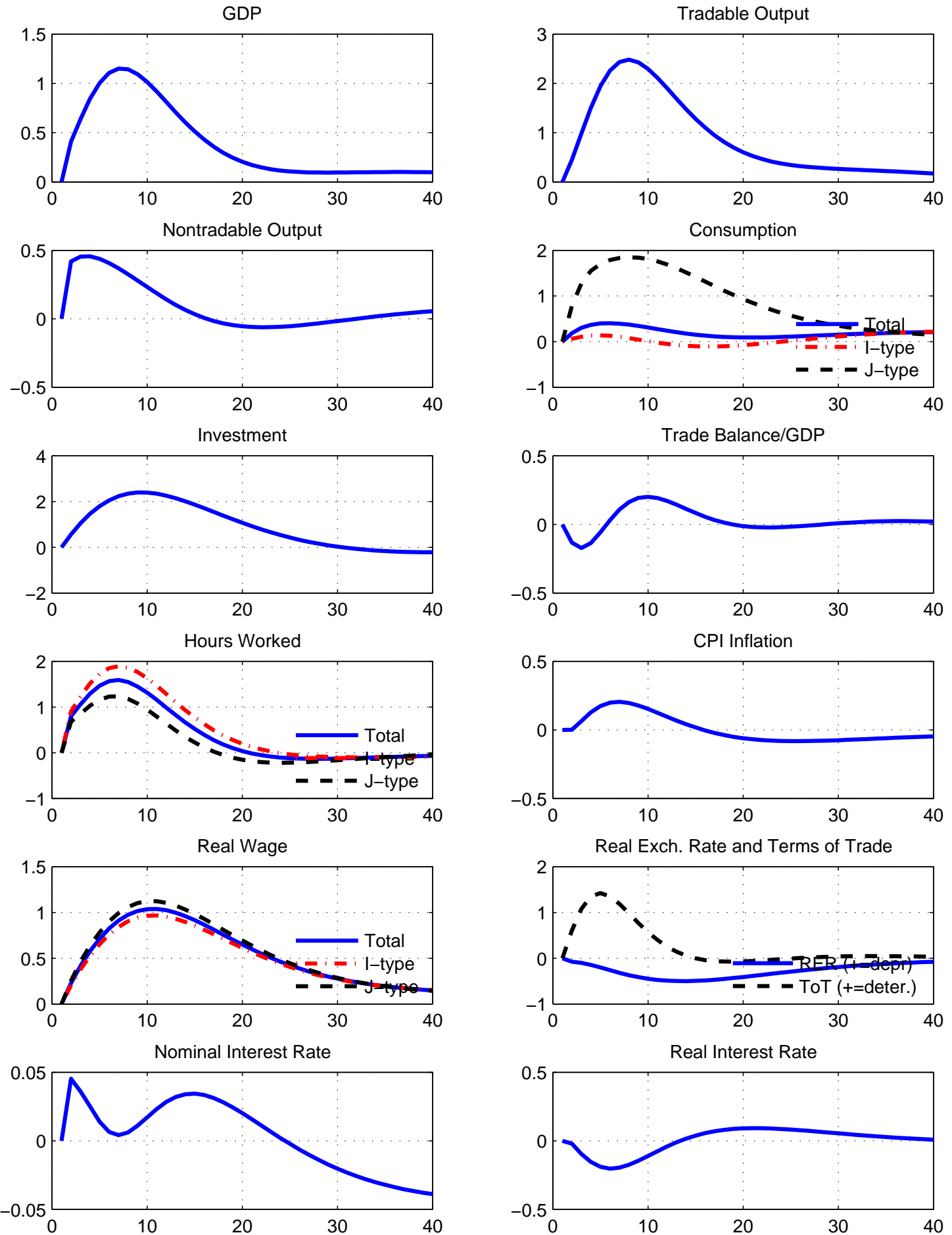

Horizontal axis: quarters. Vertical axis: percentage deviations from the baseline, except for inflation and interest rates (annualized percentage-point deviations), and the trade balance-to-GDP ratio (percentagepoint deviations). GDP and its components are reported in real terms. 
Figure 4b. Negative markup shock in the Home tradables sector - Effects on rest of euro area
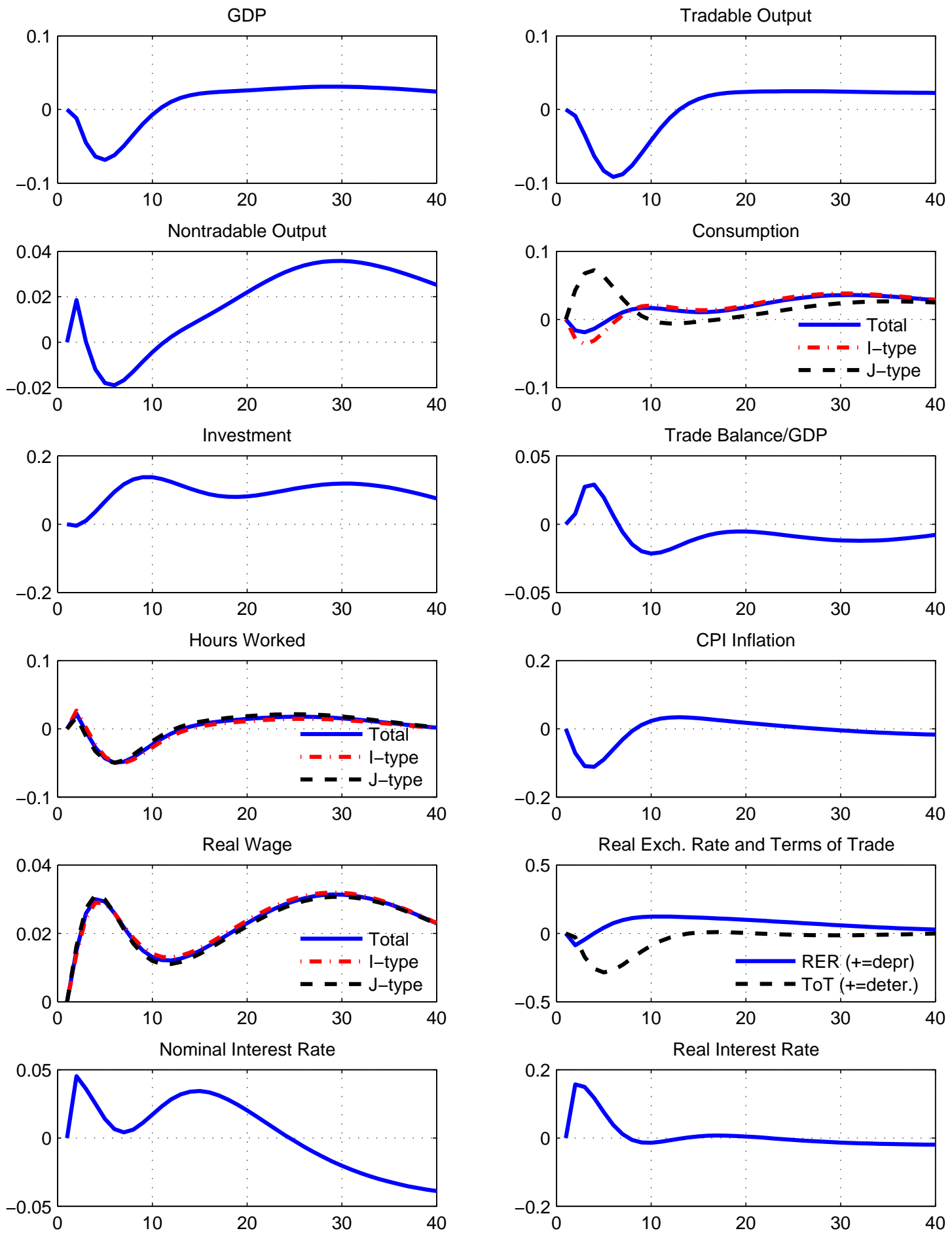

Horizontal axis: quarters. Vertical axis: percentage deviations from the baseline, except for inflation and interest rates (annualized percentage-point deviations), and the trade balance-to-GDP ratio (percentagepoint deviations). GDP and its components are reported in real terms. 
Figure 4c. Negative markup shock in the Home tradables sector - Effects on Home trade variables
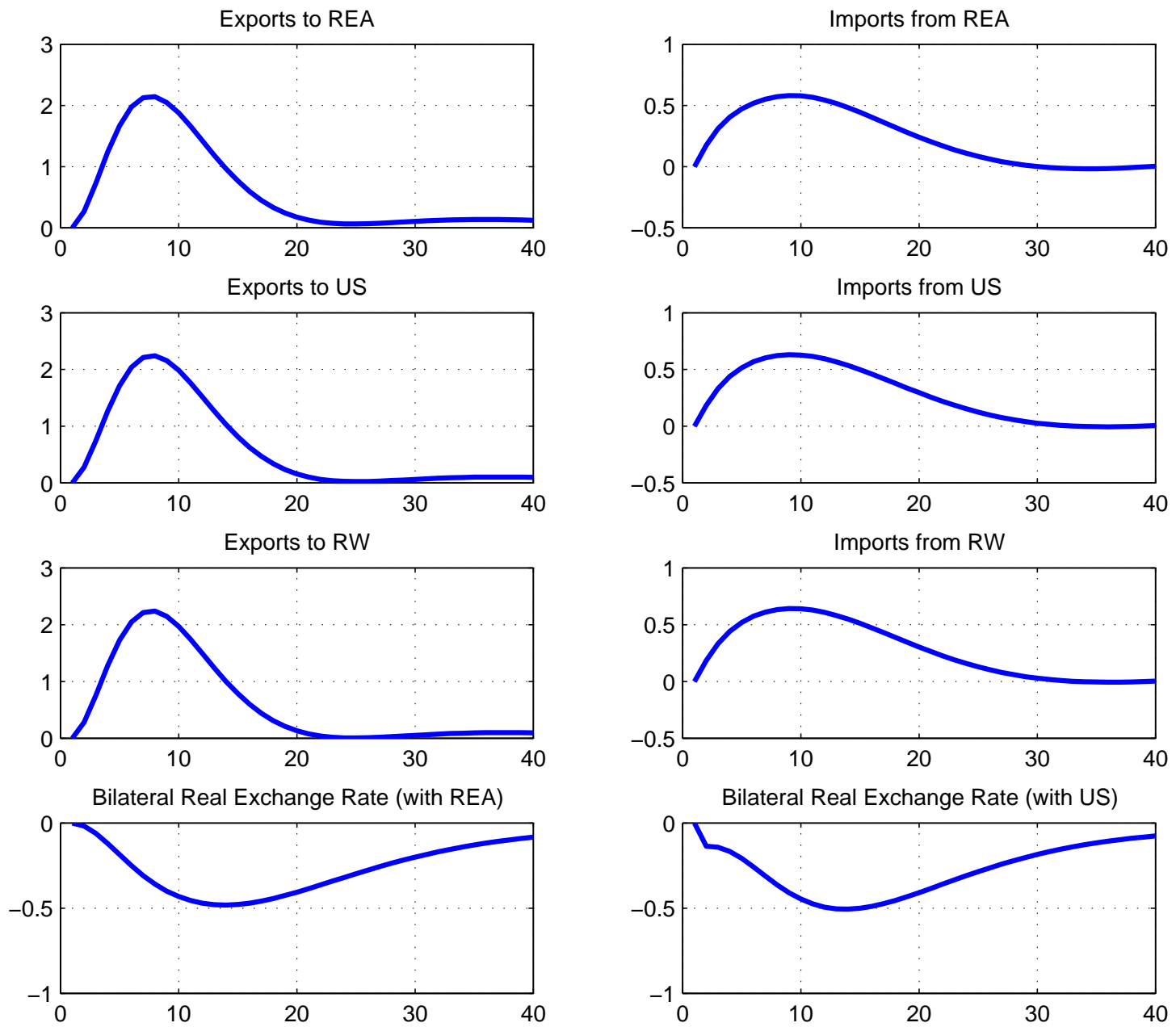

Bilateral Real Exchange Rate (with RW)

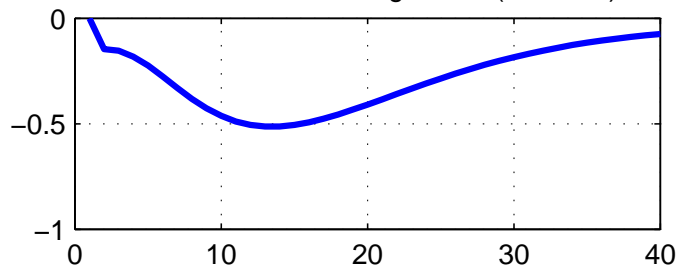

Bilateral Terms of Trade (with REA)

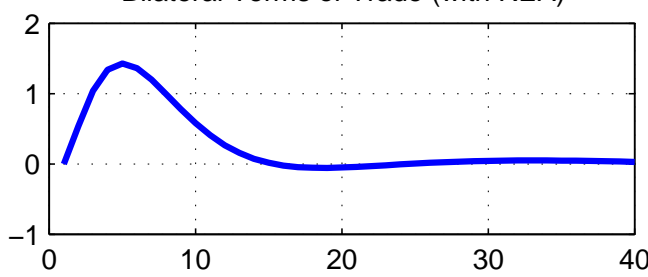

Bilateral Terms of Trade (with US)

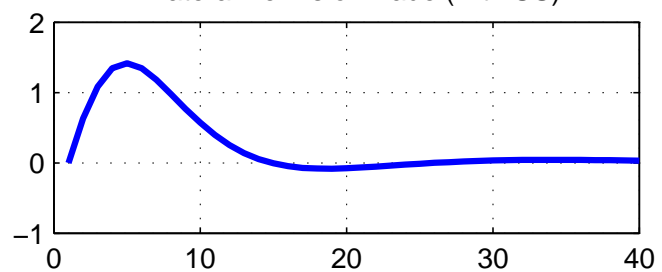

Bilateral Terms of Trade (with RW)

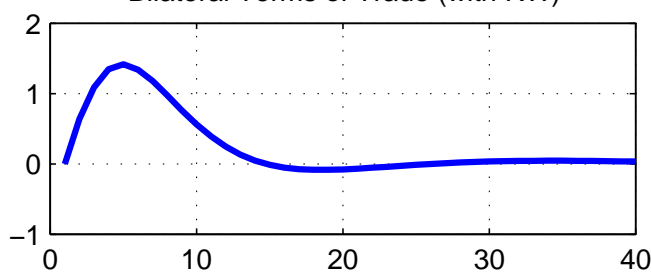

Horizontal axis: quarters. Vertical axis: percentage deviations from the baseline, except for inflation and interest rates (annualized percentage-point deviations), and the trade balance-to-GDP ratio (percentagepoint deviations). GDP and its components are reported in real terms. 
Figure 4d. Negative markup shock in the Home tradables sector - Effects on rest of euro area trade variables
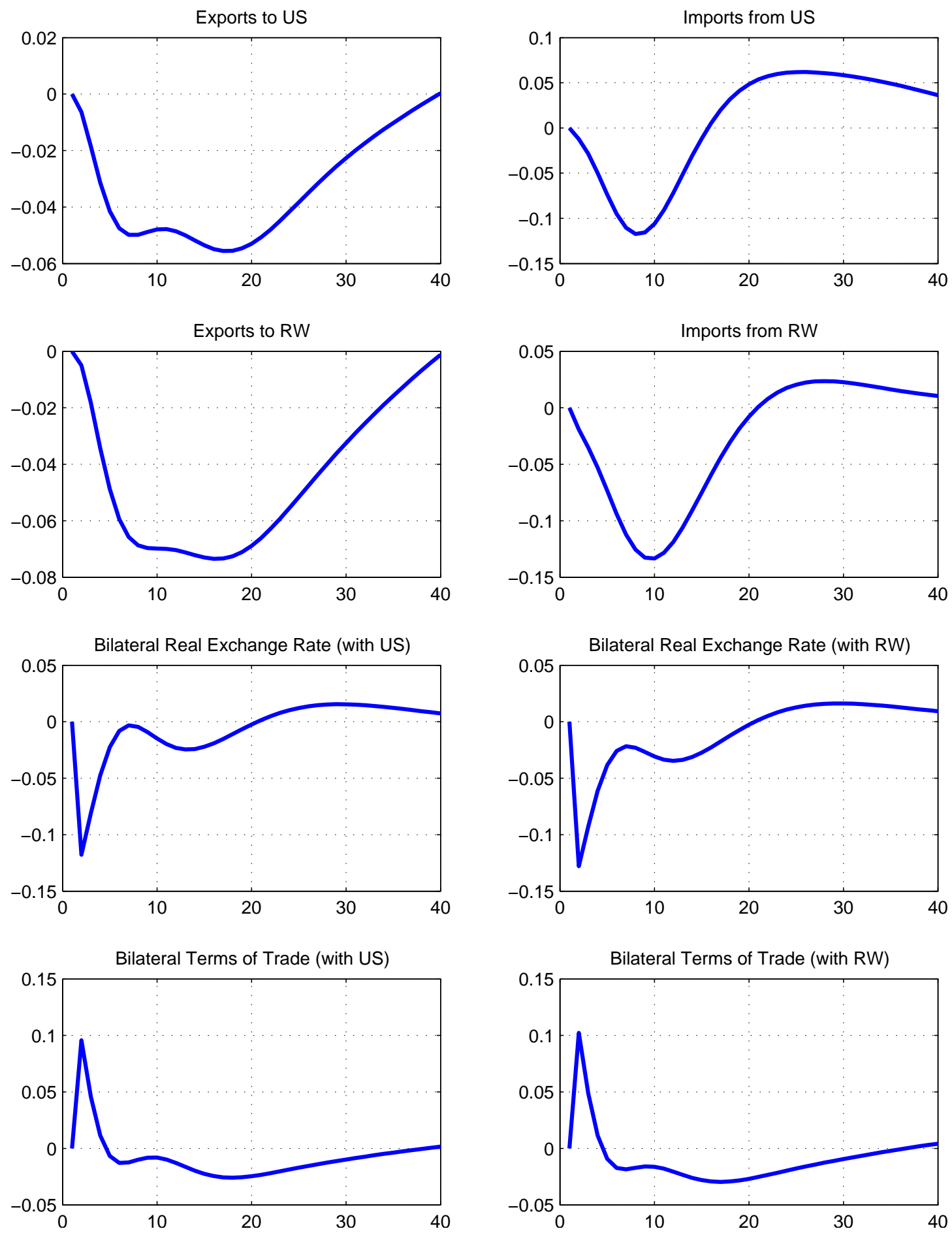

Horizontal axis: quarters. Vertical axis: percentage deviations from the baseline, except for inflation and interest rates (annualized percentage-point deviations), and the trade balance-to-GDP ratio (percentagepoint deviations). GDP and its components are reported in real terms. 
Figure 5a. Negative markup shock in the Home labor market - Domestic effects
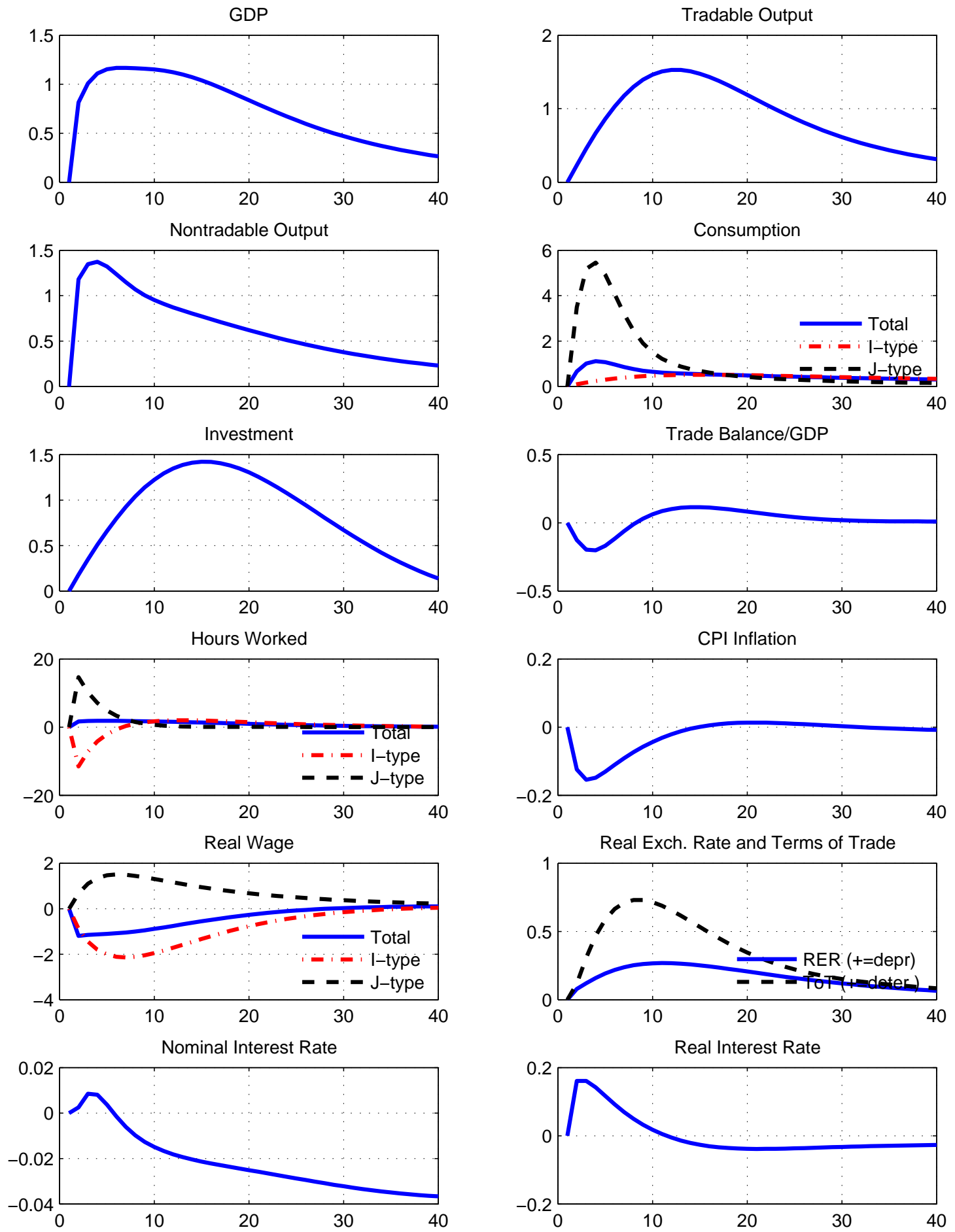

Horizontal axis: quarters. Vertical axis: percentage deviations from the baseline, except for inflation and interest rates (annualized percentage-point deviations), and the trade balance-to-GDP ratio (percentagepoint deviations). GDP and its components are reported in real terms. 
Figure 5b. Negative markup shock in the Home labor market - Effects on rest of euro area
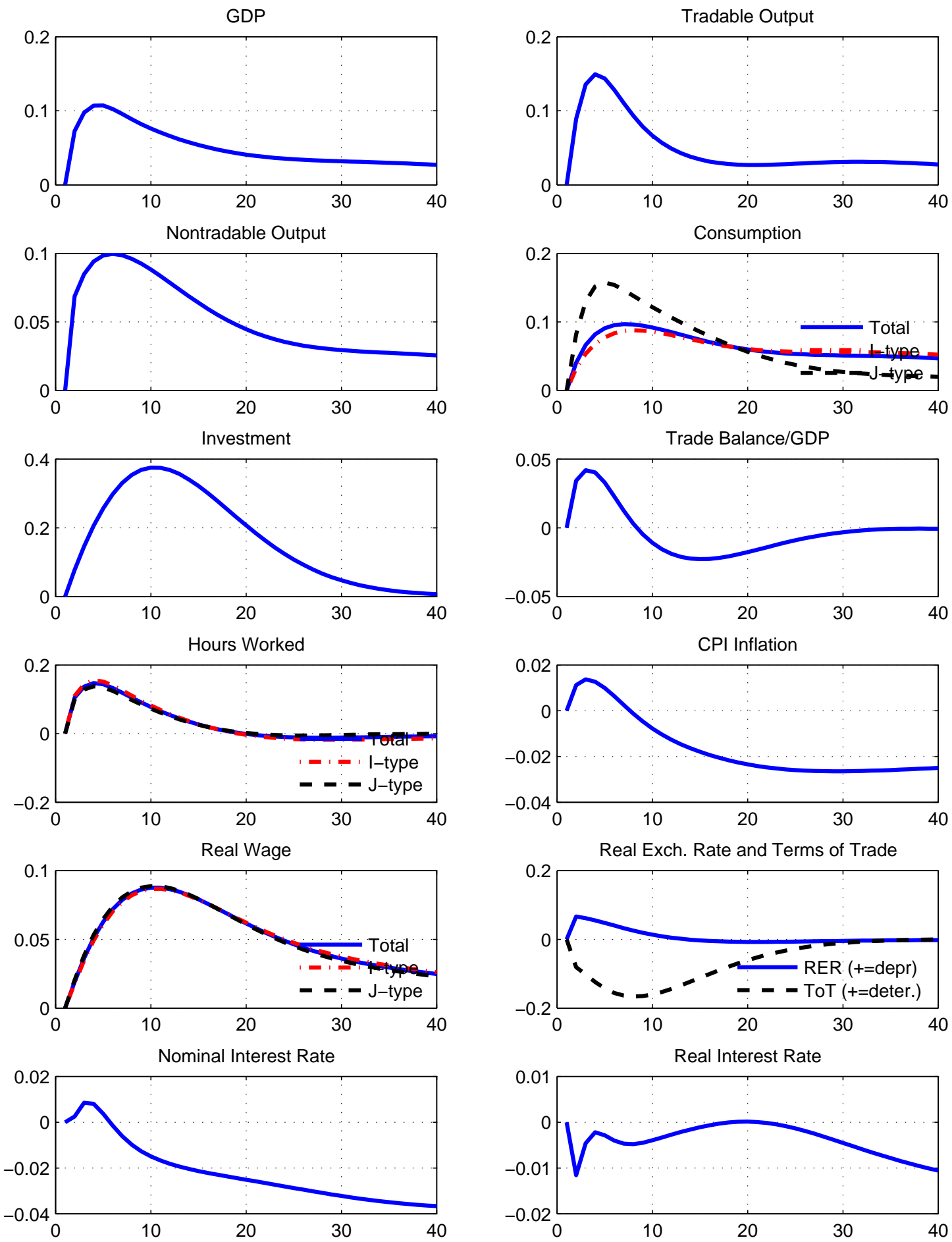

Horizontal axis: quarters. Vertical axis: percentage deviations from the baseline, except for inflation and interest rates (annualized percentage-point deviations), and the trade balance-to-GDP ratio (percentagepoint deviations). GDP and its components are reported in real terms. 
Figure 5c. Negative markup shock in the Home labor market - Effects on Home trade variables
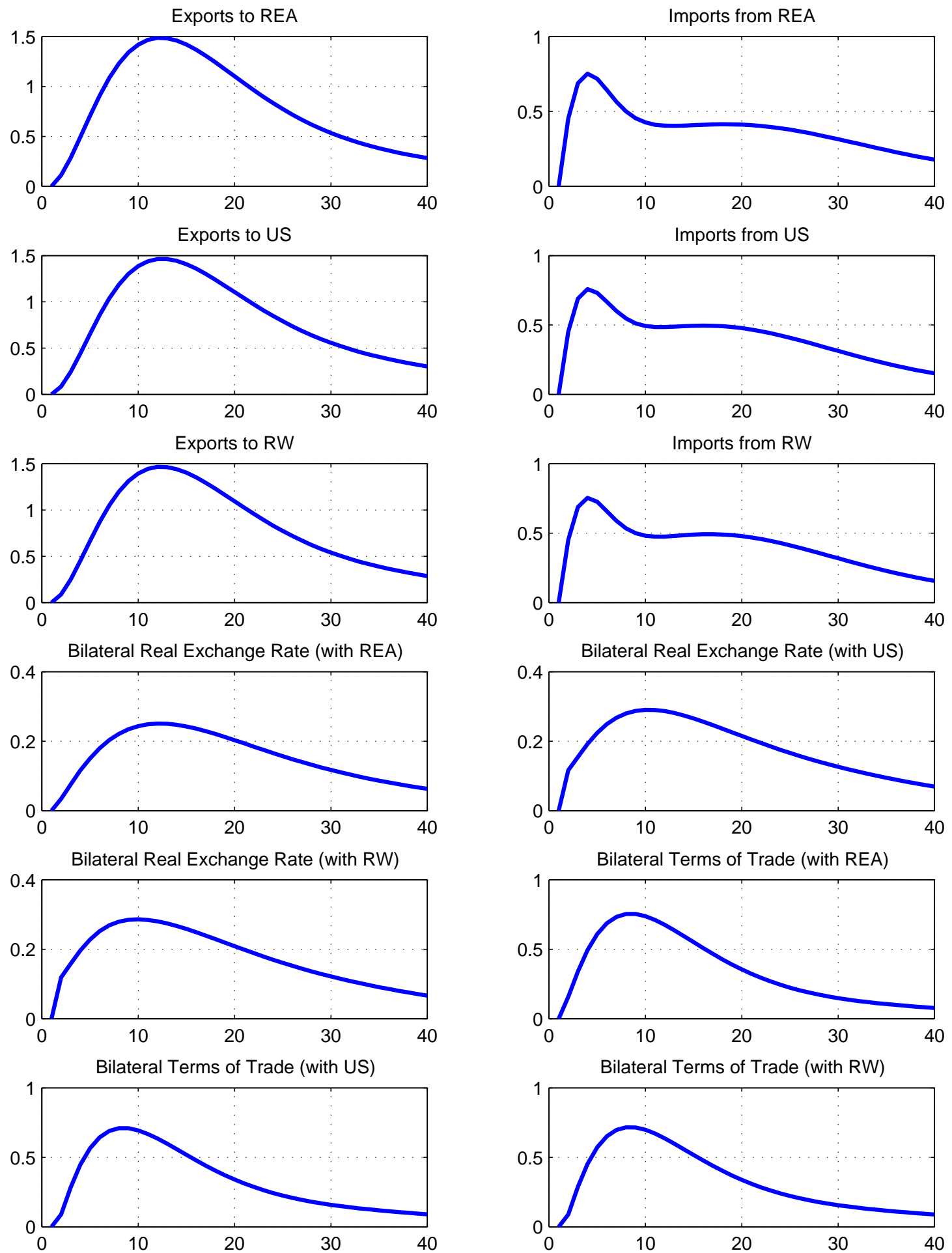

Horizontal axis: quarters. Vertical axis: percentage deviations from the baseline, except for inflation and interest rates (annualized percentage-point deviations), and the trade balance-to-GDP ratio (percentagepoint deviations). GDP and its components are reported in real terms. 
Figure 5d. Negative markup shock in the Home labor market - Effects on rest of euro area trade variables
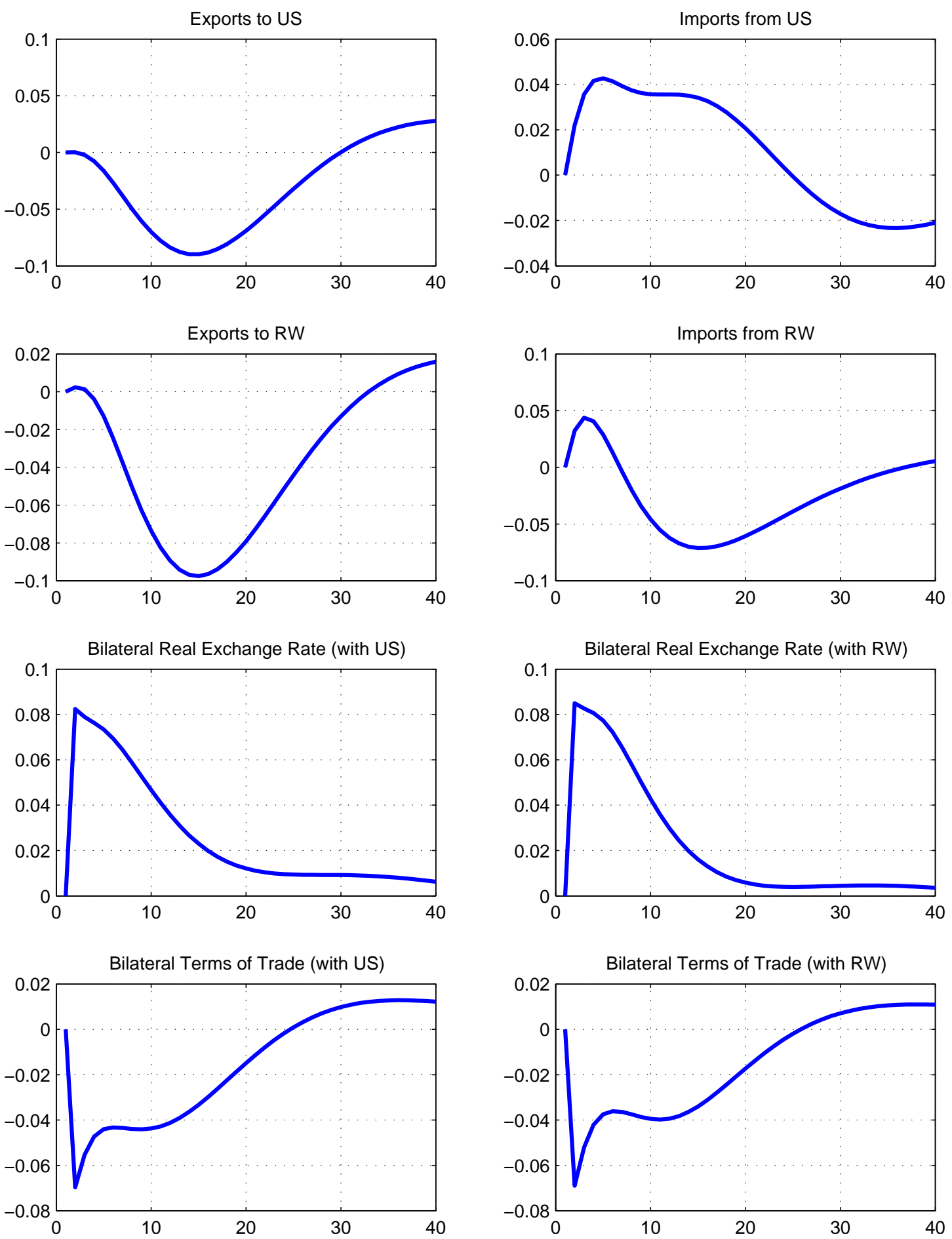

Horizontal axis: quarters. Vertical axis: percentage deviations from the baseline, except for inflation and interest rates (annualized percentage-point deviations), and the trade balance-to-GDP ratio (percentagepoint deviations). GDP and its components are reported in real terms. 
Figure 6a. Positive external risk premium shock in the euro area - Effects on Home economy
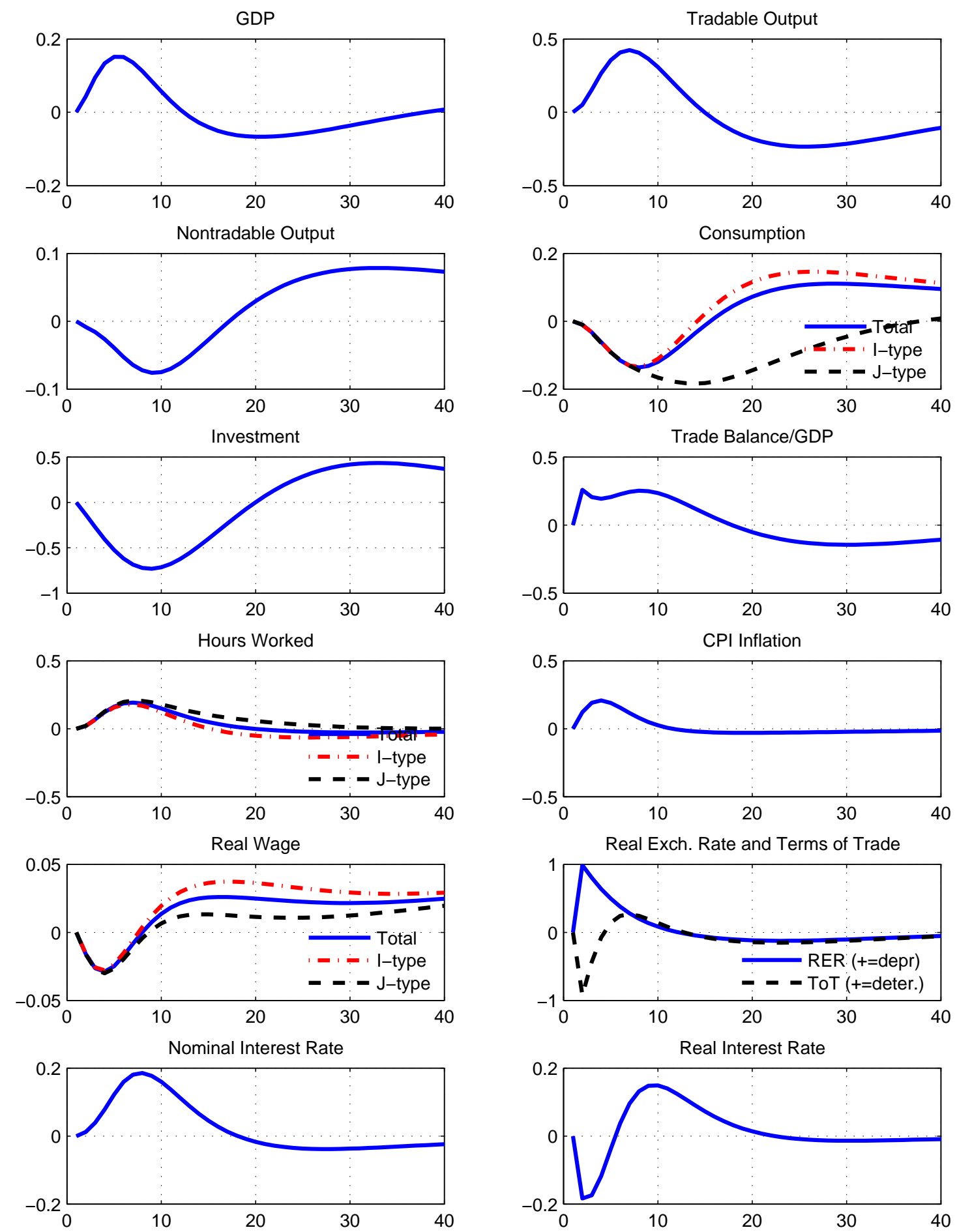

Horizontal axis: quarters. Vertical axis: percentage deviations from the baseline, except for inflation and interest rates (annualized percentage-point deviations), and the trade balance-to-GDP ratio (percentagepoint deviations). GDP and its components are reported in real terms. 
Figure 6b. Positive external risk premium shock in the euro area - Effects on rest of euro area
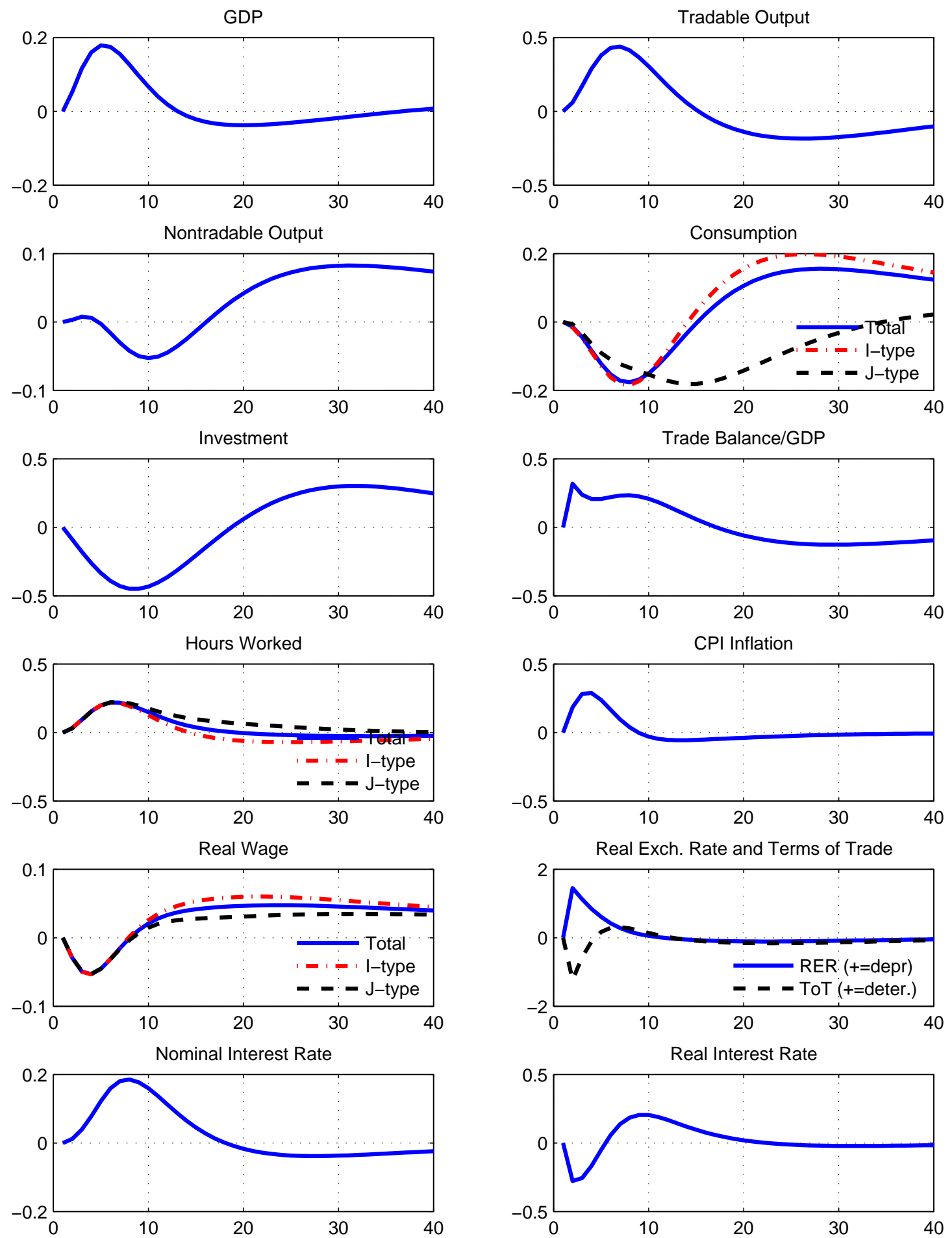

Horizontal axis: quarters. Vertical axis: percentage deviations from the baseline, except for inflation and interest rates (annualized percentage-point deviations), and the trade balance-to-GDP ratio (percentagepoint deviations). GDP and its components are reported in real terms. 
Figure 6c. Positive external risk premium shock in the euro area - Effects on Home trade variables
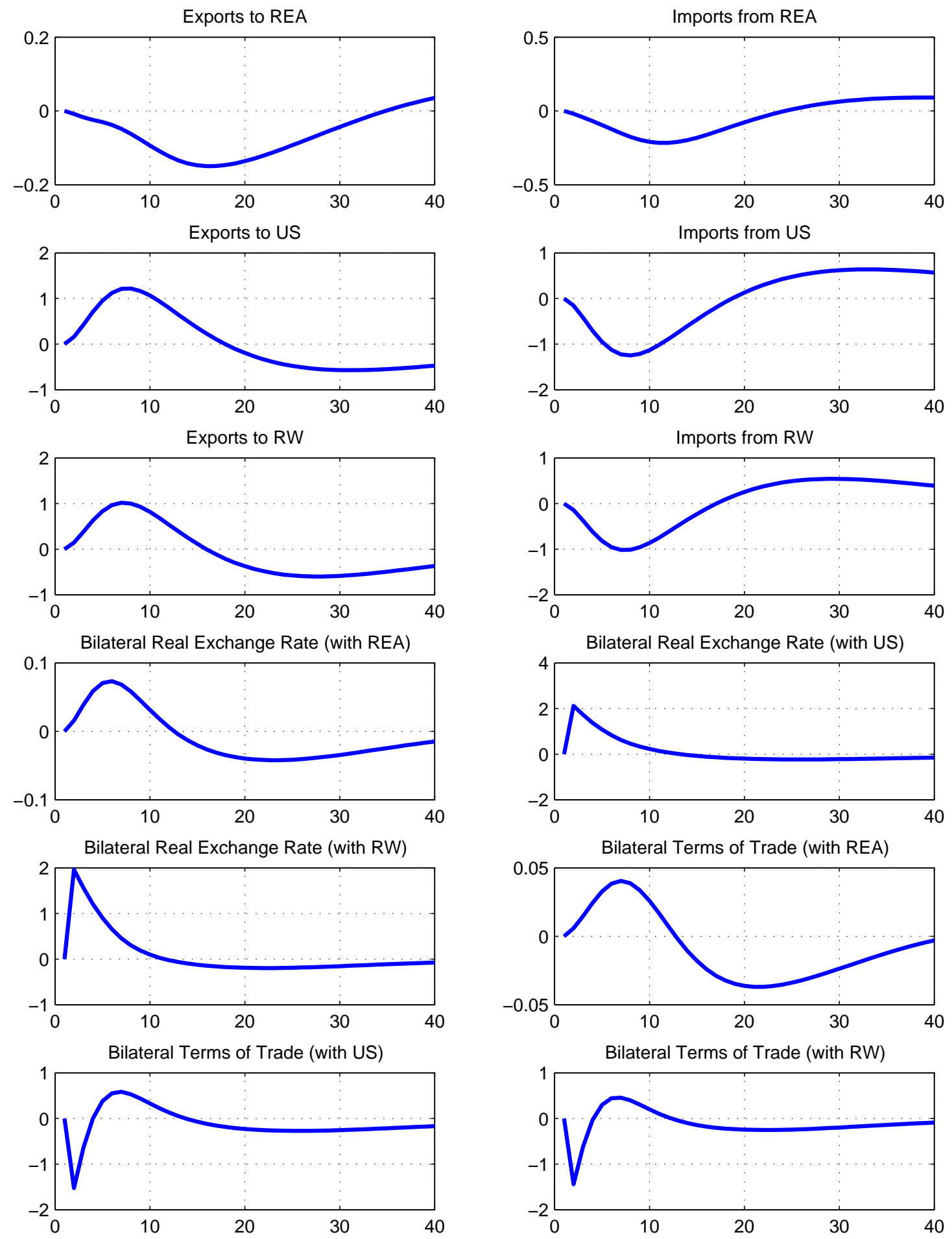

Horizontal axis: quarters. Vertical axis: percentage deviations from the baseline, except for inflation and interest rates (annualized percentage-point deviations), and the trade balance-to-GDP ratio (percentagepoint deviations). GDP and its components are reported in real terms. 
Figure 6d. Positive external premium shock in the euro area - Effects on rest of euro area trade variables
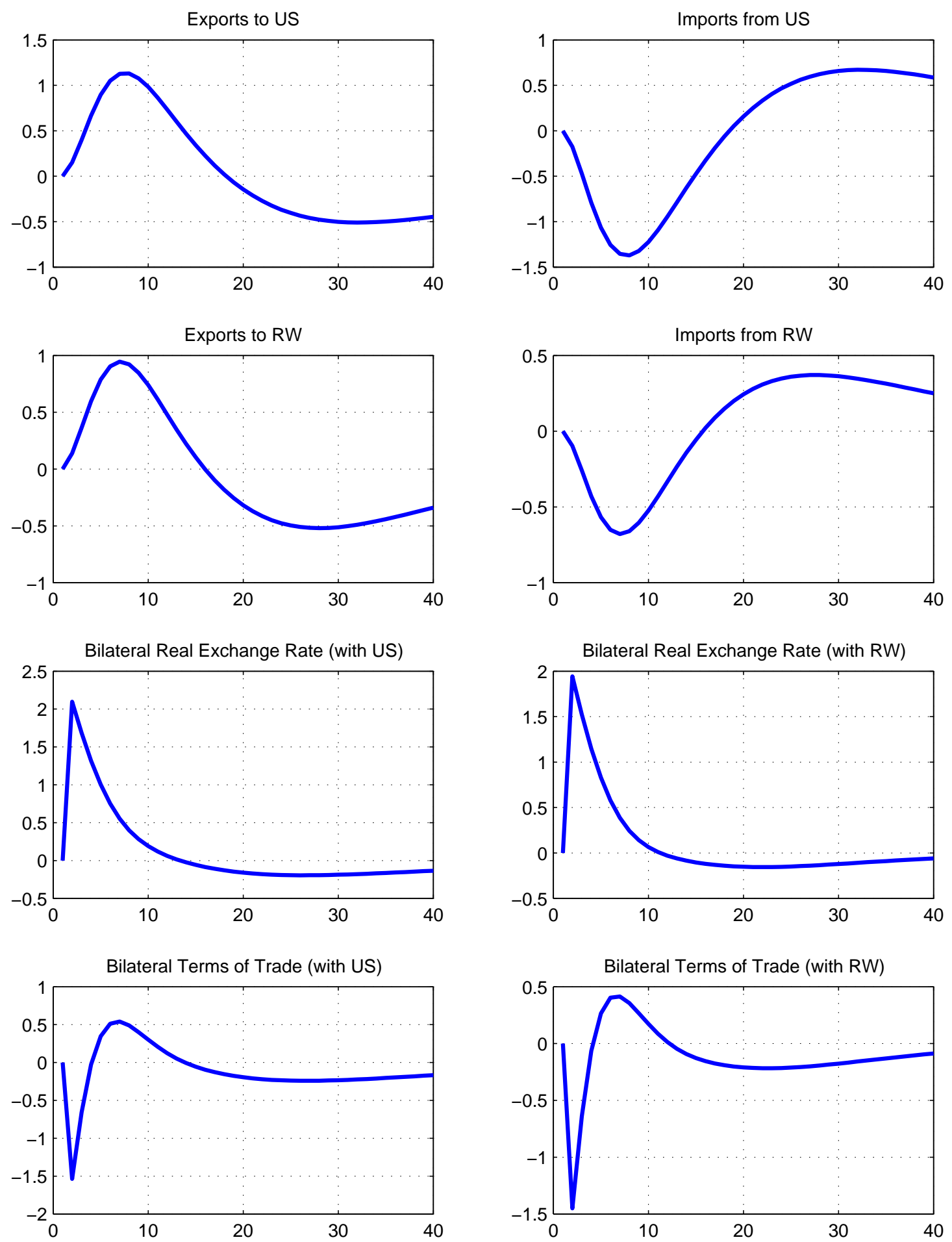

Horizontal axis: quarters. Vertical axis: percentage deviations from the baseline, except for inflation and interest rates (annualized percentage-point deviations), and the trade balance-to-GDP ratio (percentagepoint deviations). GDP and its components are reported in real terms. 
Figure 7a. Positive consumption shock in US and rest of the world - Effects on Home economy
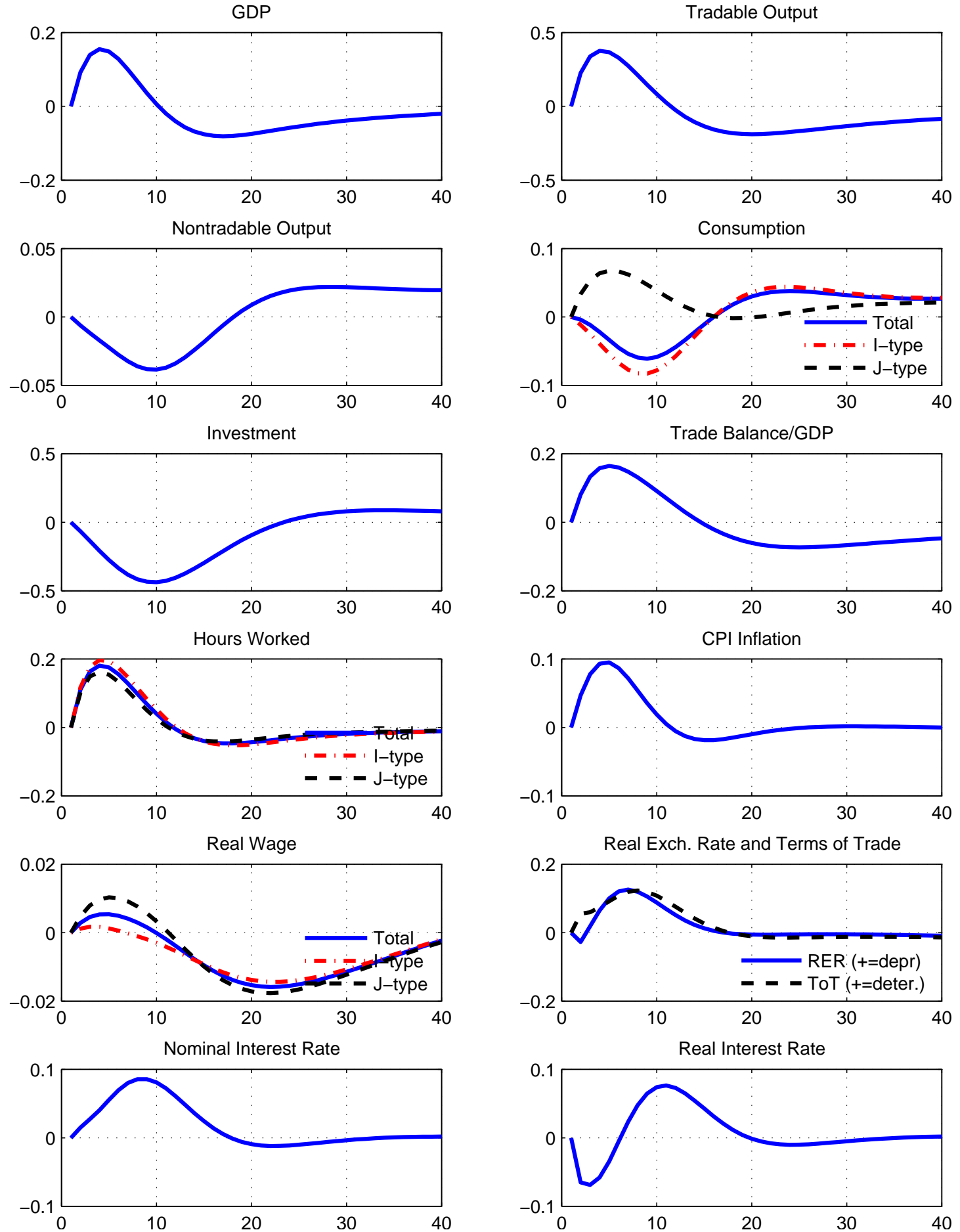

Horizontal axis: quarters. Vertical axis: percentage deviations from the baseline, except for inflation and interest rates (annualized percentage-point deviations), and the trade balance-to-GDP ratio (percentagepoint deviations). GDP and its components are reported in real terms. 
Figure 7b. Positive consumption shock in US and rest of the world - Effects on rest of euro area
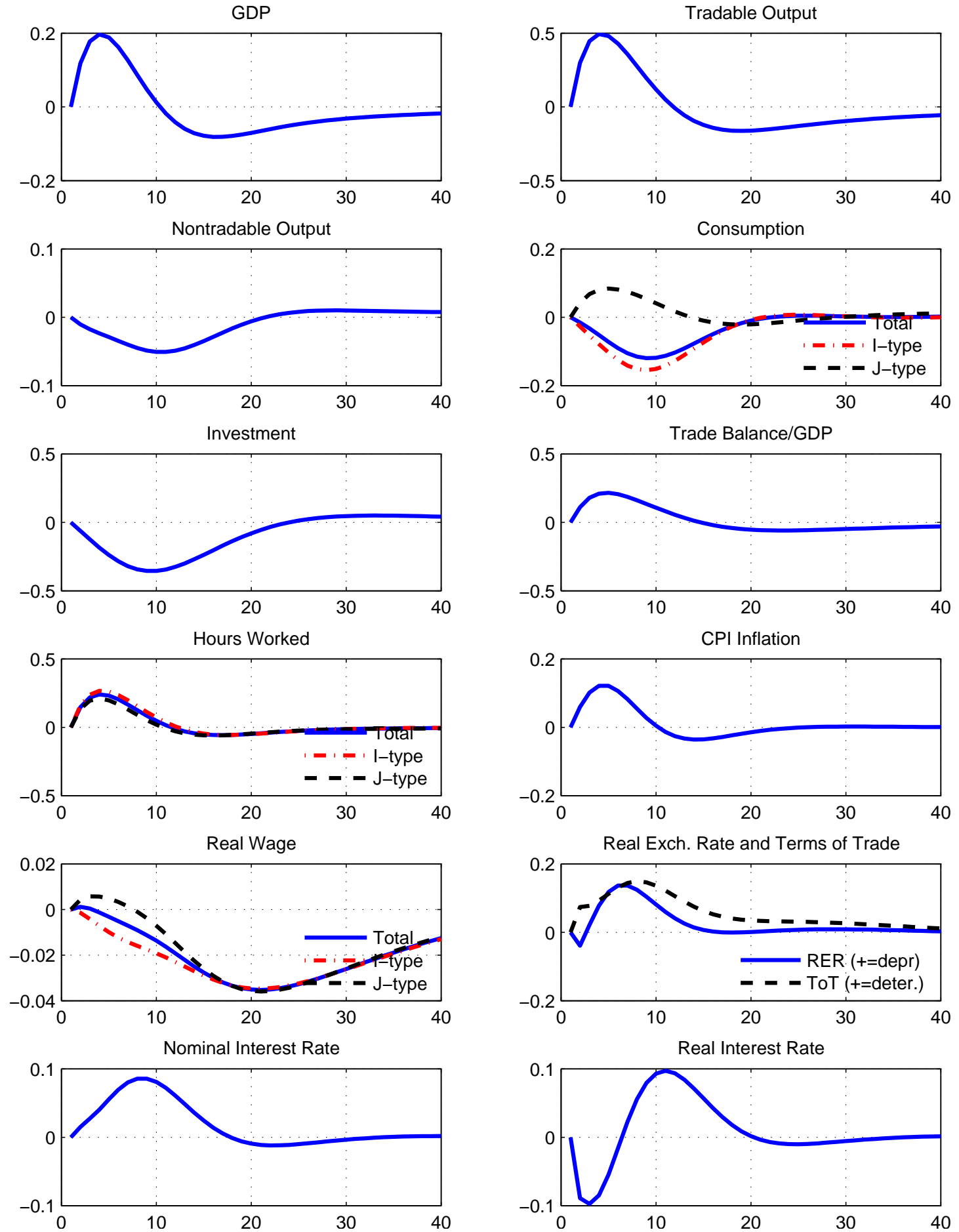

Horizontal axis: quarters. Vertical axis: percentage deviations from the baseline, except for inflation and interest rates (annualized percentage-point deviations), and the trade balance-to-GDP ratio (percentagepoint deviations). GDP and its components are reported in real terms. 
Figure 7c. Positive consumption shock in US and rest of the world - Effects on Home trade variables
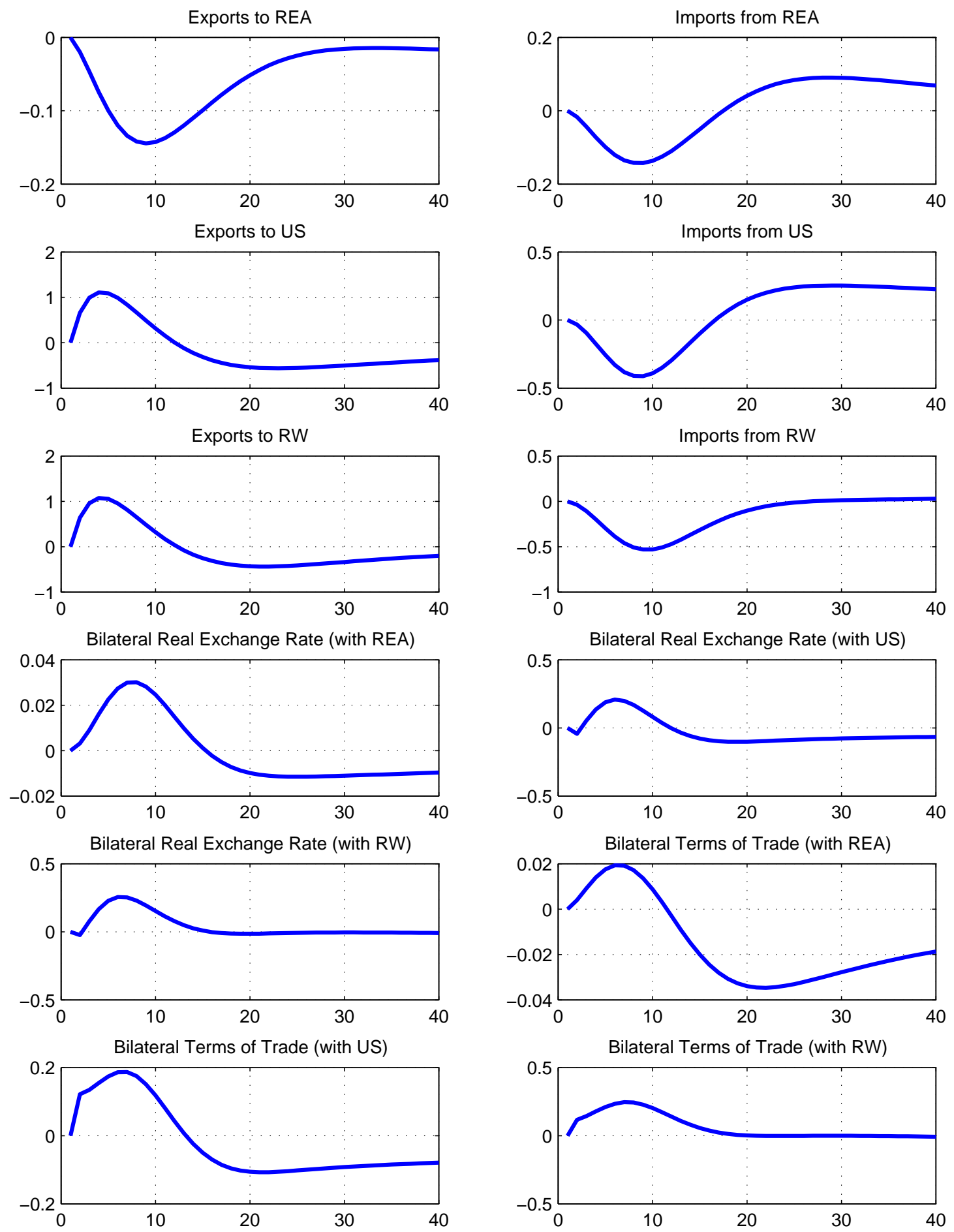

Horizontal axis: quarters. Vertical axis: percentage deviations from the baseline, except for inflation and interest rates (annualized percentage-point deviations), and the trade balance-to-GDP ratio (percentagepoint deviations). GDP and its components are reported in real terms. 
Figure 7d. Positive consumption shock in US and rest of the world - Effects on rest of euro area trade variables
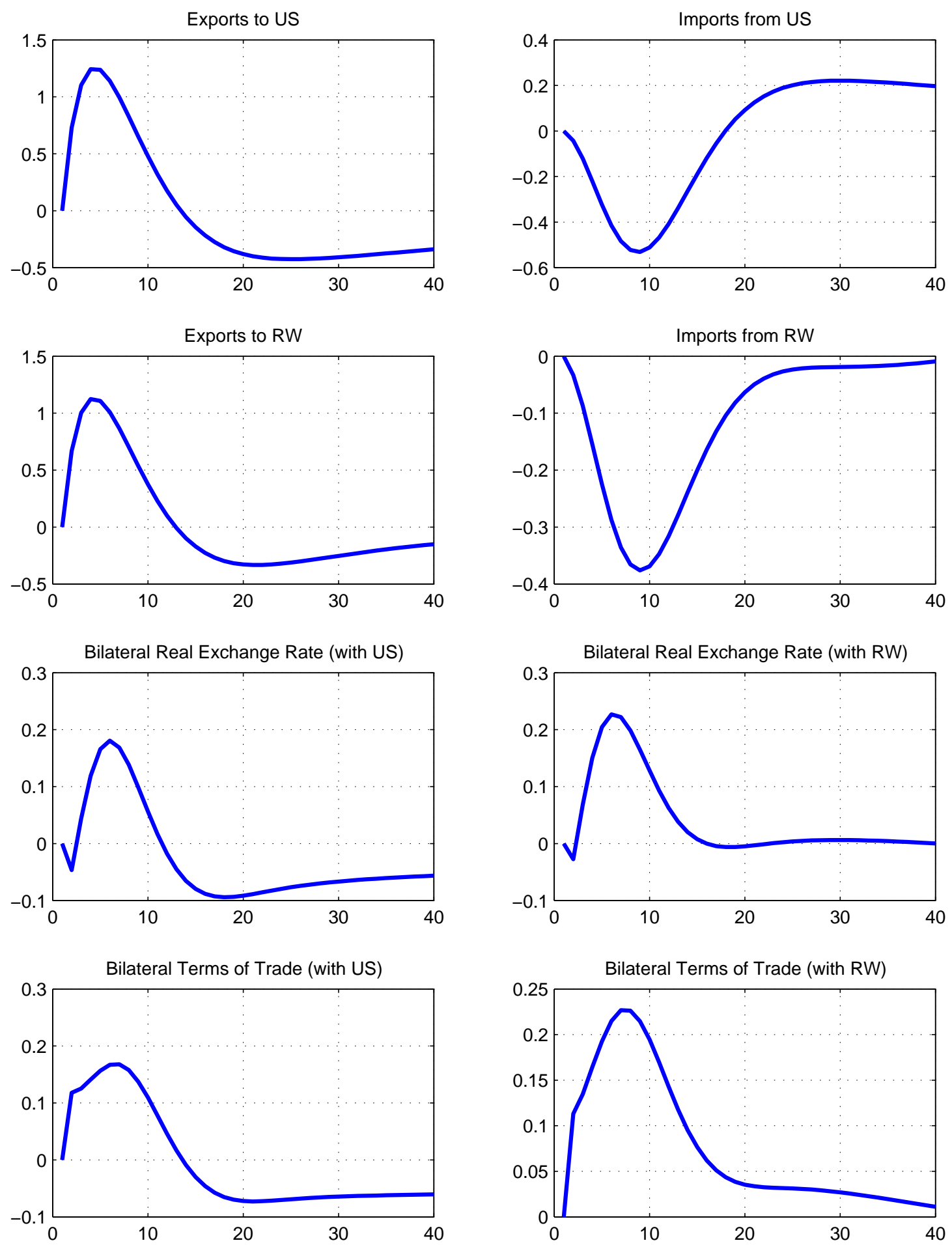

Horizontal axis: quarters. Vertical axis: percentage deviations from the baseline, except for inflation and interest rates (annualized percentage-point deviations), and the trade balance-to-GDP ratio (percentagepoint deviations). GDP and its components are reported in real terms. 


\section{A Appendix - List of equations}

In what follow we report the main equations of the Home country block, organized as follows. First, we show the equations of representative households, firms and policy authorities. Second, we report the corresponding aggregate variables. Third, we show the market clearing conditions for goods and assets. Fourth, we report some definitions. Finally, we briefly illustrate the monetary union setup. All variables, including the aggregate ones, are expressed in per capita terms. All variables, if not otherwise stated, refer to the Home country. In case of ambiguity (typically in the case of bilateral trade variables), we explicitly insert the index $H$ for Home variables. Similar equations holds for the other countries.

\section{A.1 Household I}

- utility function

$$
U_{I, t} \equiv \frac{1-\kappa}{1-\sigma}\left(\frac{C_{I, t}-\kappa C_{I, t-1}}{1-\kappa}\right)^{1-\sigma}-\frac{1}{1+\zeta}\left(N_{I, t}\right)^{1+\zeta}+\beta U_{I, t+1}
$$

- consumption Lagrange multiplier

$$
\Lambda_{I, t}=\frac{\left(\frac{C_{I, t}-\kappa C_{I, t-1}}{1-\kappa}\right)^{-\sigma}}{1+\tau_{t}^{C}+\Gamma_{v}\left(v_{I, t}\right)+\Gamma_{v}^{\prime}\left(v_{I, t}\right) v_{I, t}}
$$

- bond euler equations

$$
\begin{gathered}
\beta R_{t} E_{t}\left[\frac{\Lambda_{I, t+1}}{\Lambda_{I, t}} \Pi_{C, t+1}^{-1}\right]=1 \\
\beta R_{t}^{U S}\left(1-\Gamma_{B^{*}}\left(\frac{S_{t}^{H, U S} B_{t+1}^{*}}{P_{Y, t} Y_{t}} ; r p_{t}\right)\right) E_{t}\left[\frac{\Lambda_{I, t+1}}{\Lambda_{I, t}}\left(\Pi_{C, t+1}\right)^{-1} \frac{S_{t+1}^{H, U S}}{S_{t}^{H, U S}}\right]=1 \\
\Gamma_{B^{* C O}}\left(\frac{S_{t}^{H, U S} B_{t+1}^{*}}{P_{Y, t} Y_{t}} ; r p_{t}\right) \equiv \gamma_{B^{*}}\left(\exp \left(\frac{S_{t}^{H, U S} B_{t+1}^{*}}{P_{Y, t} Y_{t}}-\overline{B_{Y}^{*}}\right)-1\right)-r p_{t}
\end{gathered}
$$

- money holdings euler equation

$$
\begin{gathered}
\beta E_{t}\left[\frac{\Lambda_{I, t+1}}{\Lambda_{I, t}} \Pi_{C, t+1}^{-1}\right]=1-v_{I, t}^{2} \Gamma_{v}^{\prime}\left(v_{I, t}\right) \\
v_{I, t}=\frac{\left(1+\tau_{t}^{C}\right) P_{C, t} C_{I, t}}{M_{I, t}}
\end{gathered}
$$




$$
\begin{gathered}
\Gamma_{v}\left(v_{I, t}\right) \equiv \gamma_{v, 1} v_{I, t}+\gamma_{v, 2} v_{I, t}^{-1}-2 \sqrt{\gamma_{v, 1} \gamma_{v, 2}} \\
\Gamma_{v}^{\prime}\left(v_{I, t}\right) \equiv \gamma_{v, 1}-\gamma_{v, 2} v_{I, t}^{-2}
\end{gathered}
$$

- physical capital accumulation

$$
\begin{gathered}
K_{I, t+1}=(1-\delta) K_{I, t}+\left(1-\Gamma_{I}\left(\frac{I_{I, t}}{I_{I, t-1}}\right)\right) I_{I, t} \\
\Gamma_{I}\left(\frac{I_{I, t}}{I_{I, t-1}}\right) \equiv \frac{\gamma_{I}}{2}\left(\frac{I_{I, t}}{I_{I, t-1}}-1\right)^{2} \\
\Gamma_{I}^{\prime}\left(\frac{I_{I, t}}{I_{I, t-1}}\right) \equiv \gamma_{I}\left(\frac{I_{I, t}}{I_{I, t-1}}-1\right) / I_{I, t-1}
\end{gathered}
$$

- capital capacity utilization

$$
\begin{gathered}
R_{K, t}=\Gamma_{u}^{\prime}\left(u_{I, t}\right) P_{I, t} \\
\Gamma_{u}\left(u_{I, t}\right)=\frac{(1 / \beta-1+\delta) \bar{q}-\delta \overline{\tau_{k}} \overline{P_{I}}}{\left(1-\overline{\tau_{k}}\right) \overline{P_{I}}}\left(u_{I, t}-1\right)+\frac{\gamma_{u, 2}}{2}\left(u_{I, t}-1\right)^{2} \\
\Gamma_{u}^{\prime}\left(u_{I, t}\right)=\frac{(1 / \beta-1+\delta) \bar{q}-\delta \overline{\tau_{k}} \overline{P_{I}}}{\left(1-\overline{\tau_{k}}\right) \overline{P_{I}}}+\gamma_{u, 2}\left(u_{I, t}-1\right)
\end{gathered}
$$

- investment in physical capital FOC

$$
\begin{aligned}
\frac{P_{I, t}}{P_{C, t}}= & Q_{I, t}\left(1-\Gamma_{I}\left(\frac{I_{I, t}}{I_{I, t-1}}\right)-\Gamma_{I}^{\prime}\left(\frac{I_{I, t}}{I_{I, t-1}}\right) I_{I, t}\right) \\
& +\beta E_{t}\left[\frac{\Lambda_{I, t+1}}{\Lambda_{I, t}} Q_{I, t+1} \Gamma_{I}^{\prime}\left(\frac{I_{I, t+1}}{I_{I, t}}\right) \frac{I_{I, t+1}^{2}}{I_{I, t}}\right]
\end{aligned}
$$

- physical capital FOC

$$
\begin{array}{r}
Q_{I, t}=\beta E_{t}\left[\frac { \Lambda _ { I , t + 1 } } { \Lambda _ { I , t } } \left[(1-\delta) Q_{I, t+1}+\left(\left(1-\tau_{t+1}^{K}\right) \frac{R_{K, t+1}}{P_{C, t+1}} u_{I, t+1}\right.\right.\right. \\
\left.\left.\left.+\left(\tau_{t+1}^{K} \delta-\left(1-\tau_{t+1}^{K}\right) \Gamma_{u}\left(u_{I, t+1}\right)\right) \frac{P_{I, t+1}}{P_{C, t+1}}\right)\right]\right]
\end{array}
$$

- wage FOC

$$
\left(\frac{\widetilde{W}_{I, t}}{P_{C, t}}\right)^{1+\zeta \eta_{I}}=\frac{\eta_{I}}{\eta_{I}-1} \frac{f_{I, t}}{g_{I, t}}
$$




$$
\begin{gathered}
f_{I, t}=\left(\frac{W_{I, t}}{P_{C, t}}\right)^{\eta_{I}(1+\zeta)}\left(N_{I, t}^{D}\right)^{(1+\zeta)}+\beta \xi_{I} E_{t}\left[\left(\frac{\Pi_{C, t+1}}{\Pi_{C, t}^{\chi_{I}} \bar{\Pi}^{1-\chi_{I}}}\right)^{\eta_{I}(1+\zeta)} f_{I, t+1}\right] \\
g_{I, t}=\Lambda_{I, t}\left(1-\tau_{t}^{N}-\tau_{t}^{W_{h}}\right)\left(\frac{W_{I, t}}{P_{C, t}}\right)^{\eta_{I}} N_{I, t}^{D}+\beta \xi_{I} E_{t}\left[\left(\frac{\Pi_{C, t+1}}{\Pi_{C, t}^{\chi_{I}} \bar{\Pi}^{1-\chi_{I}}}\right)^{\eta_{I}-1} g_{I, t+1}\right] \\
W_{I, t}=\left[\xi_{I}\left(\left(\Pi_{C, t-1}\right)^{\chi_{I}} \bar{\Pi}^{1-\chi_{I}} W_{I, t-1}\right)^{1-\eta_{I}}+\left(1-\xi_{I}\right)\left(\widetilde{W}_{I, t}\right)^{1-\eta_{I}}\right]^{\frac{1}{1-\eta_{I}}} \\
\Pi_{C, t} \equiv \frac{P_{C, t}}{P_{C, t-1}}
\end{gathered}
$$

\section{A.2 Household J}

- utility function

$$
U_{J, t} \equiv \frac{1-\kappa}{1-\sigma}\left(\frac{C_{J, t}-\kappa C_{J, t-1}}{1-\kappa}\right)^{1-\sigma}-\frac{1}{1+\zeta}\left(N_{J, t}\right)^{1+\zeta}+\beta U_{J, t+1}
$$

- budget constraint

$$
\begin{aligned}
& \left(1+\tau_{t}^{C}+\Gamma_{v}\left(v_{J, t}\right)\right) P_{C, t} C_{J, t}+M_{J, t}+\Phi_{J, t} \\
= & \left(1-\tau_{t}^{N}-\tau_{t}^{W_{h}}\right) W_{J, t} N_{J, t}^{D}+T R_{J, t}-T_{J, t}+M_{J, t-1}
\end{aligned}
$$

- consumption Lagrange multiplier

$$
\Lambda_{J, t}=\frac{\left(\frac{C_{J, t}-\kappa C_{J, t-1}}{1-\kappa}\right)^{-\sigma}}{1+\tau_{t}^{C}+\Gamma_{v}\left(v_{J, t}\right)+\Gamma_{v}^{\prime}\left(v_{J, t}\right) v_{J, t}}
$$

- money holding euler equation

$$
\begin{gathered}
\beta E_{t}\left[\frac{\Lambda_{J, t+1}}{\Lambda_{J, t}} \Pi_{C, t+1}^{-1}\right]=1-\Gamma_{v}^{\prime}\left(v_{J, t}\right) v_{J, t}^{2} \\
v_{J, t}=\frac{\left(1+\tau_{t}^{C}\right) P_{C, t} C_{J, t}}{M_{J, t}} \\
\Gamma_{v}\left(v_{J, t}\right) \equiv \gamma_{v, 1} v_{J, t}+\gamma_{v, 2} v_{J, t}^{-1}-2 \sqrt{\gamma_{v, 1} \gamma_{v, 2}} \\
\Gamma_{v}^{\prime}\left(v_{J, t}\right) \equiv \gamma_{v, 1}-\gamma_{v, 2} v_{J, t}^{-2}
\end{gathered}
$$


- wage FOC

$$
\begin{gathered}
\left(\frac{\widetilde{W}_{J, t}}{P_{C, t}}\right)^{1+\zeta \eta_{J}}=\frac{\eta_{J}}{\eta_{J}-1} \frac{f_{J, t}}{g_{J, t}}\left(N_{J, t}^{D}\right)^{(1+\zeta)}+\beta \xi_{J} E_{t}\left[\left(\frac{\Pi_{C, t+1}}{\Pi_{C, t}^{\chi_{J}} \bar{\Pi}^{1-\chi_{J}}}\right)^{\eta_{J}(1+\zeta)} f_{J, t+1}\right] \\
f_{J, t}=\left(\frac{W_{J, t}}{P_{C, t}}\right)^{\eta_{J}(1+\zeta)}{ }_{g_{J, t}}=\Lambda_{J, t}\left(1-\tau_{t}^{N}-\tau_{t}^{W_{h}}\right)\left(\frac{W_{J, t}}{P_{C, t}}\right)^{\eta_{J}} N_{J, t}^{D}+\beta \xi_{J} E_{t}\left[\left(\frac{\Pi_{C, t+1}}{\Pi_{C, t}^{\chi_{J}} \bar{\Pi}^{1-\chi_{J}}}\right)^{\eta_{J}-1} g_{J, t+1}\right] \\
W_{J, t}=\left[\xi_{J}\left(\left(\Pi_{C, t-1}\right)^{\chi_{J}} \bar{\Pi}^{1-\chi_{J}} W_{J, t-1}\right)^{1-\eta_{J}}+\left(1-\xi_{J}\right)\left(\widetilde{W}_{J, t}\right)^{1-\eta_{J}}\right]^{\frac{1}{1-\eta_{J}}}
\end{gathered}
$$

\section{A.3 Intermediate goods}

- tradables production function

$$
\begin{aligned}
Y_{T, t}^{S}= & z_{t} z_{T, t}\left(K_{T, t}^{D}\right)^{\alpha_{T}}\left(N_{T, t}^{D}\right)^{1-\alpha_{T}}-\psi_{T} \\
& \text { if region belongs to the euro area } \\
Y_{T, t}^{S}= & z_{T, t}\left(K_{T, t}^{D}\right)^{\alpha_{T}}\left(N_{T, t}^{D}\right)^{1-\alpha_{T}}-\psi_{T}
\end{aligned}
$$

if region does not belong to the euro area

- nontradables production function

$$
\begin{aligned}
Y_{N, t}^{S}= & z_{t} z_{N, t}\left(K_{N, t}^{D}\right)^{\alpha_{N}}\left(N_{N, t}^{D}\right)^{1-\alpha_{N}}-\psi_{N} \\
& \text { if region belongs to the euro area } \\
Y_{N, t}^{S}= & z_{N, t}\left(K_{N, t}^{D}\right)^{\alpha_{N}}\left(N_{N, t}^{D}\right)^{1-\alpha_{N}}-\psi_{N}
\end{aligned}
$$

if region does not belong to the euro area

- tradables marginal costs

$$
\begin{aligned}
M C_{T, t}= & \frac{1}{z_{t} z_{T, t}\left(\alpha_{T}\right)^{\alpha_{T}}\left(1-\alpha_{T}\right)^{1-\alpha_{T}}}\left(R_{t}^{K}\right)^{\alpha_{T}}\left(\left(1+\tau_{t}^{W_{f}}\right) W_{t}\right)^{1-\alpha_{T}} \\
& \text { if region belongs to the euro area } \\
M C_{T, t}= & \frac{1}{z_{T, t}\left(\alpha_{T}\right)^{\alpha_{T}}\left(1-\alpha_{T}\right)^{1-\alpha_{T}}}\left(R_{t}^{K}\right)^{\alpha_{T}}\left(\left(1+\tau_{t}^{W_{f}}\right) W_{t}\right)^{1-\alpha_{T}} \\
& \text { if region does not belong to the euro area }
\end{aligned}
$$


- nontradables marginal costs

$$
\begin{aligned}
M C_{N, t}= & \frac{1}{z_{t} z_{N, t}\left(\alpha_{N}\right)^{\alpha_{N}}\left(1-\alpha_{N}\right)^{1-\alpha_{N}}}\left(R_{t}^{K}\right)^{\alpha_{N}}\left(\left(1+\tau_{t}^{W_{f}}\right) W_{t}\right)^{1-\alpha_{N}} \\
& \text { if region belongs to the euro area } \\
M C_{N, t}= & \frac{1}{z_{N, t}\left(\alpha_{N}\right)^{\alpha_{N}}\left(1-\alpha_{N}\right)^{1-\alpha_{N}}}\left(R_{t}^{K}\right)^{\alpha_{N}}\left(\left(1+\tau_{t}^{W_{f}}\right) W_{t}\right)^{1-\alpha_{N}} \\
& \text { if region does not belong to the euro area }
\end{aligned}
$$

- demand for capital services

$$
\begin{aligned}
R_{t}^{K} & =\alpha_{T} \frac{Y_{T, t}^{S}+\psi_{T}}{K_{T, t}^{D}} M C_{T, t} \\
R_{t}^{K} & =\alpha_{N} \frac{Y_{N, t}^{S}+\psi_{N}}{K_{N, t}^{D}} M C_{N, t}
\end{aligned}
$$

- demand for labor

$$
\begin{gathered}
N_{I, t}^{D}=(1-\omega)\left(\frac{W_{I, t}}{W_{t}}\right)^{-\eta} N_{t}^{D} \\
N_{J, t}^{D}=\omega\left(\frac{W_{J, t}}{W_{t}}\right)^{-\eta} N_{t}^{D} \\
N_{t}^{D}=\left[(1-\omega)^{\frac{1}{\eta}}\left(N_{I, t}^{D}\right)^{\frac{\eta-1}{\eta}}+\omega^{\frac{1}{\eta}}\left(N_{J, t}^{D}\right)^{\frac{\eta-1}{\eta}}\right]^{\frac{\eta}{\eta-1}}
\end{gathered}
$$

- tradables pricing (domestic market)

$$
\begin{aligned}
& \frac{\widetilde{P}_{H T, t}}{P_{H T, t}}=\frac{\theta_{T}}{\theta_{T}-1} \frac{f_{H, t}}{g_{H, t}} \\
& f_{H, t}=H T_{t} M C_{T, t}+\beta \xi_{H} E_{t}\left[\frac{\Lambda_{I, t+1}}{\Lambda_{I, t}}\left(\frac{\Pi_{H T, t+1}}{\Pi_{H T, t}^{\chi_{H}} \bar{\Pi}^{1-\chi_{H}}}\right)^{\theta_{T}} f_{H, t+1}\right] \\
& g_{H, t}=P_{H T, t} H T_{t}+\beta \xi_{H} E_{t}\left[\frac{\Lambda_{I, t+1}}{\Lambda_{I, t}}\left(\frac{\Pi_{H T, t+1}}{\Pi_{H T, t}^{\chi_{H}} \bar{\Pi}^{1-\chi H}}\right)^{\theta_{T}-1} g_{H, t+1}\right] \\
& P_{H T, t}=\left[\xi_{H}\left(\Pi_{H T, t-1}^{\chi_{H}} \bar{\Pi}^{1-\chi_{H}} P_{H T, t-1}\right)^{1-\theta_{T}}+\left(1-\xi_{H}\right)\left(\widetilde{P}_{H T, t}\right)^{1-\theta_{T}}\right]^{\frac{1}{1-\theta_{T}}} \\
& \Pi_{H T, t} \equiv \frac{P_{H T, t}}{P_{H T, t-1}}
\end{aligned}
$$


- tradables pricing (export)

$$
\begin{aligned}
& \frac{\widetilde{P}_{I M, t}^{C O, H}}{P_{I M, t}^{C O, H}}=\frac{\theta_{T}}{\theta_{T}-1} \frac{f_{X, t}^{H, C O}}{g_{X, t}^{H, C O}}, \text { for all } C O \neq H \\
f_{X, t}^{H, C O}= & M C_{T, t} \frac{s^{C O}}{s^{H}} I M_{t}^{C O, H} \\
& +\beta \xi_{X} E_{t}\left[\frac{\Lambda_{I, t+1}}{\Lambda_{I, t}}\left(\frac{\Pi_{I M, t+1}^{C O, H}}{\left(\Pi_{I M, t}^{C O, H}\right)^{\chi X} \bar{\Pi}^{1-\chi X}}\right)^{\theta_{T}} f_{X, t+1}^{H, C O}\right]
\end{aligned}
$$

for all $C O \neq H$

$$
\begin{aligned}
g_{X, t}^{H, C O}= & S_{t}^{H, C O} P_{I M, t}^{C O, H} \frac{s^{C O}}{s^{H}} I M_{t}^{C O, H} \\
& +\beta \xi_{X} E_{t}\left[\frac{\Lambda_{I, t+1}}{\Lambda_{I, t}}\left(\frac{\Pi_{I M, t+1}^{C O, H}}{\left(\Pi_{I M, t}^{C O, H}\right)^{\chi X} \bar{\Pi}^{1-\chi X}}\right)^{\theta_{T}-1} g_{X, t+1}^{H, C O}\right]
\end{aligned}
$$

for all $C O \neq H$

$$
\begin{aligned}
& P_{I M, t}^{C O, H}=\left[\xi_{X}\left(\left(\Pi_{I M, t-1}^{C O, H}\right)^{\chi X} \bar{\Pi}^{1-\chi x} P_{I M, t-1}^{C O, H}\right)^{1-\theta_{T}}+\left(1-\xi_{X}\right)\left(\widetilde{P}_{I M, t}^{C O, H}\right)^{1-\theta_{T}}\right]^{\frac{1}{1-\theta_{T}}} \\
& \text { for all } C O \neq H \\
& \Pi_{I M, t}^{C O, H} \equiv \frac{P_{I M, t}^{C O, H}}{P_{I M, t-1}^{C O, H}}
\end{aligned}
$$

- nontradables pricing

$$
\begin{gathered}
\frac{\widetilde{P}_{N T, t}}{P_{N T, t}}=\frac{\theta_{N}}{\theta_{N}-1} \frac{f_{N, t}}{g_{N, t}} \\
f_{N, t}=N T_{t} M C_{N, t}+\beta \xi_{N} E_{t}\left[\frac{\Lambda_{I, t+1}}{\Lambda_{I, t}}\left(\frac{\Pi_{N T, t+1}}{\Pi_{N T, t}^{\chi_{N}} \bar{\Pi}^{1-\chi_{N}}}\right)^{\theta_{N}} f_{N, t+1}\right] \\
g_{N, t}=P_{N T, t} N T_{t}+\beta \xi_{N} E_{t}\left[\frac{\Lambda_{I, t+1}}{\Lambda_{I, t}}\left(\frac{\Pi_{N, t+1}}{\Pi_{N T, t}^{\chi_{N}} \bar{\Pi}^{1-\chi_{N}}}\right)^{\theta_{N}-1} g_{N, t+1}\right] \\
P_{N T, t}=\left[\xi_{N}\left(\Pi_{N T, t-1}^{\chi_{N}} \bar{\Pi}^{1-\chi_{N}} P_{N T, t-1}\right)^{1-\theta_{N}}+\left(1-\xi_{N}\right)\left(\widetilde{P}_{N T, t}\right)^{1-\theta_{N}}\right]^{\frac{1}{1-\theta_{N}}} \\
\Pi_{N T, t} \equiv \frac{P_{N T, t}}{P_{N T, t-1}}
\end{gathered}
$$




\section{A.4 Final goods}

- consumption bundle

$$
\begin{aligned}
& Q_{t}^{C}=\left[v_{C}^{\frac{1}{\mu_{C}}}\left(T T_{t}^{C}\right)^{\frac{\mu_{C}-1}{\mu_{C}}}+\left(1-v_{C}\right)^{\frac{1}{\mu_{C}}}\left(N T_{t}^{C}\right)^{\frac{\mu_{C}-1}{\mu_{C}}}\right]^{\frac{\mu_{C}}{\mu_{C}-1}} \\
& N T_{t}^{C}=\left(1-v_{C}\right)\left(\frac{P_{N T, t}}{P_{C, t}}\right)^{-\mu_{C}} Q_{t}^{C} \\
& T T_{t}^{C}=\left[v_{T C}^{\frac{1}{\mu_{T C}}}\left(H T_{t}^{C}\right)^{\frac{\mu_{T C}-1}{\mu_{T C}}}+\left(1-v_{T C}\right)^{\frac{1}{\mu_{T C}}}\left(I M_{t}^{C}\right)^{\frac{\mu_{T C}-1}{\mu_{T C}}}\right]^{\frac{\mu_{T C}}{\mu_{T C}-1}} \\
& H T_{t}^{C}=v_{T C}\left(\frac{P_{H T, t}}{P_{T T^{C}, t}}\right)^{-\mu_{T C}} T T_{t}^{C} \\
& I M_{t}^{C}=\left[\sum_{C O \neq H}\left(v_{I M^{C}}^{H, C O}\right)^{\frac{1}{\mu_{I M C}}}\left(I M_{t}^{C, C O}\left(1-\Gamma_{I M^{C}}^{H, C O}\left(\frac{I M_{t}^{C, C O}}{Q_{t}^{C}}\right)\right)\right)^{\frac{\mu_{I M C}-1}{\mu_{I M C}}}\right]^{\frac{\mu_{I M C}}{\mu_{I M C}-1}} \\
& \text { with } \sum v_{I M C}^{H, C O}=1 \\
& I M_{t}^{C, C O}=v_{I M^{C}}^{H, C O}\left(\frac{P_{I M, t}^{H, C O}}{P_{I M^{C}, t} \Gamma_{I M^{C}}^{H, C O \dagger}\left(I M_{t}^{C, C O} / Q_{t}^{C}\right)}\right)^{-\mu_{I M C}} \frac{I M_{t}^{C}}{1-\Gamma_{I M^{C}}^{H, C O}\left(I M_{t}^{C, C O} / Q_{t}^{C}\right)} \\
& \text { for all } C O \neq H \\
& \Gamma_{I M^{C}}^{H, C O}\left(\frac{I M_{t}^{C, C O}}{Q_{t}^{C}}\right) \equiv \frac{\gamma_{I M C}}{2}\left(\frac{I M_{t}^{C, C O} / Q_{t}^{C}}{I M_{t-1}^{C, C O} / Q_{t-1}^{C}}-1\right)^{2} \\
& \Gamma_{I M^{C}}^{H, C O \dagger}\left(\frac{I M_{t}^{C, C O}}{Q_{t}^{C}}\right) \equiv 1-\Gamma_{I M^{C}}^{H, C O}\left(\frac{I M_{t}^{C, C O}}{Q_{t}^{C}}\right)-\left(\Gamma_{I M^{C}}^{H, C O}\left(\frac{I M_{t}^{C, C O}}{Q_{t}^{C}}\right)\right)^{\prime} I M_{t}^{C, C O}
\end{aligned}
$$

- investment bundle

$$
\begin{gathered}
Q_{t}^{I}=\left[v_{I}^{\frac{1}{\mu_{I}}}\left(T T_{t}^{I}\right)^{\frac{\mu_{I}-1}{\mu_{I}}}+\left(1-v_{I}\right)^{\frac{1}{\mu_{I}}}\left(N T_{t}^{I}\right)^{\frac{\mu_{I}-1}{\mu_{I}}}\right]^{\frac{\mu_{I}}{\mu_{I-1}}} \\
N T_{t}^{I}=\left(1-v_{I}\right)\left(\frac{P_{N T, t}}{P_{I, t}}\right)^{-\mu_{I}} Q_{t}^{I} \\
T T_{t}^{I}=\left[v_{T I}^{\frac{1}{\mu_{T I}}}\left(H T_{t}^{I}\right)^{\frac{\mu_{T I}-1}{\mu_{T I}}}+\left(1-v_{T I}\right)^{\frac{1}{\mu_{T I}}}\left(I M_{t}^{I}\right)^{\frac{\mu_{T I}-1}{\mu_{T I}}}\right]^{\frac{\mu_{T I}}{\mu_{T I-1}}}
\end{gathered}
$$




$$
\begin{aligned}
& H T_{t}^{I}=v_{T I}\left(\frac{P_{H T, t}}{P_{T T^{I}, t}}\right)^{-\mu_{T I}} T T_{t}^{I} \\
& I M_{t}^{I}=\left[\sum_{C O \neq H}\left(v_{I M^{I}}^{H, C O}\right)^{\frac{1}{\mu_{I M I}}}\left(I M_{t}^{I, C O}\left(1-\Gamma_{I M^{I}}^{H, C O}\left(\frac{I M_{t}^{I, C O}}{Q_{t}^{I}}\right)\right)\right)^{\frac{\mu_{I M I}-1}{\mu_{I M I}}}\right]^{\frac{\mu_{I M I}}{\mu_{I M I}-1}} \\
& \text { with } \sum v_{I M^{I}}^{H, C O}=1 \\
& I M_{t}^{I, C O}=v_{I M^{I}}^{H, C O}\left(\frac{P_{I M, t}^{H, C O}}{\Gamma_{I M^{I}}^{H, C O \dagger}\left(I M_{t}^{I, C O} / Q_{t}^{I}\right) P_{I M^{I}, t}}\right)^{-\mu_{I M I}} \frac{I M_{t}^{I}}{\left(1-\Gamma_{I M^{I}}^{H, C O}\left(I M_{t}^{I, C O} / Q_{t}^{I}\right)\right)} \\
& \text { for all } C O \neq H \\
& \Gamma_{I M^{I}}^{H, C O \dagger}\left(\frac{I M_{t}^{I, C O}}{Q_{t}^{I}}\right) \equiv 1-\Gamma_{I M^{I}}^{H, C O}\left(\frac{I M_{t}^{I, C O}}{Q_{t}^{I}}\right)-\left(\Gamma_{I M^{I}}^{H, C O}\left(\frac{I M_{t}^{I, C O}}{Q_{t}^{I}}\right)\right)^{\prime} I M_{t}^{I, C O}
\end{aligned}
$$

- consumption prices

$$
\begin{gathered}
P_{C, t}=\left[v_{C}\left(P_{T T^{C}, t}\right)^{1-\mu_{C}}+\left(1-v_{C}\right)\left(P_{N T, t}\right)^{1-\mu_{C}}\right]^{\frac{1}{1-\mu_{C}}} \\
P_{T T^{C}, t}=\left[v_{T C}\left(P_{H T, t}\right)^{1-\mu_{T C}}+\left(1-v_{T C}\right)\left(P_{I M^{C}, t}\right)^{1-\mu_{T C}}\right]^{\frac{1}{1-\mu_{T C}}} \\
P_{I M^{C}, t}=\left(\sum_{C O \neq H} v_{I M^{C}}^{H, C O}\left(\frac{P_{I M, t}^{C O}}{\Gamma_{I M^{C}}^{H, C O \dagger}\left(I M_{t}^{C, C O} / Q_{t}^{C}\right)}\right)^{1-\mu_{I M C}}\right)^{\frac{1}{1-\mu_{I M C}}}
\end{gathered}
$$

- investment prices

$$
\begin{gathered}
P_{I, t}=\left[v_{I}\left(P_{T T^{I}, t}\right)^{1-\mu_{I}}+\left(1-v_{I}\right)\left(P_{N T, t}\right)^{1-\mu_{I}}\right]^{\frac{1}{1-\mu_{I}}} \\
P_{T T^{I}, t}=\left[v_{T I}\left(P_{H T, t}\right)^{1-\mu_{T I}}+\left(1-v_{T I}\right)\left(P_{I M^{I}, t}\right)^{1-\mu_{T I}}\right]^{\frac{1}{1-\mu_{T I}}} \\
P_{I M^{I}, t}=\left(\sum_{C O \neq H} v_{I M^{I}}^{H, C O}\left(\frac{P_{I M, t}^{C O}}{\Gamma_{I M^{I}}^{H, C O \dagger}\left(I M_{t}^{I, C O} / Q_{t}^{I}\right)}\right)^{1-\mu_{I M I}}\right)^{\frac{1}{1-\mu_{I M I}}}
\end{gathered}
$$




\section{A.5 Monetary and fiscal authorities}

- monetary authority

$$
\begin{aligned}
\left(R_{t}^{C O}\right)^{4}= & \phi_{R}^{C O}\left(R_{t-1}^{C O}\right)^{4}+\left(1-\phi_{R}^{C O}\right)\left[\bar{R}^{4}+\phi_{\Pi}^{C O}\left(\Pi_{t}^{C O, 4}-\bar{\Pi}^{C O, 4}\right)\right] \\
& +\phi_{Y}^{C O}\left(Y \operatorname{gr}_{t}^{C O}-1\right)+\varepsilon_{R, t}^{C O},
\end{aligned}
$$

if region does not belong to the euro area

$$
\begin{gathered}
\left(R_{t}^{E A}\right)^{4=} \phi_{R}^{E A}\left(R_{t-1}^{E A}\right)^{4}+\left(1-\phi_{R}^{E A}\right)\left[\left(\bar{R}^{E A}\right)^{4}+\phi_{\Pi}^{E A}\left(\Pi_{t}^{E A, 4}-\bar{\Pi}^{E A, 4}\right)\right] \\
+\phi_{Y}^{E A}\left(Y \operatorname{gr}_{t}^{E A}-1\right)+\varepsilon_{R, t}^{E A} \\
\Pi_{t}^{C O, 4} \equiv \Pi_{C, t}^{C O} \Pi_{C, t-1}^{C O} \Pi_{C, t-2}^{C O} \Pi_{C, t-3}^{C O}
\end{gathered}
$$

- fiscal authority

$$
\begin{gathered}
P_{N T, t} G_{t}+T R_{t}+B_{t}+M_{t-1} \\
=\tau_{t}^{C} P_{C, t} C_{t}+\left(\tau_{t}^{N}+\tau_{t}^{W_{h}}\right) \frac{1}{s^{H}}\left(\int_{0}^{s^{H}(1-\omega)} W_{t}(i) N_{t}(i) d i+\int_{s^{H}(1-\omega)}^{s^{H}} W_{t}(j) N_{t}(j) d j\right) \\
+\tau_{t}^{W_{f}} W_{t} N_{t}+\tau_{t}^{K}\left(R_{k, t} u_{t}-\left(\Gamma_{u}\left(u_{t}\right)+\delta\right) P_{I, t}\right) K_{t} \\
+\tau_{t}^{D} D_{t}+T_{t}+R_{t}^{-1} B_{t+1}+M_{t} \\
P_{N T, t} G_{t} \equiv g_{t} \overline{P_{Y} Y} \\
T R_{t} \equiv t r_{t} \overline{P_{Y} Y} \\
T_{t} \equiv t_{t} \overline{P_{Y} Y} \\
t_{t}=\phi_{B_{Y}}\left(\frac{B_{t}}{\overline{P_{Y} Y}-\overline{B_{Y}}}\right)
\end{gathered}
$$




\section{A.6 Aggregate variables}

$$
\begin{aligned}
C_{t} & =(1-\omega) C_{I, t}+\omega C_{J, t} \\
M_{t} & =(1-\omega) M_{I, t}+\omega M_{J, t} \\
K_{t} & =(1-\omega) K_{I, t} \\
I_{t} & =(1-\omega) I_{I, t} \\
T R_{t} & =(1-\omega) T R_{I, t}+\omega T R_{J, t} \\
T_{t} & =(1-\omega) T_{I, t}+\omega T_{J, t} \\
\Gamma_{v, t} & =(1-\omega) \Gamma_{v I, t}\left(v_{I, t}\right)+\omega \Gamma_{v J, t}\left(v_{J, t}\right) \\
N_{t}^{D} & =N_{T, t}^{D}+N_{N, t}^{D} \\
D_{t} & =(1-\omega) D_{I, t} \\
D_{t} & \equiv P_{Y, t} Y_{, t}-r_{t}^{K} K_{t}^{D}-\left(1+\tau_{t}^{W_{f}}\right) W_{t} N_{t}^{D} \\
K_{t}^{D} & =K_{T, t}^{D}+K_{N, t}^{D} \\
B_{t} & =(1-\omega) B_{I, t} \\
B_{t}^{*} & =(1-\omega) B_{I, t}^{*}
\end{aligned}
$$

\section{A.7 Market clearing conditions}

- final consumption good

$$
Q_{t}^{C}=C_{t}+\Gamma_{v, t}
$$

- final investment good

$$
Q_{t}^{I}=I_{t}+\Gamma_{u}\left(u_{t}\right) K_{t}
$$

- nontradable intermediate goods

$$
\begin{gathered}
Y_{N, t}^{S}=s_{N, t} N T_{t} \\
N T_{t}=N T_{t}^{C}+N T_{t}^{I}+G_{t} \\
s_{N, t}=\left(1-\xi_{N}\right)\left(\frac{\tilde{P}_{N T, t}}{P_{N T, t}}\right)^{-\theta_{N}}+\xi_{N}\left(\frac{\Pi_{N T, t}}{\Pi_{N T, t-1}^{\chi_{N}} \bar{\Pi}^{-\chi_{N T}}}\right)^{\theta_{N}} s_{N, t-1}
\end{gathered}
$$


- tradable intermediate goods

$$
\begin{gathered}
Y_{t}=s_{H T, t} H T_{t}+\sum_{C O \neq H}\left(\frac{s^{C O}}{s^{H}}\right) s_{X, t}^{C O} I M_{t}^{C O, H} \\
H T_{t}=H T_{t}^{C}+H T_{t}^{I} \\
s_{H T, t}=\left(1-\xi_{H}\right)\left(\frac{\tilde{P}_{H T, t}}{P_{H T, t}}\right)^{-\theta_{T}}+\xi_{H}\left(\frac{\Pi_{H T, t}}{\Pi_{H T, t-1}^{\chi_{H}} \bar{\Pi}^{1-\chi_{H}}}\right)^{\theta_{T}} s_{H T, t-1} \\
s_{X, t}^{C O}=\left(1-\xi_{X}^{C O}\right)\left(\frac{\tilde{P}_{X, t}^{C O}}{P_{X, t}^{C O}}\right)^{-\theta_{T}}+\xi_{X}^{C O}\left(\frac{\Pi_{X, t}^{C O}}{\Pi_{X}^{\chi_{X}^{C O}} \bar{\Pi}^{1-\chi_{X}^{C O}}}\right)^{\theta_{T}} s_{X, t-1}^{C O}
\end{gathered}
$$

- labor

$$
\begin{gathered}
N_{I, t}=s_{I, t} N_{I, t}^{D} \\
N_{J, t}=s_{J, t} N_{J, t}^{D} \\
s_{I, t}=\left(1-\xi_{I}\right)\left(\frac{\tilde{W}_{I, t}}{W_{I, t}}\right)^{-\eta_{I}}+\xi_{I}\left(\frac{W_{I, t}}{W_{I, t-1} \Pi_{C, t-1}^{\chi_{I}} \bar{\Pi}^{1-\chi I}}\right)^{\eta_{I}} s_{I, t-1} \\
s_{J, t}=\left(1-\xi_{J}\right)\left(\frac{\tilde{W}_{J, t}}{W_{J, t}}\right)^{-\eta_{J}}+\xi_{J}\left(\frac{W_{J, t}}{W_{J, t-1} \Pi_{C, t-1}^{\chi_{J}} \bar{\Pi}^{1-\chi J}}\right)^{\eta_{J}} s_{J, t-1}
\end{gathered}
$$

- capital services

$$
u_{t} K_{t}=K_{t}^{D}
$$

- internationally traded bond

$$
\sum_{C O} s^{C O} B_{t}^{* C O}=0, \sum_{C O} s^{C O}=1
$$

A.8 Resource constraint, trade balance and net foreign asset position

$$
\begin{aligned}
P_{Y, t} Y_{t}= & P_{C, t} Q_{t}^{C}+P_{I, t} Q_{t}^{I}+P_{N T, t} G_{t}+\sum_{C O \neq H} S_{t}^{H, C O} P_{X, t}^{H, C O} X_{t}^{H, C O} \\
& -\sum_{C O \neq H} P_{I M, t}^{H, C O} I M_{t}^{H, C O}
\end{aligned}
$$




$$
\begin{gathered}
I M_{t}^{H, C O} \equiv I M_{t}^{C, C O} \frac{1-\Gamma_{I M^{C}}^{H, C O}\left(I M_{t}^{C, C O} / Q_{t}^{C}\right)}{\Gamma_{I M^{C}}^{H, C O \dagger}\left(I M_{t}^{C, C O} / Q_{t}^{C}\right)}+I M_{t}^{I, C O} \frac{1-\Gamma_{I M^{I}}^{H, C O}\left(I M_{t}^{I, C O} / Q_{t}^{I}\right)}{\Gamma_{I M^{I}}^{H, C O \dagger}\left(I M_{t}^{I, C O} / Q_{t}^{I}\right)} \\
X_{t}^{H, C O} \equiv \frac{s^{C O}}{s^{H}} I M_{t}^{C O, H} \\
Y_{t} \equiv Y_{T, t}^{S}+Y_{N, t}^{S} \\
T B_{t}=\sum_{C O \neq H} S_{t}^{H, C O} P_{X, t}^{H, C O} I M_{t}^{C O, H}-\sum_{C O \neq H} P_{I M, t}^{H, C O} I M_{t}^{H, C O} \\
R_{t-1}^{*-1} B_{t}^{*}=B_{t-1}^{*}+\frac{T B_{t-1}}{S_{t-1}^{H, U S}}
\end{gathered}
$$

\section{A.9 Relative prices}

- bilateral terms of trade

$$
T O T_{t}^{H, C O} \equiv \frac{P_{I M, t}^{H, C O}}{S_{t}^{H, C O} P_{X, t}^{H, C O}}, \text { for all } C O \neq H
$$

- bilateral real exchange rate

$$
R E R_{t}^{H, C O} \equiv \frac{S^{H, C O} P_{C, t}^{C O}}{P_{C, t}^{H}}, \text { for all } C O \neq H
$$

- effective real exchange rate

$$
\begin{gathered}
R E E R_{t}^{H} \equiv \prod_{C O \neq H}\left(R E R_{t}^{H, C O}\right)^{\nu^{H, C O}} \\
\nu^{H, C O} \equiv \frac{P_{X, t}^{H} X_{t}^{H}}{P_{I M, t}^{H} I M_{t}^{H}+P_{X, t}^{H} X_{t}^{H}} \nu_{X}^{H, C O}+\frac{P_{I M, t}^{H} I M_{t}^{H}}{P_{I M, t}^{H} I M_{t}^{H}+P_{X, t}^{H} X_{t}^{H}} \nu_{I M}^{H, C O} \\
\nu_{X}^{H, C O} \equiv \frac{X_{t}^{H, C O}}{X_{t}} \frac{R E R_{t}^{H, C O} P_{Y, t}^{C O} Y_{t}^{C O}}{R E R_{t}^{H, C O}} P_{Y, t}^{C O} Y_{t}^{C O}+\sum_{K \neq\{C O, H\}} R E R_{t}^{H, K} P_{X, t}^{K} X_{t}^{K, C O} \\
+\sum_{K \neq\{C O, H\}} \frac{X_{t}^{H, K}}{X_{t}} \frac{R E R_{t}^{H, C O} P_{X, t}^{C O} X_{t}^{C O, K}}{P_{Y, t}^{K} Y_{t}^{K}+\sum_{J \neq K} R E R_{t}^{H, J} P_{X, t}^{J} X_{t}^{J, K}} \\
\nu_{I M}^{H, C O} \equiv R E R_{t}^{H, C O} \frac{P_{X, t}^{C O} I M_{t}^{H, C O}}{P_{I M, t}^{H} I M_{t}^{H}} \\
P_{I M, t}^{H} I M_{t}^{H} \equiv P_{I M, t}^{C} I M_{t}^{C}+P_{I M, t}^{I} I M_{t}^{I}
\end{gathered}
$$




$$
\begin{gathered}
X_{t}^{H} \equiv \sum_{C O \neq H} \frac{s^{C O}}{s^{H}} I M_{t}^{C O, H} \\
P_{X, t}^{H} X_{t}^{H} \equiv \sum_{C O \neq H} \frac{s^{C O}}{s^{H}} R E R_{t}^{H, C O} P_{X, t}^{H, C O} I M_{t}^{C O, H} \\
P_{I M, t}^{H} I M_{t}^{H} \equiv \sum_{C O \neq H} P_{I M, t}^{H, C O} I M_{t}^{H, C O}
\end{gathered}
$$

- bilateral exchange rate depreciation (real terms)

$$
R E R D E P_{t}^{H, C O} \equiv \frac{R E R_{t}^{H, C O}}{R E R_{t-1}^{H, C O}}
$$

- bilateral exchange rate depreciation (nominal terms)

$$
N E R D E P_{t}^{H, C O} \equiv \frac{S_{t}^{H, C O}}{S_{t-1}^{H, C O}} \equiv \operatorname{RERDEP_{t}^{H,CO}} \frac{\pi_{C, t}^{H}}{\pi_{C, t}^{C O}}
$$

Euro area variables

$$
\begin{aligned}
& C_{t}^{E A} \equiv \frac{s^{R E A}{\overline{P_{C}}}^{R E A} C_{t}^{R E A}+s^{H} \bar{S}^{H, R E A}{\overline{P_{C}}}^{H} C_{t}^{H}}{s^{R E A}+s^{H}} \\
& I_{t}^{E A} \equiv \frac{s^{R E A}{\overline{P_{I}}}^{R E A} I_{t}^{R E A}+s^{H} \bar{S}^{H, R E A}{\overline{P_{I}}}^{H} I_{t}^{H}}{s^{R E A}+s^{H}} \\
& Y_{t}^{E A} \equiv \frac{s^{R E A} \bar{P}_{Y}^{R E A} Y_{t}^{R E A}+s^{H} \bar{S}^{H, R E A}{\overline{P_{Y}}}^{H} Y_{t}^{H}}{s^{R E A}+s^{H}} \\
& M_{t}^{E A} \equiv \frac{s^{R E A} M_{t}^{R E A}+s^{H} M_{t}^{H}}{s^{R E A}+s^{H}} \\
& B_{t}^{* E A} \equiv \frac{s^{R E A} B_{t}^{* R E A}+s^{H} B_{t}^{* H}}{s^{R E A}+s^{H}} \\
& X_{t}^{E A} \equiv \sum_{C O=\{R E A, H\}} \sum_{K=\{U S, R W\}} \frac{s^{H}}{s^{R E A}+s^{H}} \frac{\bar{S}^{K, R E A}}{\bar{S}^{K, H}} P I M^{K, C O}\left(I M C_{t}^{K, C O}+I M I_{t}^{K, C O}\right) \\
& I M_{t}^{E A} \equiv \sum_{C O=\{R E A, H\}} \sum_{K=\{U S, R W\}} \frac{s^{C O}}{s^{R E A}+s^{H}}\left(I M C_{t}^{C O, K}+I M I_{t}^{C O, K}\right) \\
& \Pi_{t}^{E A, 4} \equiv\left(\frac{P_{C, t}^{H}}{P_{C, t-4}^{H}}\right)^{\frac{s^{H}}{s^{H}+s^{R E A}}}\left(\frac{P_{C, t}^{R E A}}{P_{C, t-4}^{R E A}}\right)^{\frac{s^{R E A}}{s^{H}+s^{R E A}}}
\end{aligned}
$$


Conditions for calibration and reporting

$$
\begin{gathered}
R R_{t}-1=\frac{R_{t}}{\Pi_{t+1}}-1 \\
C Y_{t} \equiv \frac{P_{C, t} C_{t}}{P_{Y, t} Y_{t}} \\
I Y_{t} \equiv \frac{P_{I, t} I_{t}}{P_{Y, t} Y_{t}} \\
I M^{C} Y_{t} \equiv \frac{P_{I M^{C}, t} I M_{t}^{C}}{P_{Y, t} Y_{t}} \\
I M^{I} Y_{t} \equiv \frac{P_{I M^{I}, t} I M_{t}^{I}}{P_{Y, t} Y_{t}} \\
I M Y_{t} \equiv \frac{P_{I M^{C}, t} I M_{t}^{C}+P_{I M^{I}, t} I M_{t}^{I}}{P_{Y, t} Y_{t}} \\
B Y_{t} \equiv \frac{B_{t}}{\overline{P_{Y} Y}} \\
T Y_{t} \equiv \frac{T_{t}}{\overline{P_{Y} Y}} \\
Y g a p_{t} \equiv \frac{Y_{t}}{\bar{Y}}-1 \\
Y \operatorname{gr}_{t} \equiv \frac{Y_{t}}{Y_{t-1}} \\
s^{H} P_{Y, t} \frac{Y_{t}}{R E R_{t}} \\
\sum s^{C O} P_{Y, t}^{C O} \frac{Y_{t}^{C O}}{R E R_{t}^{C O}}
\end{gathered}
$$

Autoregressive shocks

$$
\begin{gathered}
\ln \left(z_{T, t}\right)=\left(1-\rho_{z_{T}}\right) \ln \left(\overline{z_{T}}\right)+\rho_{z_{T}} \ln \left(z_{T, t-1}\right)+\varepsilon_{z_{T}, t} \\
\ln \left(z_{N, t}\right)=\left(1-\rho_{z_{N}}\right) \ln \left(\overline{z_{N}}\right)+\rho_{z_{N}} \ln \left(z_{N, t-1}\right)+\varepsilon_{z_{N}, t} \\
\ln \left(z_{t}\right)=\left(1-\rho_{z}\right) \ln (\bar{z})+\rho_{z} \ln \left(z_{t-1}\right)+\varepsilon_{z, t} \\
g_{t}=\left(1-\rho_{g}\right) \bar{g}+\rho_{g} g_{t-1}+\varepsilon_{g, t} \\
t r_{t}=\left(1-\rho_{t r}\right) \overline{t r}+\rho_{t r} t r_{t-1}+\varepsilon_{t r, t} \\
\tau_{t}^{C}=\left(1-\rho_{\tau^{C}}\right) \bar{\tau}^{C}+\rho_{\tau^{C}} \tau_{t-1}^{C}+\varepsilon_{\tau^{C}, t}
\end{gathered}
$$




$$
\begin{gathered}
\tau_{t}^{D}=\left(1-\rho_{\tau^{D}}\right) \bar{\tau}^{D}+\rho_{\tau^{D}} \tau_{t-1}^{D}+\varepsilon_{\tau^{D}, t} \\
\tau_{t}^{K}=\left(1-\rho_{\tau^{K}}\right) \bar{\tau}^{K}+\rho_{\tau^{K}} \tau_{t-1}^{K}+\varepsilon_{\tau^{K}, t} \\
\tau_{t}^{N}=\left(1-\rho_{\tau^{N}}\right) \bar{\tau}^{N}+\rho_{\tau^{N}} \tau_{t-1}^{N}+\varepsilon_{\tau^{N}, t} \\
\tau_{t}^{W_{h}}=\left(1-\rho_{\tau^{W_{h}}}\right) \bar{\tau}^{W_{h}}+\rho_{\tau^{W_{h}}} \tau_{t-1}^{W_{h}}+\varepsilon_{\tau^{W_{h}, t}} \\
\tau_{t}^{W_{f}}=\left(1-\rho_{\tau^{W_{f}}}\right) \bar{\tau}^{W_{f}}+\rho_{\tau^{W_{f}}} \tau_{t-1}^{W_{f}}+\varepsilon_{\tau^{W_{f}, t}} \\
r p_{t}=\rho_{R P} r p_{t-1}+\varepsilon_{t}^{R P}
\end{gathered}
$$

\section{A.10 The monetary union setup}

In EAGLE the euro area is a two-region monetary union. We call one region Home, the other rest of the euro area. As such, the two regions should share a common nominal interest rate and nominal exchange rate against third countries. Moreover, the nominal exchange rate between Home and rest of the euro area should be constant. Consistently, we do the following assumptions: (a) Home and rest of the euro area trade a one-period riskless bond issued by the Home region, $B^{E A}$, denominated in the Home currency and paying a gross interest rate $R^{E A}$; (b) the rest of the euro area pays a transaction cost on $B^{E A}$; (c) the latter cost also applies to rest of the euro area domestic bonds, that are traded only in the rest of the euro area, are denominated in domestic (rest of the euro area) currency and pay the gross interest rate $R^{R E A}$. We have that the following equations hold in the rest of the euro area (respectively the FOC from holding bonds $B^{E A}$, the definition of the transaction costs, the FOC from holding domestic bonds):

$$
\begin{gathered}
\beta R_{t}^{E A}\left(1-\Gamma_{B^{E A}}\left(\frac{S_{t}^{R E A, H} B_{t+1}^{E A, R E A}}{P_{Y, t}^{R E A} Y_{t}^{R E A}}\right)\right) E_{t}\left[\frac{\Lambda_{I, t+1}^{R E A}}{\Lambda_{I, t}^{R E A}}\left(\Pi_{C, t+1}^{R E A}\right)^{-1} \frac{S_{t+1}^{R E A, H}}{S_{t}^{R E A, H}}\right]=1 \\
\Gamma_{B^{E A}}\left(\frac{S_{t}^{R E A, H} B_{t+1}^{E A, R E A}}{P_{Y, t}^{R E A} Y_{t}^{R E A}}\right) \equiv \gamma_{B^{E A}}\left(\exp \left(\frac{S_{t}^{R E A, H} B_{t+1}^{E A, R E A}}{P_{Y, t}^{R E A} Y_{t}^{R E A}}-B_{Y}^{E A, R E A}\right)-1\right) \\
\beta R_{t}^{R E A}\left(1-\Gamma_{B^{E A}}\left(\frac{S_{t}^{R E A, H} B_{t+1}^{E A, R E A}}{P_{Y, t}^{R E A} Y_{t}^{R E A}}\right)\right) E_{t}\left[\frac{\Lambda_{I, t+1}^{R E A}}{\Lambda_{I, t}^{R E A}}\left(\Pi_{C, t+1}^{R E A}\right)^{-1}\right]=1
\end{gathered}
$$

Moreover (assumption d), the rest of the euro area monetary policy authority sets the interest rate so that the nominal exchange rate against the Home currency is constant (peg regime): 


$$
\frac{S_{t}^{R E A, H}}{S_{t-1}^{R E A, H}}=1
$$

Finally (assumption e), the monetary policy in the Home country sets the interest rate by reacting to a weighted average of Home and rest of euro area inflation and output growth rates (see equation A.85). Assumption (a) implies that for the rest of the euro area an uncovered interest parity, linking the interest rate differential between Home and rest of euro area to the expected (next period) bilateral exchange rate depreciation, holds. So for the rest of the euro area two uncovered interest parity conditions hold. One condition determines the nominal exchange rate changes against the US dollar. The other determines the nominal exchange rate changes against the euro (assumed to be the Home currency). Assumption (b) guarantees the stationarity of the model. Assumption (a), (b), (c), and (d) imply, through the uncovered interest parity condition, that the Home and rest of the euro area interest rates are equal $\left(R^{H}=R^{R E A}=R^{E A}\right)$ and simultaneously that the bilateral nominal exchange rate between Home and rest of the euro area is constant. As such, variations in the Home and rest of the euro area nominal exchange rates against third countries are the same. The assumption (e) allows to stabilize the monetary union economy. Finally, as the bond $B^{E A}$ is traded only in the euro area, the following market clearing condition holds:

$$
s^{H} B_{t}^{E A, H}+s^{R E A} B_{t}^{E A, R E A}=0
$$


